\title{
Nanostructured Materials: A Novel Approach to Enhanced Performance Final Report
}

\author{
RECEIVED \\ OCT 071996 \\ OSTI
}

G. E. Korth

F. H. Froes

C. Suryanarayana

P. R. Taylor

D. K. Mukhopadhyay

G.-H. Chen

A. Frefer

G. Cizmich

S. A. Pirzada

D. L. Marshall

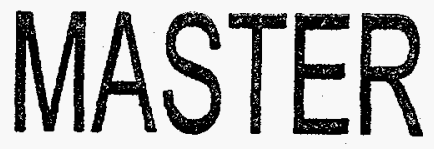

S. M. Donahue

DISTRIBUTON OF THIS DOCUMENT IS UMLAITED

चेLockheed

Idaho Technologies Company 
INEL-96/0181

\title{
Nanostructured Materials: A Novel Approach to Enhanced Performance Final Report
}

\author{
G. E. Korth \\ F. H. Froes \\ C. Suryanarayana \\ P. R. Taylor \\ D. K. Mukhopadhyay \\ G.-H. Chen \\ A. Frefer \\ G. Cizmich \\ S. A. Pirzada \\ D. L. Marshall \\ S. M. Donahue
}

Published May 1996
Idaho National Engineering Laboratory Lockheed Martin Idaho Technologies Idaho Falls, Idaho $\mathbf{8 3 4 1 5}$

\author{
University of Idaho \\ Institute for Materials and Advanced Processes \\ Moscow, Idaho 83844
}

Prepared for the

U.S. Department of the Interior

U.S. Bureau of Mines and for the

U.S. Department of Energy

Under DOE Idaho Operations Office

Contract DE-AC07-94ID13223 


\section{DISCLAIMER}

Portions of this document may be illegible in electronic image products. Images are produced from the best available original document. 


\section{DISCLAIMER}

This report was prepared as an account of work sponsored by an agency of the United States Government. Neither the United States Government nor any agency thereof, nor any of their employees, makes any warranty, express or implied, or assumes any legal liability or responsibility for the accuracy, completeness, or usefulness of any information, apparatus, product, or process disclosed, or represents that its use would not infringe privately owned rights. Reference herein to any specific commercial product, process, or service by trade name, trademark, manufacturer, or otherwise does not necessarily constitute or imply its endorsement, recommendation, or favoring by the United States Government or any agency thereof. The views and opinions of authors expressed herein do not necessarily state or reflect those of the United States Government or any agency thereof. 


\section{EXECUTIVE SUMMARY}

Nanostructured materials are an emerging class of materials that can exhibit physical and mechanical characteristics often exceeding those exhibited by conventional coarse-grained materials. A number of different techniques can be employed to produce these materials. In this program, the synthesis methods chosen were (a) mechanical alloying (MA), (b) physical vapor deposition, and (c) plasma processing. The physical vapor deposition and plasma processing methods were discontinued after the initial exploration stage of the program, with subsequent efforts focussed on mechanical alloying.

The physical vapor deposition process was used to produce co-deposited $\mathrm{Cu}-\mathrm{Al}_{2} \mathrm{O}_{3}$ samples using different processing parameters, and the properties correlated with the processing conditions. Attempts were made to produce microlaminate nanostructured material of alternating layers of $\mathrm{Al}$ and $\mathrm{Fe}$. Discrete layers were not observed, but rather a dispersion of $\mathrm{Fe}$ islands in an Al matrix.

A thermal plasma reactor was designed and constructed, and nanocrystalline metals $(\mathrm{Al}, \mathrm{Ni}$, and $\mathrm{Fe}$ ) were produced. Preliminary tests were conducted on the synthesis of nanostructured intermetallics, and the reactor appears to be capable of producing sufficient quantities of material for subsequent consolidation and analysis.

The major emphasis of the program was on the synthesis, consolidation, and characterization of nanostructured $\mathrm{Al}-\mathrm{Fe}, \mathrm{Ti}-\mathrm{Al}, \mathrm{Ti}-\mathrm{Al}-\mathrm{Nb}$, and $\mathrm{Fe}-\mathrm{Al}$ by $\mathrm{MA}$ intermetallics with a view to increase their ductilities. The major findings of this project are:

\section{$\underline{\text { Al-Fe System }}$}

1. The solid solubility of $\mathrm{Fe}$ in $\mathrm{Al}$ was extended to 4.5 at.\% $\mathrm{Fe}$, up from the equilibrium value of 0.025 at.\%.

2. The crystal size of the solid solution was about $10 \mathrm{~nm}$ after milling for $\mathbf{3 0}$ hours.

3. The $\mathrm{Al}_{5} \mathrm{Fe}_{2}$ intermetallic could be synthesized directly by $\mathrm{MA}$ in the $\mathrm{Al}-25$ at.\% $\mathrm{Fe}$ composition. Heat treatment of the milled powders in other compositions produced the $\mathrm{Al}_{3} \mathrm{Fe}$ intermetallic.

4. A fully amorphous phase was produced in Al-25 at.\% Fe composition after milling for 50 hours; this observation is in agreement with the predictions of the Miedema model.

5. Shock consolidation of $\mathrm{Al}-10.7$ and 25 at.\% Fe powders milled for 65 hours and 15 hours, respectively, produced near $100 \%$ dense compacts; nanometer-sized grains of 25 to $30 \mathrm{~nm}$ were retained in both the compositions. 


\section{$\underline{\text { Ti-Al System }}$}

1. Mechanical alloying of blended elemental Ti-Al powders in the range of 24 to 60 at. $\%$ $\mathrm{Al}$ led sequentially to the formation of a $\mathrm{Ti}(\mathrm{Al})$ solid solution, an amorphous phase, and at the longest times investigated, an f.c.c. phase.

2. The crystal size of the solid solution phase decreased with increasing milling time and reached about $10 \mathrm{~nm}$ after milling for 7 hours.

3. Consolidation of the milled Ti-55 at.\% $\mathrm{Al}$ amorphous powder by shock consolidation, hot isostatic pressing (HIP'ing), and the Ceracon process led to crystallization and the formation of $\gamma$-TiAl and $\alpha_{2}-\mathrm{Ti}_{3} \mathrm{Al}$ phases. Near-nanometer-sized grains were retained after consolidation by all the above methods.

4. Full consolidation could be achieved on HIP'ing at a temperature as low as $800^{\circ} \mathrm{C}$.

5. The hardness of the HIP'ed Ti-55 at.\% Al compacts increased with a decreasing grain size and reached a value of $980 \mathrm{~kg} / \mathrm{mm}^{2}$ for a grain size of $40 \mathrm{~nm}$.

\section{$\underline{\text { Ti-Al-Nb System }}$}

1. Mechanical alloying of blended elemental $\mathrm{Ti}-\mathrm{Al}-\mathrm{Nb}$ powders of different compositions led sequentially to the formation of a $\mathrm{Ti}(\mathrm{Al}, \mathrm{Nb})$ solid solution, a b.c.c. phase, an amorphous phase, and at the longest times investigated, an f.c.c. phase.

2. In the prealloyed $\mathrm{Ti}-24 \mathrm{Al}-11 \mathrm{Nb}$ (at.\%) powder (which contained the $\mathrm{B} 2$ phase in the as-received condition), an amorphous phase and an f.c.c. phase formed with increasing milling time.

3. The b.c.c. phase powder was in the nanostructure size range on mechanically alloying for 5 hours for all the compositions studied.

4. On HIP consolidation, the b.c.c. phase partially transformed to the orthorhombic "O" phase. The grain size of both the b.c.c. and "O" phase were larger at higher HIP temperatures.

5. The hardness of the HIP'ed compacts was nearly $1,000 \mathrm{~kg} / \mathrm{mm}^{2}$.

The f.c.c. phase obtained at long milling times in all the alloys has been found to be due to contamination of the powder by nitrogen from the atmosphere. The consolidated specimens showed heavy cracking, so a determination of the ductility could not be made. 


\section{CONTENTS}

EXECUTIVE SUMMARY $\ldots \ldots \ldots \ldots \ldots \ldots \ldots \ldots \ldots \ldots \ldots \ldots \ldots \ldots \ldots \ldots$

INTRODUCTION $\ldots \ldots \ldots \ldots \ldots \ldots \ldots \ldots \ldots \ldots \ldots \ldots \ldots \ldots \ldots \ldots \ldots$

HIGH-RATE PHYSICAL VAPOR DEPOSITION $\ldots \ldots \ldots \ldots \ldots \ldots \ldots \ldots \ldots \ldots$

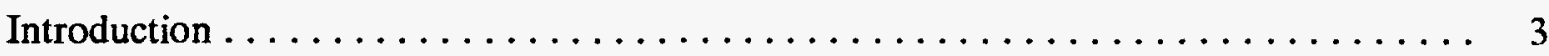

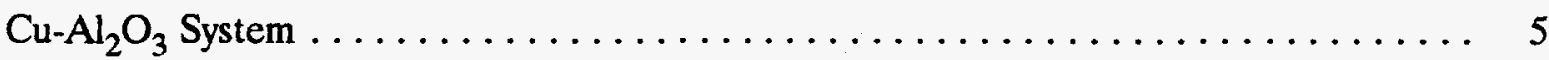

Al-Fe System $\ldots \ldots \ldots \ldots \ldots \ldots \ldots \ldots \ldots \ldots \ldots \ldots \ldots \ldots \ldots \ldots \ldots \ldots$

THERMAL PLASMA REACTOR PROCESSING $\ldots \ldots \ldots \ldots \ldots \ldots \ldots \ldots \ldots \ldots$

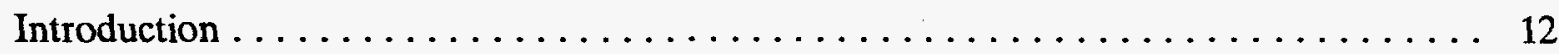

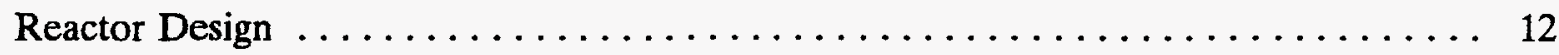

Experimental Setup $\ldots \ldots \ldots \ldots \ldots \ldots \ldots \ldots \ldots \ldots \ldots \ldots \ldots \ldots \ldots$

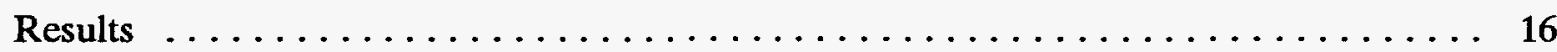

Conclusions $\ldots \ldots \ldots \ldots \ldots \ldots \ldots \ldots \ldots \ldots \ldots \ldots \ldots \ldots \ldots \ldots \ldots \ldots$

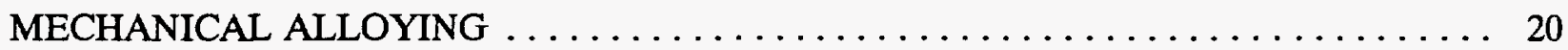

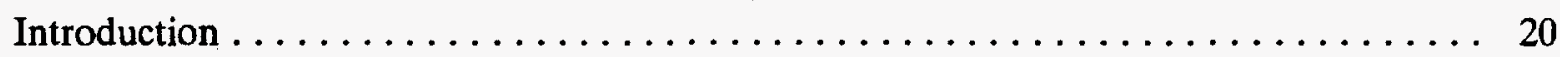

Experimental Procedure $\ldots \ldots \ldots \ldots \ldots \ldots \ldots \ldots \ldots \ldots \ldots \ldots \ldots \ldots$

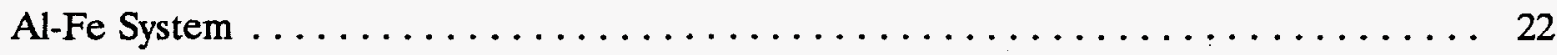

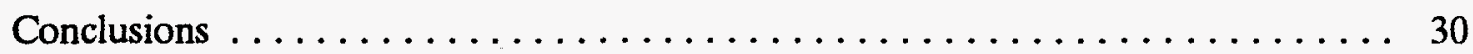

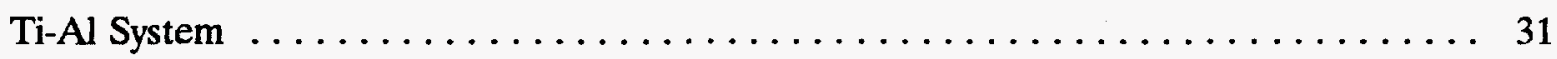

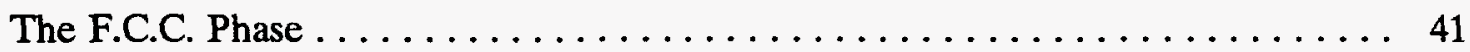

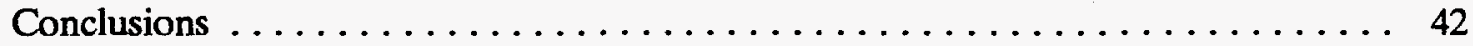

Ti-Al-Nb System $\ldots \ldots \ldots \ldots \ldots \ldots \ldots \ldots \ldots \ldots \ldots \ldots \ldots \ldots \ldots \ldots \ldots \ldots \ldots$

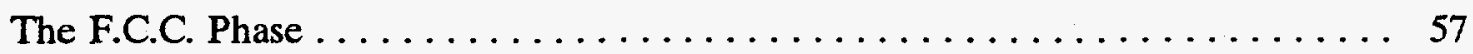

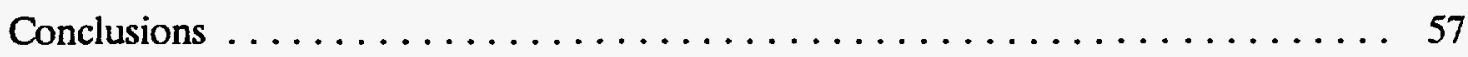

REFERENCES $\ldots \ldots \ldots \ldots \ldots \ldots \ldots \ldots \ldots \ldots \ldots \ldots \ldots \ldots \ldots \ldots$

RESEARCH PAPERS PUBLISHED $\ldots \ldots \ldots \ldots \ldots \ldots \ldots \ldots \ldots \ldots \ldots \ldots \ldots$ 


\section{FIGURES}

1. Schematic of the high-rate physical vapor deposition (HRPVD) system. . . . . . . 3

2. Experimental configuration for (a) co-deposition and (b) layered deposition using the HRPVD process.

3. (a) Hardness and (b) tensile strength of co-deposited $\mathrm{Cu}-\mathrm{Al}_{2} \mathrm{O}_{3}, \ldots \ldots \ldots$

4. Effect of processing parameters on the properties of co-deposited $\mathrm{Cu}-1$ vol.\% $\mathrm{Al}_{2} \mathrm{O}_{3}$. Top $=$ effect of deposition rate on hardness; bottom $=$ effect of substrate temperature

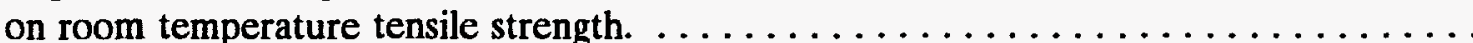

5. Full thickness (upper) cross-section of sample 1d-14 (Al:Fe $61: 5 \mathrm{~nm}$ ) with higher magnifications of areas near the free surface (middle) and substrate (lower). . . . . . .

6. X-ray diffraction pattern of a crushed (powdered) sample from 1d-14 showing $\mathrm{Al}, \mathrm{Fe}$, and unidentified peaks, compared with $\mathrm{Al}$ and Fe standards.

7. TEM dark field of sample $1 \mathrm{~d}-15$ showing multiple islands of $\mathrm{Fe}$ in $\mathrm{Al}$ rather than a layered structure. . . . . . . . . . . . . . . . . . . . .

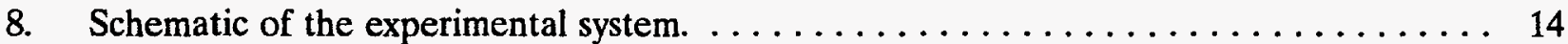

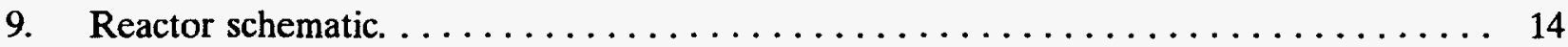

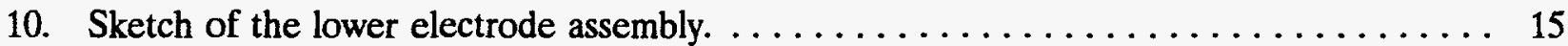

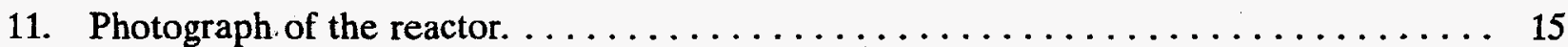

12. Arc emerging from the lower electrode (Ar-plasma gas). $\ldots \ldots \ldots \ldots \ldots \ldots \ldots$

13. SEM micrograph of nickel feed powder. $\ldots \ldots \ldots \ldots \ldots \ldots \ldots \ldots \ldots \ldots \ldots$

14. SEM micrograph of nickel powder produced. $\ldots \ldots \ldots \ldots \ldots \ldots \ldots \ldots \ldots \ldots$

15. SEM micrograph of iron powder produced. $\ldots \ldots \ldots \ldots \ldots \ldots \ldots \ldots \ldots \ldots$

16. Size distribution of iron powder produced. . . . . . . . . . . . . . . . . . . . . 19

17. Schematic of the three consolidation methods used on the MA powder. . . . . . 22

18. Scanning electron micrographs of the Al-4 at.\% Fe powder (a) as-blended, (b) milled for 10 hours, and (c) milled for 20 hours showing a decrease in the particle size with milling time. . . . . . . . . . . . . . . . . . . . . . . . .

19. Scanning electron micrograph of the Al-10.7 at.\% Fe powder MA for 30 hours, showing the presence of nanometer sized crystals. 
20. X-ray diffraction patterns of Al-7.3 at.\% Fe powder as a function of MA time.

21. Plot showing the variation of crystal size with milling time in $\mathrm{Al}-4,10.7$ and 25 at.\% $\mathrm{Fe}$ powders.

22. X-ray diffraction patterns of blended elemental nominal Al-25 at.\% Fe mechanically alloyed powders (a) as-mixed, (b) after milling for 5 hours, (c) 15 hours, (d) 30 hours, and (e) 50 hours.

23. X-ray diffraction patterns of the Al-25 at.\% Fe powders, (a) mechanically alloyed for 30 hours, (b) mechanically alloyed for 30 hours and heat treated at $625^{\circ} \mathrm{C}$ for 324 hours. .

24. Transmission electron micrographs of the shock-consolidated specimens of (a) $\mathrm{Al}-10.7$ at.\% Fe powder MA for 65 hours and (b) Al-25 at.\% Fe powder MA for 15 hours showing the presence of $25-$ to 30 -nm nanocrystals.

25. Calculated enthalpy versus composition diagram for the Al-Fe system using the Miedema model.

26. Electron diffraction pattern of Al-25 at.\% Fe powder MA for 50 hours showing full

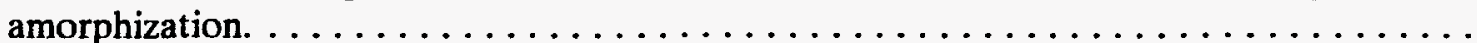

27. Crystal size as a function of milling time in binary $\mathrm{Ti}-\mathrm{Al}$ powder mixes. $\ldots \ldots \ldots \ldots$

28. X-ray diffraction patterns of Ti-24 at.\% $\mathrm{Al}$ powder as a function of milling time: (a) asmixed, 0 hours, and MA for (b) 3 hours, (c) 11 hours, and (d) 36 hours. . . . . . . .

29. X-ray diffraction patterns of Ti-55 at.\% $\mathrm{Al}$ powder as a function of milling time: (a) asmixed, 0 hours, and MA for (b) 5 hours, (c) 10 hours, and (d) 30 hours. . . . . . .

30. Electron diffraction pattern of Ti-55 at.\% Al powder MA for 10 hours showing the formation of an amorphous phase. $\ldots \ldots \ldots \ldots \ldots \ldots \ldots \ldots \ldots$

31. Electron diffraction patterns of $\mathrm{Ti}-55$ at.\% $\mathrm{Al}$ powder $\mathrm{MA}$ for 30 hours showing the formation of an f.c.c. phase.

32. Milling map for a $\mathrm{Ti}-33$ at.\% $\mathrm{Al}$ alloy powder relating the ball-to-powder ratio and

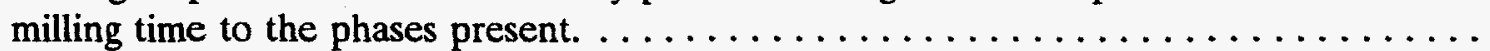

33. X-ray diffraction patterns of Ti-55 at.\% Al powder (a) milled for 115 hours in the attritor showing the amorphous phase, and (b) HIP'ed at $975^{\circ} \mathrm{C}, 207 \mathrm{MPa}$ for 2 hours showing a mixture of the $\mathrm{TiAl}$ and $\mathrm{Ti}_{3} \mathrm{Al}$ phases.

34. Transmission electron micrographs of the MA Ti-55 at.\% Al powder HIP'ed for 2 hours at $207 \mathrm{MPa}$ pressure and at (a) $800^{\circ} \mathrm{C}$, (b) $900^{\circ} \mathrm{C}$, and (c) $975^{\circ} \mathrm{C}$.

35. High-resolution electron micrograph of MA blended elemental Ti-55 at.\% $\mathrm{Al}$ powder HIP'ed at $900^{\circ} \mathrm{C} / 207 \mathrm{MPa} / 2$ hours. 
36. Transmission electron micrographs and diffraction patterns of shock-consolidated Ti-55 at.\% $\mathrm{Al}$ powder compact: (a) bright-field micrograph, (b) dark-field micrograph, and (c) diffraction pattern. . . . . . . . . . . . . . . . . . . . . . . .

37. Hall-Petch plot for the Ti-55 at.\% Al as-milled powder HIP-consolidated compacts. ...

38. X-ray diffraction patterns of blended elemental Ti-24Al-11Nb (at.\%) powders as a function of milling time. . . . . . . . . . . . . . . . . . .

39. X-ray diffraction patterns of PA Ti-24Al-11Nb powder as a function of milling time. ...

40. Schematic representation of phases present in different $\mathrm{Ti}-\mathrm{Al}-\mathrm{Nb}$ alloys as a function of

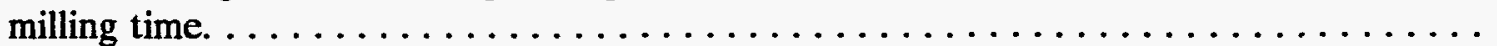

41. Schematic representation of phases present in the Ti-25Al-25Nb powder as a function of milling time in different atmospheres. $\ldots \ldots \ldots \ldots \ldots \ldots \ldots \ldots \ldots \ldots \ldots \ldots$

42. Crystal size as a function of milling time in ternary $\mathrm{Ti}-\mathrm{Al}-\mathrm{Nb}$ powder mixtures. . . . . .

43. Transmission electron micrograph showing $15-\mathrm{nm}$ size crystals in BE Ti-24Al-11-Nb (at.\%) after MA for 14 hours. . . . . . . . . . . . . . . . . . . .

44. Scanning electron micrograph showing transverse cross-section of cylindrical sample of Ti-24Al-11Nb (at.\%) powder that was dynamically consolidated (shot \#253) . . . . . . .

45. Transmission electron micrographs and diffraction pattern of dynamically consolidated Ti-24Al-Nb (at.\%) powder (shot \#253). . . . . . . . . . . . . . . . . .

46. X-ray diffraction pattern of the Ti-24Al-11Nb (at.\%) MA powder HIP'ed at $975^{\circ} \mathrm{C} / 207$ $\mathrm{MPa} / 2$ hours showing the presence of the B2/b.c.c. and orthorhombic phases. . . . . .

47. Transmission electron micrographs of the MA blended elemental Ti-24Al-11Nb (at.\%) powder HIP'ed for 2 hours at $207 \mathrm{MPa}$ pressure and at (a) $800^{\circ} \mathrm{C}$, (b) $900^{\circ} \mathrm{C}$, and (c) $975^{\circ} \mathrm{C}$

48. High-resolution electron micrograph of MA blended elemental Ti-24Al-11Nb (at.\%) powder HIP'ed at $900^{\circ} \mathrm{C} / 207 \mathrm{MPa} / 2$ hours showing that the grain boundaries and grain

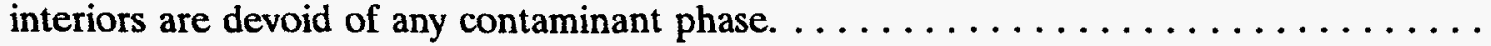

49. Hall-Petch plot for the blended elemental Ti-24Al-11Nb (at.\%) as-milled powder and HIP-consolidated compacts.

50. Transmission electron micrograph of the PA Ti-24Al-11Nb (at.\%) powder milled for 2 hours and HIP'ed at $800^{\circ} \mathrm{C} / 207 \mathrm{MPa} / 2$ hours. Note the bimodal distribution of grain sizes. 


\section{TABLES}

1. Processing parameters of co-deposited $\mathrm{Cu}-\mathrm{Al}_{2} \mathrm{O}_{3}, \ldots \ldots \ldots \ldots \ldots \ldots \ldots \ldots \ldots$

2. Processing parameters for layered structures. $\ldots \ldots \ldots \ldots \ldots \ldots \ldots \ldots \ldots$

3. General operating conditions for the experiments. $\ldots \ldots \ldots \ldots \ldots \ldots \ldots \ldots$

4. Purity and size of starting powders for ma. ................... 21

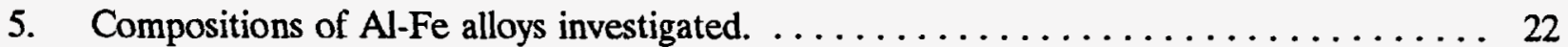

6. Compositions of binary $\mathrm{Ti}-\mathrm{Al}$ powders investigated. $\ldots \ldots \ldots \ldots \ldots \ldots \ldots \ldots$

7. Consolidation parameters for the mechanically alloyed $\mathrm{Ti}-55$ at.\% Al powders. . . . . 36

8. Summary of results on consolidated $\mathrm{Ti}-55$ at.\% $\mathrm{Al}$ powder mechanically alloyed for 35 hours in a Szegvari 01-HD attritor under argon with a 20:1 ball-to-powder ratio. . . . . 39

9. $\mathrm{H}_{\mathrm{o}}$ and $\mathrm{K}$ values in the Hall-Petch equation. $\ldots \ldots \ldots \ldots \ldots \ldots \ldots \ldots \ldots$

10. Compositions of $\mathrm{Ti}-\mathrm{Al}-\mathrm{Nb}$ powders investigated. $\ldots \ldots \ldots \ldots \ldots \ldots \ldots \ldots \ldots$

11. Grain size and microhardness values of the $\mathrm{Ti}-24 \mathrm{Al}-11 \mathrm{Nb}$ (at.\%) samples. . . . . . 54 


\section{Nanostructured Materials: A Novel Approach to Enhanced Performance Final Report}

\section{INTRODUCTION}

As the mechanical and physical requirements of systems and devices become more demanding, the performance characteristics of the structural materials must be enhanced. ${ }^{1,2}$ To achieve these increased levels of performance, compositions and microstructures farther and farther away from equilibrium are being explored. 3,4 For metallic systems, techniques such as rapid solidification, vapor deposition, ion implantation, irradiation, mechanical alloying, and thermochemical processing are now at various stages of maturity. ${ }^{2,3}$ An extremely promising approach is synthesis of nanostructured materials, 5,6 the object of the present investigation.

Nanostructured materials are an emerging class of materials that can exhibit physical and mechanical characteristics differing from, and which often exceed, those exhibited by conventional coarse-grained materials., ${ }^{5,6}$ Nanostructures (also known as nanocrystals or nanophase materials) are single-phase or multi-phase polycrystalline materials in which the crystal size is of the order of a few (typically 1 to 100$)$ nanometers $\left(10^{-9} \mathrm{~m}\right)$ in at least one dimension. Nanostructures can be basically equiaxed in nature, which have been termed nanostructured crystallites (3-D nanostructures), or they can be fibrous or filamentary in nature (2-D nanostructures), and finally they can consist of layered or lamellar structure (1-D nanostructure). Nanostructures can be made up of any of the three basic material classes-metals, ceramics, or polymers-or combinations of these classes and, with appropriate processing techniques, could be graded structures.

Nanostructured materials have been synthesized by a number of techniques including physical vapor deposition, mechanical alloying, molecular beam epitaxy, rapid solidification, ion beam, reactive sputtering, sol-gel, and electrochemical deposition processes. ${ }^{5,6}$ However, while most of these techniques are capable of producing "gram" quantities of material for characterization (or as surface coatings), only physical vapor deposition, chemical vapor deposition, mechanical alloying, and plasma processing have the potential for producing "pound" quantities suitable for full-scale evaluation, including determination of a spectrum of mechanical and physical properties. The goal of the present investigation was two-fold: (1) explore three of these processes that have good potential for scale-up and transfer to commercial processes, and (2) determine the properties of the product as a function of process parameters. The three processes selected were high-rate physical vapor deposition (HRPVD), mechanical alloying (MA) of metallic powder mixtures, and plasma processing.

The HRPVD investigation was performed at the Idaho National Engineering Laboratory (INEL), and the other two processing methods were pursued under subcontract at the University of Idaho. Even though HRPVD and plasma processing were discontinued after the initial exploration stage of the program so that the effort could be focused on MA, the progress that was made with these processing methods before their termination is reported. The product form from HRPVD is a thin sheet that could be characterized directly, but both the MA and plasma 
method produced powder that would have to be consolidated before properties could be determined. Consolidation investigations of the MA powders and most of the characterization of the consolidated product were performed at the INEL. Ceracon consolidations were performed under subcontract with Ceracon, Inc. 


\section{HIGH-RATE PHYSICAL VAPOR DEPOSITION}

\section{Personnel}

1. Gary E. Korth

\section{Introduction}

The vapor deposition system comprised a dual electron beam melting system with associated power supplies and controls, a collection mechanism, a vacuum chamber, and s pumping station. A schematic of the system is shown in Figure 1. Both co-deposited $\left(\mathrm{Cu}-\mathrm{Al}_{2} \mathrm{O}_{3}\right)$ and 1-D layered (alternating layers of $\mathrm{Al}$ and $\mathrm{Fe}$ ) samples were produced. The schematic for co-deposition is shown in Figure 2a and for 1-D layer deposition in Figure $2 b$.

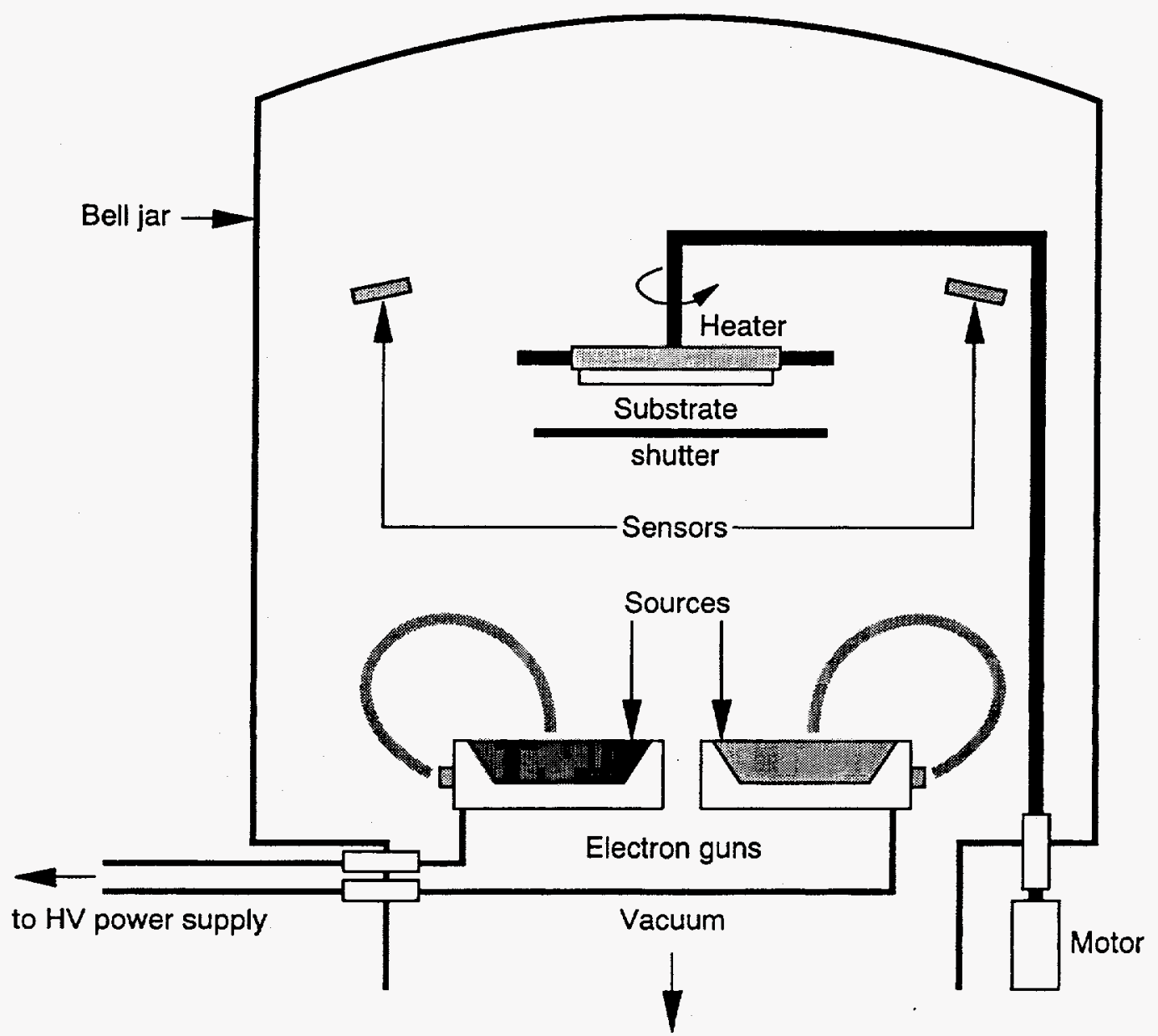

N91 0320

Figure 1. Schematic of the high-rate physical vapor deposition (HRPVD) system. 


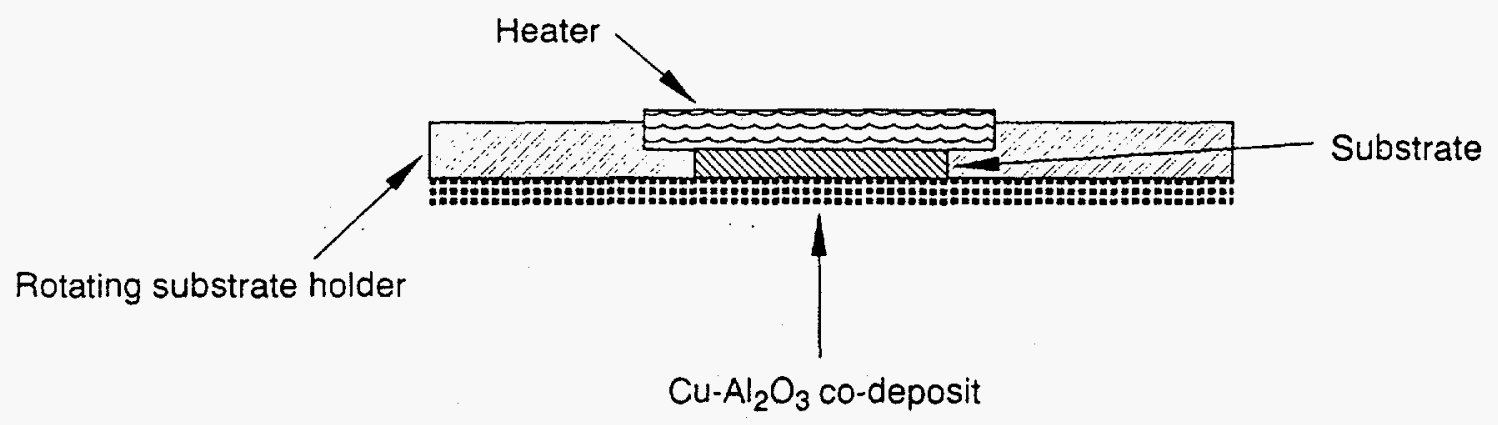

Cu source

$\mathrm{Al}_{2} \mathrm{O}_{3}$ source
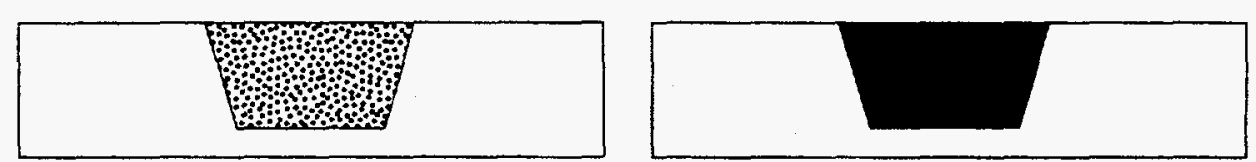

(a)

e-guns

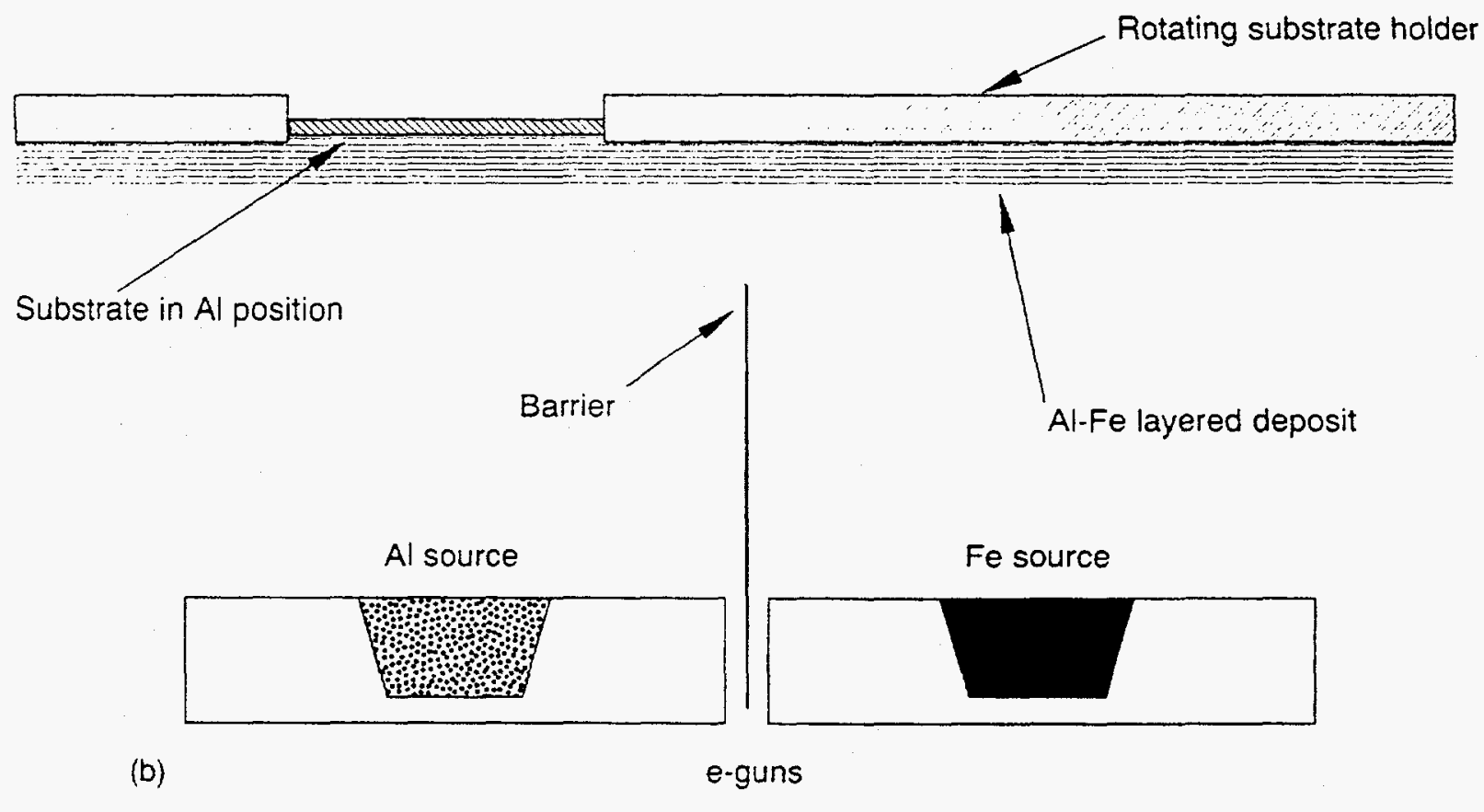

Q92 $0222 \cdot 223$

Figure 2. Experimental configuration for (a) co-deposition and (b) layered deposition using the HRPVD process. 


\section{$\mathrm{Cu}-\mathrm{Al}_{2} \mathrm{O}_{3}$ System}

The addition of small amounts ( 0.5 to 4.0 vol.\%) of $\mathrm{Al}_{2} \mathrm{O}_{3}$ in a predominantly $\mathrm{Cu}$ matrix changes the properties quite markedly. Figure 3a compares the hardness values obtained as various amounts of $\mathrm{Al}_{2} \mathrm{O}_{3}$ are added to copper by physical vapor deposition. In addition to the quantity of $\mathrm{Al}_{2} \mathrm{O}_{3}$, other parametric changes included the rate of $\mathrm{Cu}$ deposition and substrate temperature. Figure $3 \mathrm{~b}$ shows the tensile strength of those samples that were of sufficient quality to permit fabrication of tensile bars. Table 1 lists the co-deposited $\mathrm{Cu}-\mathrm{Al}_{2} \mathrm{O}_{3}$ samples produced with the processing parameters and properties measured. Observations from the hardness and tensile data show that although the addition of $\mathrm{Al}_{2} \mathrm{O}_{3}$ makes the most marked effect, increasing the rate of deposition (sample CD-20) also results in an increase in hardness (Figure 4) with an associated apparent loss in ductility since these samples were too brittle to even allow a valid tensile test. The best tensile properties (highest strength and still some ductility) were realized when the substrate temperature was lowered from 700 to $600^{\circ} \mathrm{C}$ (sample CD-22). A substrate temperature of $800^{\circ} \mathrm{C}$ resulted in lower hardness and strength with no improvement in ductility. The effects of substrate temperature on tensile strength are also illustrated in Figure 4. X-ray diffraction analysis of the co-deposited $\mathrm{Cu}-\mathrm{Al}_{2} \mathrm{O}_{3}$ samples failed to reveal the presence of $\mathrm{Al}_{2} \mathrm{O}_{3}$ at these low concentrations, and line broadening analysis of the copper peaks did not indicate that the grains were in the nanosize regime, but the distribution of the $\mathrm{Al}_{2} \mathrm{O}_{3}$ was definitely on an atomic scale. Earlier examinations with the transmission electron microscope (TEM) on samples CD-1 and CD-4 failed to even resolve the alumina.

Table 1. Processing parameters of co-deposited $\mathrm{Cu}-\mathrm{Al}_{2} \mathrm{O}_{3}$.

\begin{tabular}{ccccccccc}
\hline $\begin{array}{c}\text { Sample } \\
\text { No. }\end{array}$ & $\begin{array}{c}\text { Vol.\% } \\
\mathrm{Al}_{2} \mathrm{O}_{3}\end{array}$ & $\begin{array}{c}\text { Temperature, } \\
{ }^{\circ} \mathrm{C}\end{array}$ & $\begin{array}{c}\text { Copper } \\
\text { Deposition } \\
\text { Rate, } \mathrm{A} / \mathrm{s}\end{array}$ & $\begin{array}{c}\text { Total } \\
\text { Run } \\
\text { Time, } \mathrm{h}\end{array}$ & $\begin{array}{c}\text { Sample } \\
\text { Thickness, } \\
\mathrm{mm}\end{array}$ & $\begin{array}{c}\text { Hardness, } \\
\mathrm{DPH}\end{array}$ & $\begin{array}{c}\text { Tensile } \\
\text { Strength, } \\
\mathrm{MPa}\end{array}$ & $\begin{array}{c}\text { Total } \\
\text { Elongation, } \\
\%\end{array}$ \\
\hline $\mathrm{CD}-1$ & 0.5 & 700 & 300 & 1.83 & 0.186 & 144 & $>387^{\mathrm{a}}$ & - \\
$\mathrm{CD}-4$ & 2.0 & 700 & 265 & 2.00 & 0.195 & 160 & 352 & 0 \\
$\mathrm{CD}-5$ & 2.0 & 700 & 270 & 1.10 & 0.110 & 162 & -- & -- \\
$\mathrm{CD}-6$ & 4.0 & 700 & 260 & 3.03 & 0.293 & 177 & -- & -- \\
$\mathrm{CD}-18$ & 1.0 & 700 & 374 & 1.75 & 0.238 & 144 & 396 & 1.4 \\
$\mathrm{CD}-19$ & 0 & 700 & 482 & 1.27 & 0.220 & 71 & 186 & 9.8 \\
$\mathrm{CD}-20$ & 1.0 & 700 & 713 & 0.98 & 0.255 & 187 & $>380^{\mathrm{a}}$ & -- \\
$\mathrm{CD}-22$ & 1.0 & 600 & 396 & 2.00 & 0.288 & 154 & 572 & 1.3 \\
$\mathrm{CD}-23$ & 1.0 & 800 & 463 & 1.63 & 0.275 & 145 & 333 & 0.4 \\
$\mathrm{CD}-24$ & 1.0 & 700 & 450 & 2.07 & 0.338 & 169 & 423 & 0.5 \\
\hline
\end{tabular}

a. Had reached this stress value when failure occurred in the grip area. 

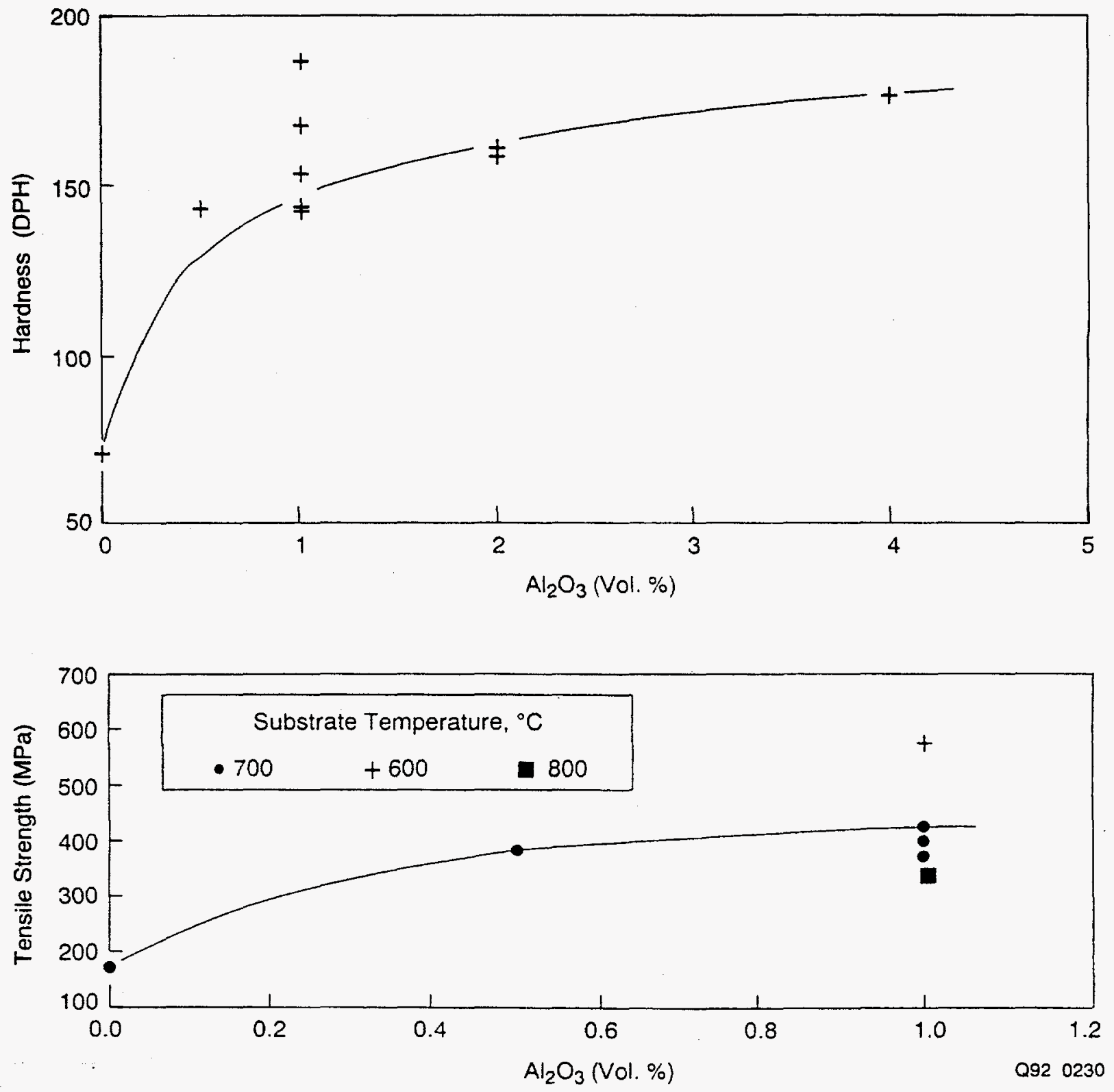

Figure 3. (a) Hardness and (b) tensile strength of co-deposited $\mathrm{Cu}-\mathrm{Al}_{2} \mathrm{O}_{3}$. 

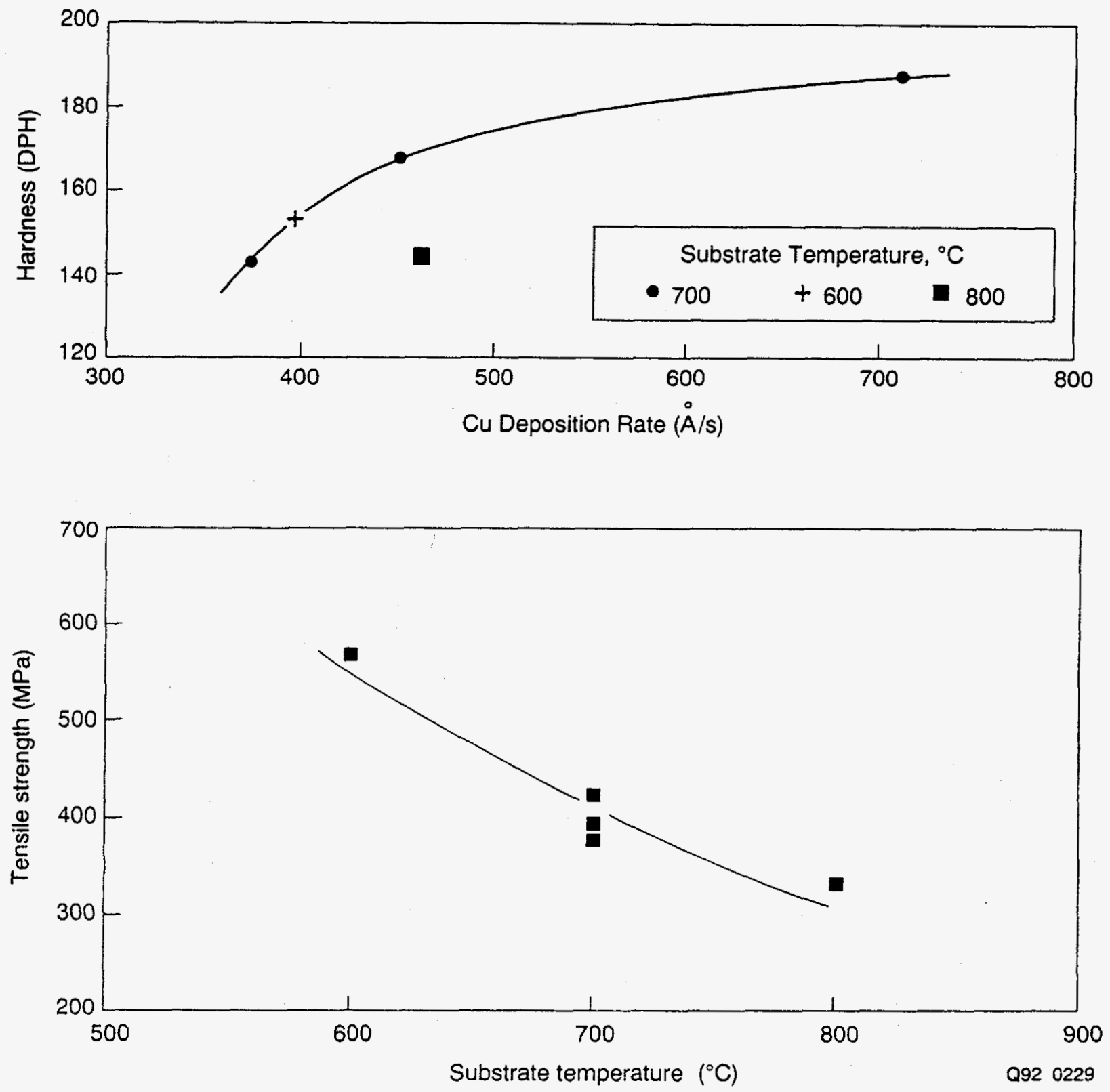

Figure 4. Effect of processing parameters on the properties of co-deposited $\mathrm{Cu}-1$ vol. $\% \mathrm{Al}_{2} \mathrm{O}_{3}$. Top = effect of deposition rate on hardness; bottom $=$ effect of substrate temperature on room temperature tensile strength. 


\section{Al-Fe System}

Two samples of $\mathrm{Al}$ and $\mathrm{Fe}$ were produced with the equipment configured for a 1-D layered structure. The processing parameters were adjusted to produce microlaminates with alternating layers of $\mathrm{Al}: \mathrm{Fe}$ as $61: 5 \mathrm{~nm}$ (sample 1d-14) and 43:10 nm (sample 1d-15). The rotating silicon substrate (see Figure 2a) was neither externally heated nor cooled, but allowed to come to an equilibrium temperature from the radiant heat of the crucibles. This temperature is estimated to be in the vicinity of $350^{\circ} \mathrm{C}$. Scanning electron microscopy (SEM) micrographs of the full thickness and higher magnification of areas near the free deposition surface and substrate of one of the samples are shown in Figure 5. Even higher magnifications (up to 25,000X) failed to resolve any layered structure. Energy dispersive spectroscopy (EDS) analysis on the SEM showed only the presence of $\mathrm{Al}$ and $\mathrm{Fe}$, and the ratio of the two coincided with that expected from the processing parameters, which are listed in Table 2 with the EDS data. X-ray diffraction analysis of sample 1d-14 showed prominent peaks of $\mathrm{Al}$ and $\mathrm{Fe}$ with evidence of a minor constituent(s) of undoubtedly some non-equilibrium $\mathrm{Al}_{x} \mathrm{Fe}_{y}$, which was not identified. The x-ray diffraction pattern is shown in Figure 6. Foils of a cross-section of sample 1d-15 were prepared by ion milling techniques and examined in a TEM at magnifications of over $200,000 \mathrm{X}$, but still no evidence of distinct layers was obtained, but rather a structure of multiple islands was noted using dark field techniques (Figure 7). Differential thermal analysis was performed on a crushed piece of sample 1d-14. The results showed no evidence of exothermic reaction between $\mathrm{Al}$ and $\mathrm{Fe}$ up to $1,300^{\circ} \mathrm{C}$, but a fairly large endotherm at $660^{\circ} \mathrm{C}$ (the melting point of aluminum) was observed. It is speculated that to achieve a true microlaminate structure, either the substrate temperature has to be lowered or processing parameters will have to be adjusted so the free surface where deposition

Table 2. Processing parameters for layered structures.

\begin{tabular}{lcc}
\hline Sample No. & $1 \mathrm{~d}-14$ & $1 \mathrm{~d}-15$ \\
\hline Predicted layer thickness, nm & & 43 \\
Al & 61 & 10 \\
Fe & 5 & 15 \\
Rotation Speed, RPM & 15 & 1.46 \\
Run Time, h & 2.50 & 0.069 \\
Sample Thickness, mm & 0.148 & 274 \\
Hardness, DPH & 271 & Silicon \\
Substrate Material (unheated) & Silicon & \\
Calculated wt.\% & & 60.0 \\
Al & 81.1 & 40.0 \\
Fe & 18.9 & \\
EDS Analysis, wt.\% & & 59.5 \\
Al & 77.5 & 40.5 \\
Fe & 22.5 & \\
\hline
\end{tabular}




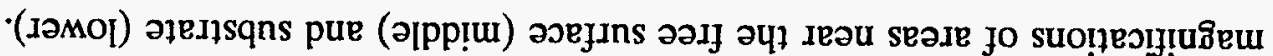

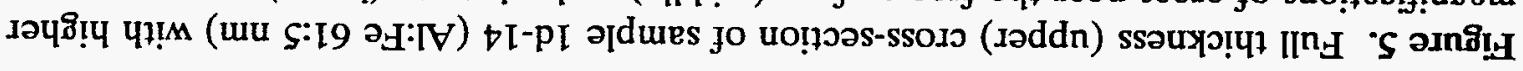
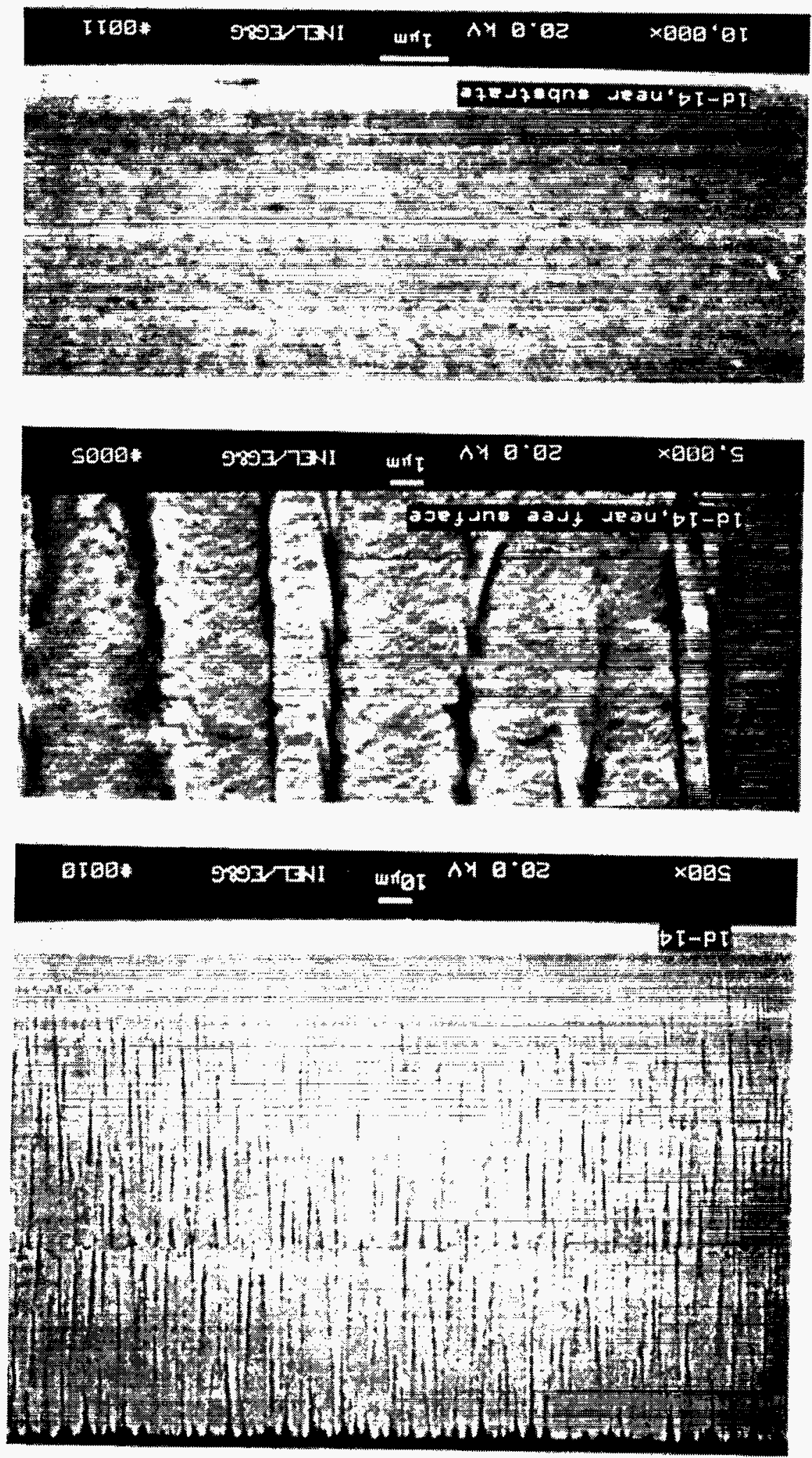

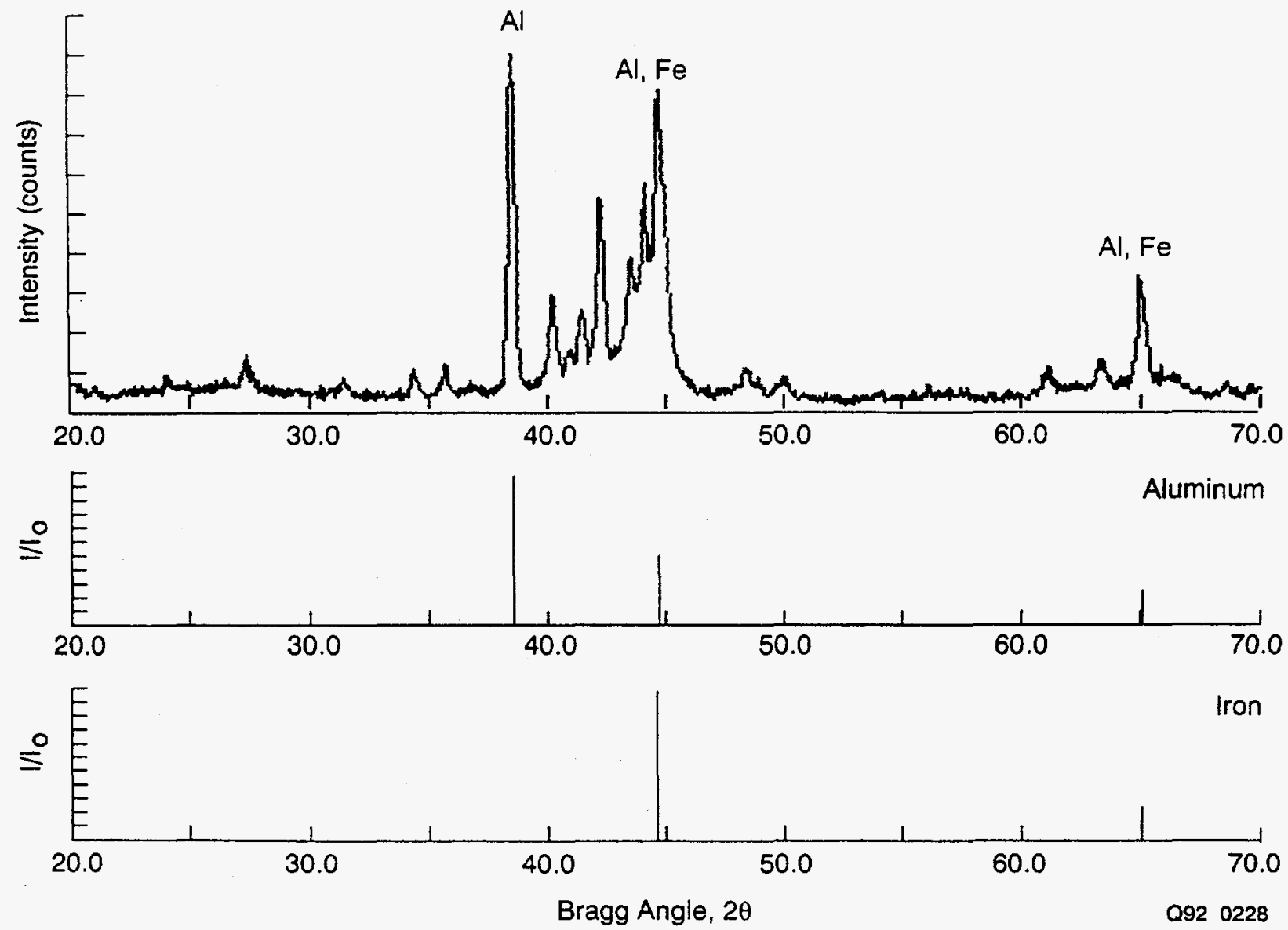

Figure 6. X-ray diffraction pattern of a crushed (powdered) sample from $1 \mathrm{~d}-14$ showing $\mathrm{Al}, \mathrm{Fe}$, and unidentified peaks, compared with $\mathrm{Al}$ and $\mathrm{Fe}$ standards.

is taking place remains flat (see the peak and valley free surface illustrated in the upper SEM micrographs of Figures 5 and 6 ). Bickerdike et al. ${ }^{7}$ reported a similar problem (separate particles and columnar structure) when attempting to produce an $\mathrm{A} / \mathrm{Ni}$ layered deposit at substrate temperatures of $360^{\circ} \mathrm{C}$. The problem was solved by lowering the collector temperature to near $90^{\circ} \mathrm{C}$. Adding cooling capability to a rotating substrate inside a vacuum chamber is possible, but requires a fairly significant modification, which was not done before this phase of the project was terminated. 


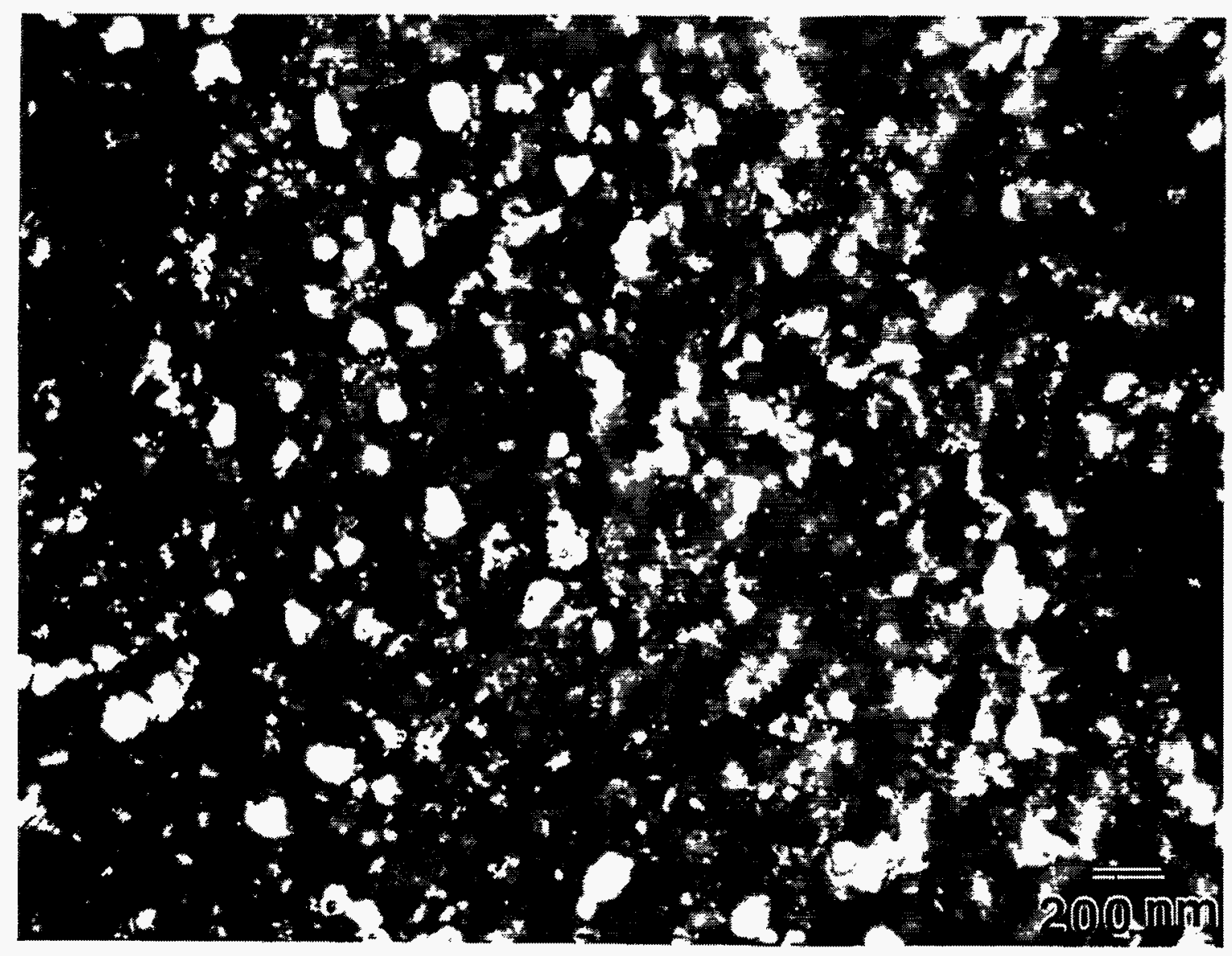

Figure 7. TEM dark field of sample $1 \mathrm{~d}-15$ showing multiple islands of $\mathrm{Fe}$ in $\mathrm{Al}$ rather than a layered structure. 


\section{THERMAL PLASMA REACTOR PROCESSING}

\section{$\underline{\text { Personnel }}$}

1. P.R. Taylor

2. S.A. Pirzada

3. D.L. Marshall

4. S.M. Donahue

\section{Introduction}

Plasma synthesis of pure and fine (submicron) ceramic and metallic powders is a widely studied area of plasma processing. Numerous laboratory systems have been designed and operated to generate fine (submicron) ceramic materials (such as carbides, nitrides, oxides, etc.) ${ }^{8-10}$ Plasma processing may also have potential for the generation of nanocrystalline metals/ materials. There have been some successful attempts to produce nanosize materials in plasma reactors. ${ }^{11,12}$ An important attraction in using plasma reactors for the generation of nanocrystalline materials seems to be the possibility of producing substantial quantities of these types of materials in a very clean atmosphere. The highly concentrated enthalpy available in the plasma flame has the ability to vaporize virtually any refractory material provided the reactant is properly injected into the plasma arc and has sufficient residence time in the hot zone. The steep temperature gradients available in plasma reactors may lead to homogeneous nucleation, which can result in the generation of nanosize materials.

In the present program, a novel transferred arc plasma system was designed, built, and operated. Preliminary experiments were performed to generate nanocrystalline-sized powder of metals such as aluminum, nickel, and iron.

\section{Reactor Design}

In designing the reactor, classical metallurgical engineering considerations of thermodynamics, reaction kinetics, momentum, heat, and mass transfer were employed. The primary limiting design factors were the following:

- Injection of feed material into the hot zone.

- Residence time of the feed material in the hot zone.

- Heat transfer to the solid particulates, reactor walls, and outer electrode.

- $\quad$ Plasma-particle interaction.

- Nucleation, condensation, and quenching of the products.

Under plasma conditions, the presence of charged particles and very steep temperature gradients in the boundary layer can have a substantial effect on the flow and temperature fields around the solid feed through its influence on the local fluid properties. ${ }^{13}$ Boulos et al. ${ }^{13}$ performed fundamental studies on plasma-particle momentum and heat transfer. Several correlations regarding drag, heat, and mass transfer coefficients under plasma conditions were 
developed, which were taken into account for the momentum, heat, and mass transfer calculations.

In producing nanocrystalline metals, one of the most important aspects of processing is that the injected feed material should be exposed to high temperature for a sufficient period of time to ensure their complete vaporization. To increase the residence time of the entrained particles in the plasma arc, the length of the arc was increased by establishing it between a variable height electrode in the torch (which acts as the anode) and a donut-shaped electrode, which was mounted down from the torch.

To ensure the proper penetration of the feed material into the highly dense column of plasma arc, the feed powders were injected through an injection ring mounted on the torch with a high velocity of carrier gas and with a counter swirl direction relative to the plasma gas swirl.

\section{Experimental Setup}

A schematic of the experimental system is given in Figure 8. The central part of the setup is the reactor which is shown in Figure 9. The reactor is made of steel and can be divided into three zones. The first is the plasma jet zone, second is the extended flow zone and reaction zone, and third is the rapid quench zone. The hot zones are tubular in geometry and are designed to allow for the high temperatures generated by the plasma arc. Theoretical calculations were performed for the temperature and velocity profiles expected in the hot zone. An energy balance was performed to establish the reactor diameter and to identify the proper feed rates. The time for complete vaporization was calculated using kinetic equations. Knowing the estimated time for complete reaction, the length of the hot zone was determined to ensure complete vaporization for the particulate material.

The plasma arc was established between the vertically mounted torch (fitted with a linear actuator), which acted as an anode, and a donut-shaped cathode located in the central part of the hot zone. The distance between these two electrodes was adjusted to increase the arc length and for the proper attachment of the arc on the lower cathode. This lower electrode was held in place by a boron nitride ring. A schematic of the electrode is shown in Figure 10. This part was electrically isolated from the upper section. The donut, which was made of copper, was intensively water-cooled to avoid any film boiling. A mixture of argon and helium was used as plasma gas. The hot zone was lined with a graphite lining and insulated with graphite felt. All of these zones of the reactor were water-cooled. Powders were injected into the reactor by a powder feeder through a graphite ring placed at the end of the plasma torch. Argon was used as carrier gas for the powder feeding. A two-color pyrometer was used to measure the temperature in the hot zone.

The hot section was attached to the quench box through a funnel section. The quench box contained two water-cooled copper disks placed facing the discharge end of the hot zone. Most of the powder was collected from these disks. The disks were removable from the quench section by a hydraulic lift. Gases leaving the quench section were passed through a water collection system. Very fine particles entrained in the gaseous stream were captured in liquid and were recovered later by using appropriate settling reagents. A photograph of the experimental reactor is shown in Figure 11. 


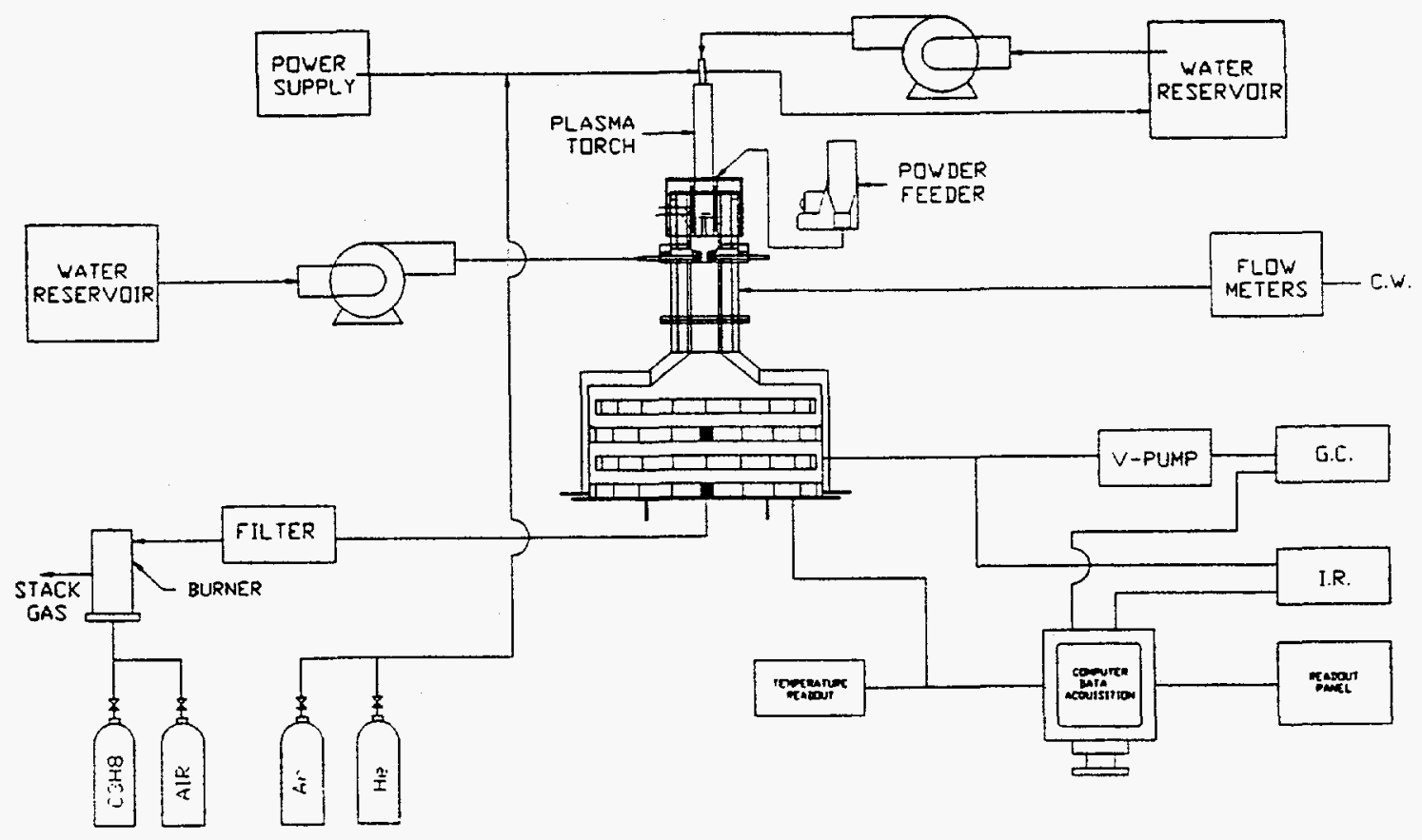

Figure 8. Schematic of the experimental system.

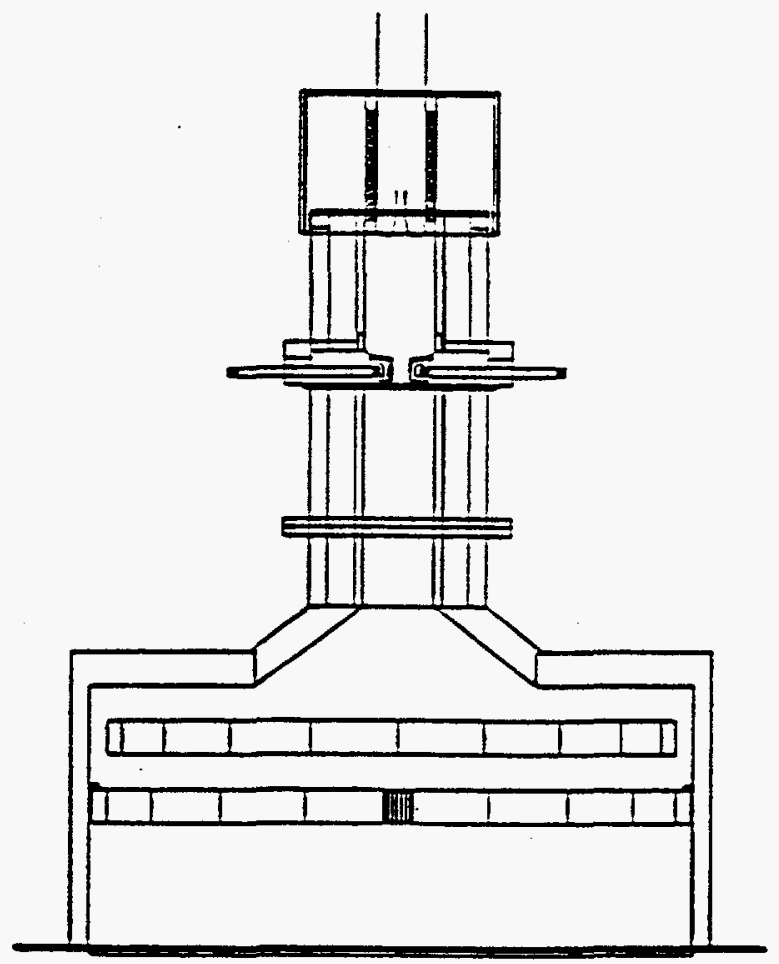

Figure 9. Reactor schematic. 

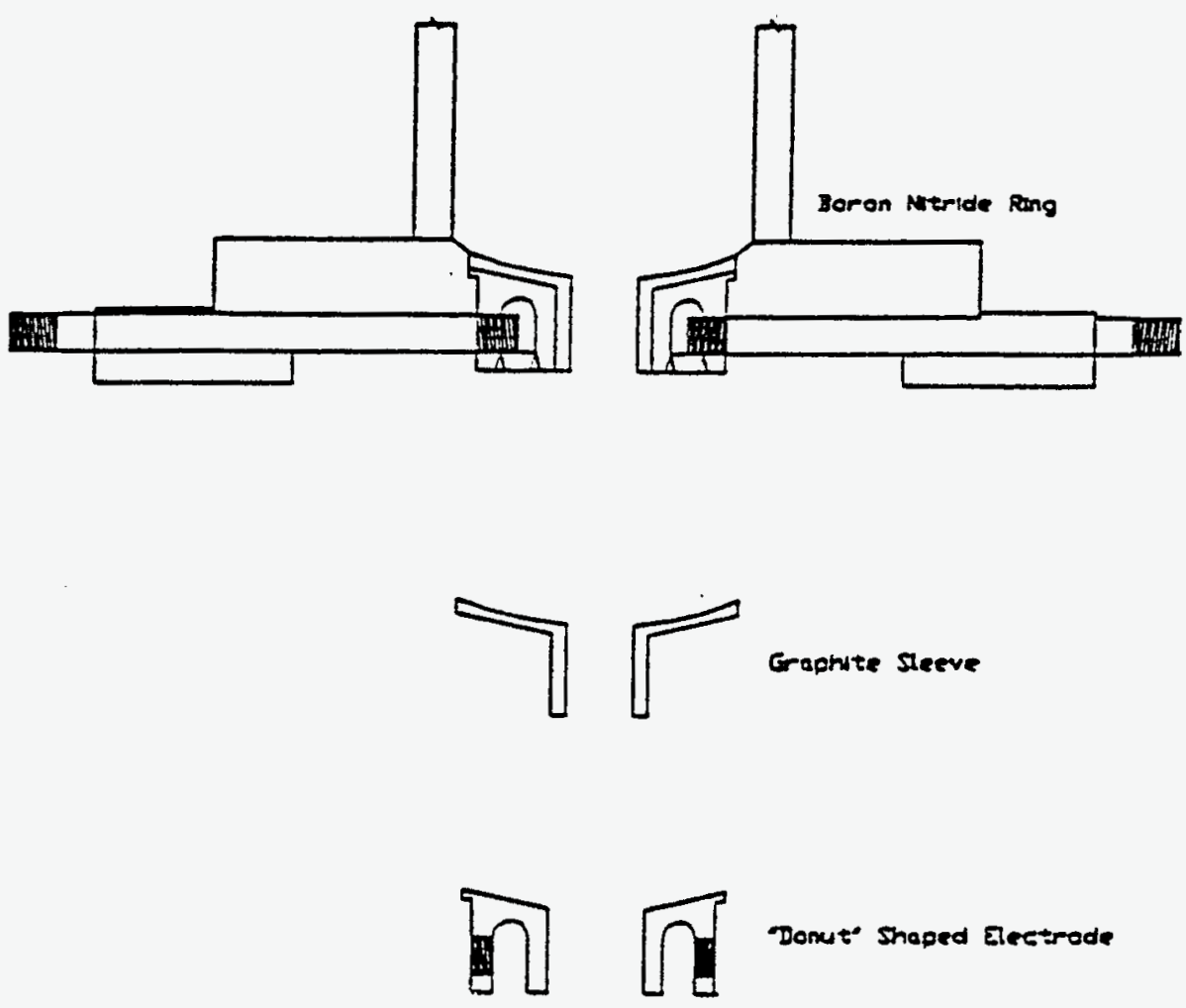

Figure 10. Sketch of the lower electrode assembly.

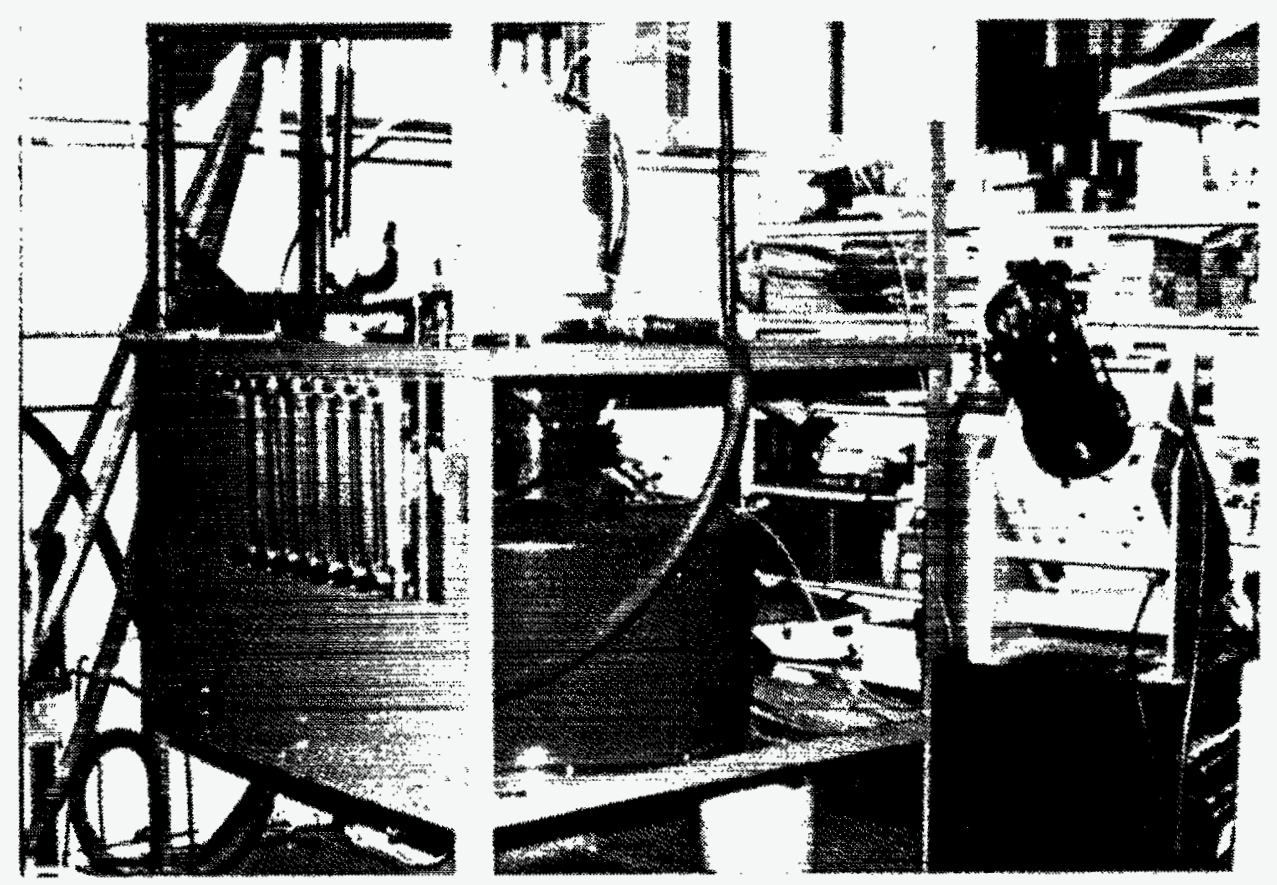

Figure 11. Photograph of the reactor. 
All of the information from the experiments such as temperature, gas, and water flow rates and other torch operating parameters was collected through an interface with a data acquisition system.

The general operating conditions for the experiments are given in Table 3. The first few runs were performed without any feed material to evaluate the operating behavior and performance of the experimental setup and to establish the proper running conditions for smooth operation, especially from the arc stability point of view. In the initial experiments, the second section (extended flow zone) of the reactor was removed in order to observe the arc behavior under different operating conditions. Figure 12 shows the arc emerging from the lower electrode (cathode). After the initial open section experiments, an energy balance was performed at different electrode gaps from 2 to 7 inches.

\section{Results}

Aluminum, nickel, and iron were chosen to produce them in a nanocrystalline state. Reagent-grade pure metal powders of different sizes were used as the feed material. The experimental conditions (shown in Table 3) were kept similar for all these metals. Aluminum powder $(-325 \mathrm{mesh})$ was fed for 20 minutes at a rate of $5 \mathrm{~g} / \mathrm{min}$. About half of the produced nanosize powder was collected from the copper disk in the quench box. About $30 \%$ was recovered from the water filter, and the rest ended up in the funnel section and the top of the quench box. The particles are mostly in the range of 50 to $80 \mathrm{~nm}$.

Next in the series of experiments was the nickel feed. Reagent-grade nickel powder was used. Figure 13 shows the SEM micrograph of the nickel feed powder, which consists of particles mainly from 5 to $20 \mu \mathrm{m}$. Nickel powder was fed at a rate of $3 \mathrm{~g} / \mathrm{min}$ for 15 minutes. The produced powder was collected from the quench box and the water collection system. An SEM micrograph of the powder collected from the quench box is shown in Figure 14. The powder consists of particles mainly from 50 to $80 \mathrm{~nm}$.

Iron has higher melting and vaporization temperatures than the metals mentioned above. Reagent-grade iron powder ( $-325 \mathrm{mesh})$ was fed into the plasma reactor at a rate of $2.5 \mathrm{~g} / \mathrm{min}$.

Table 3. General operating conditions for the experiments.

\begin{tabular}{ll}
\hline Power & $32 \mathrm{~kW}$ \\
\hline Voltage & $160 \mathrm{~V}$ \\
Current & $200 \mathrm{~A}$ \\
Argon flow rate & $3.0 \mathrm{SCFM}$ \\
Helium flow rate & $3.0 \mathrm{SCFM}$ \\
Distance between the electrodes & $4.5^{\prime \prime}$ \\
Powder feed rate & $2.5-5 \mathrm{~g} / \mathrm{min}$ \\
\hline
\end{tabular}




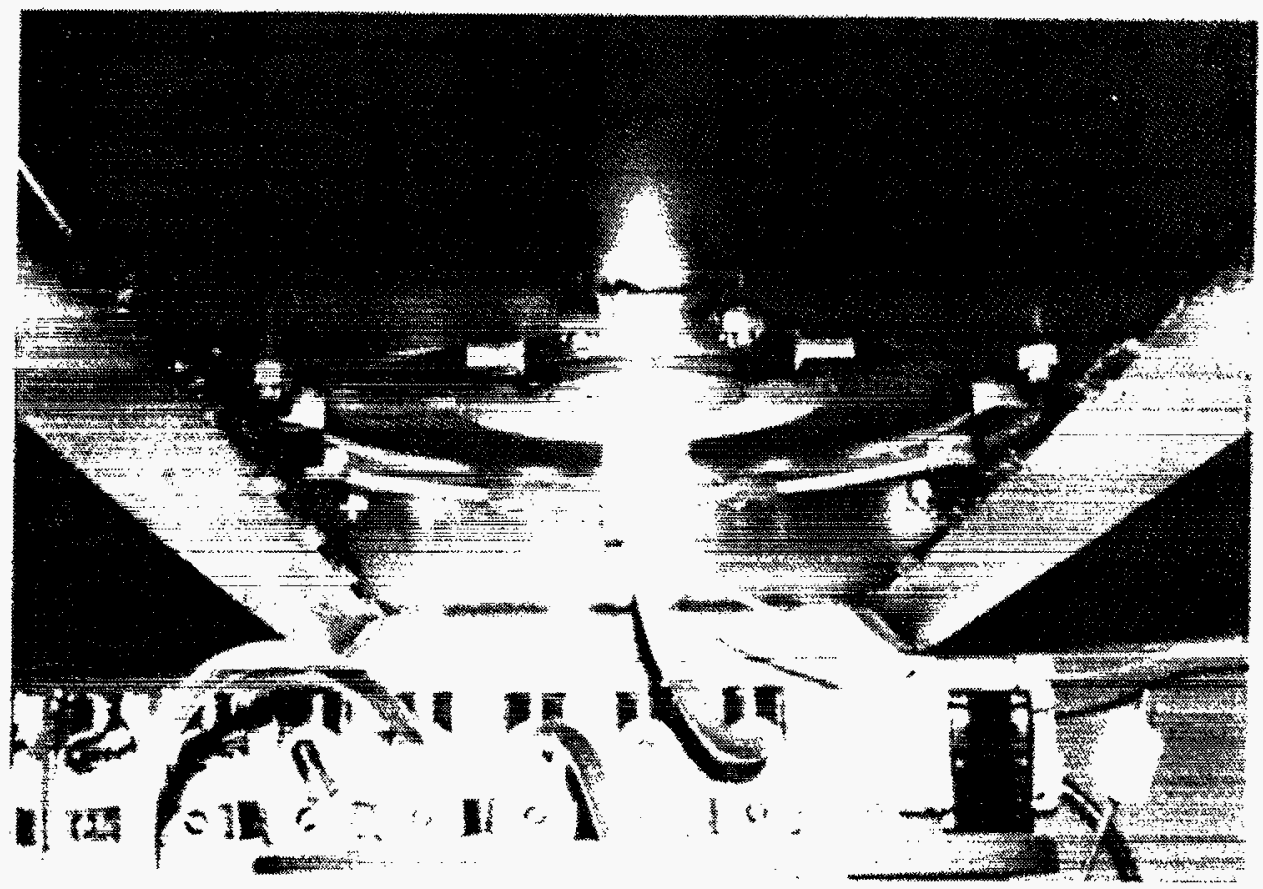

Figure 12. Arc emerging from the lower electrode (Ar-plasma gas).

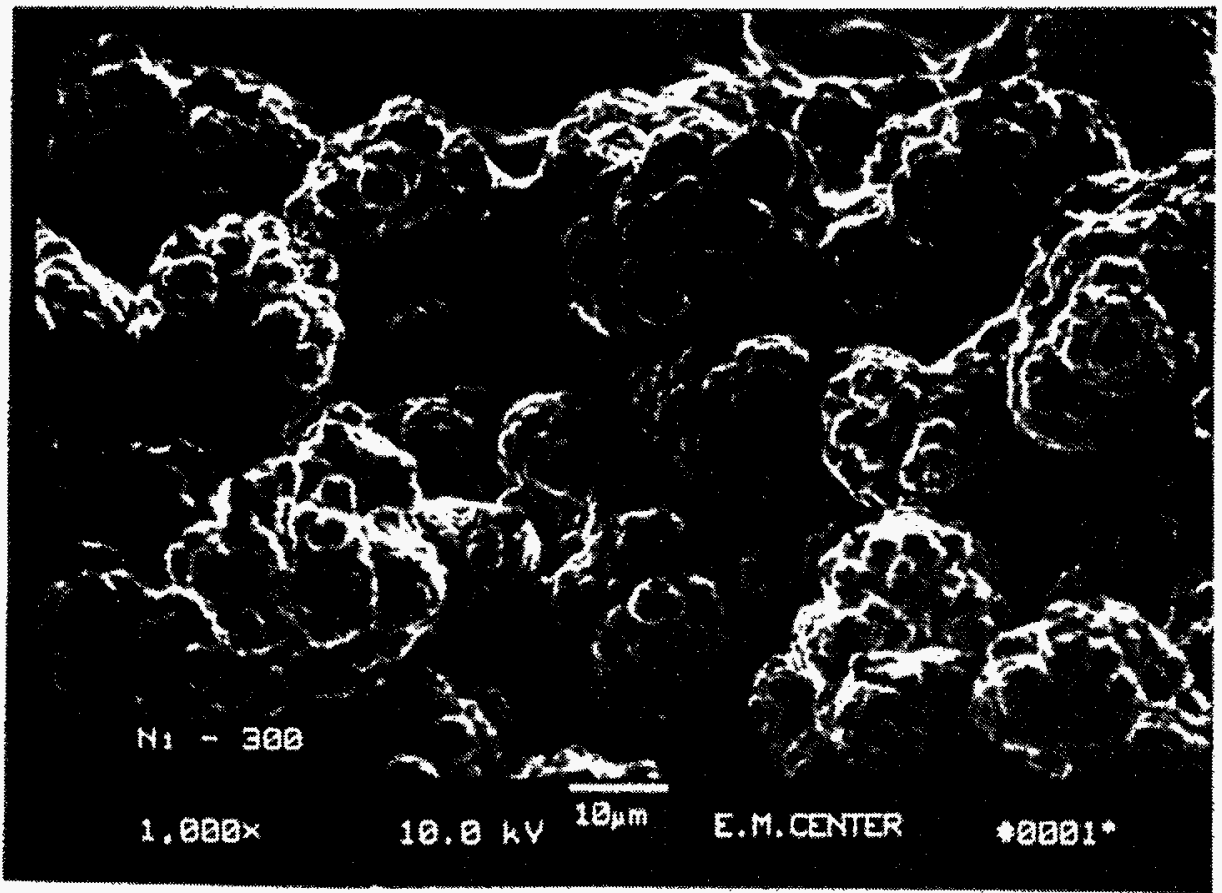

Figure 13. SEM micrograph of nickel feed powder. 


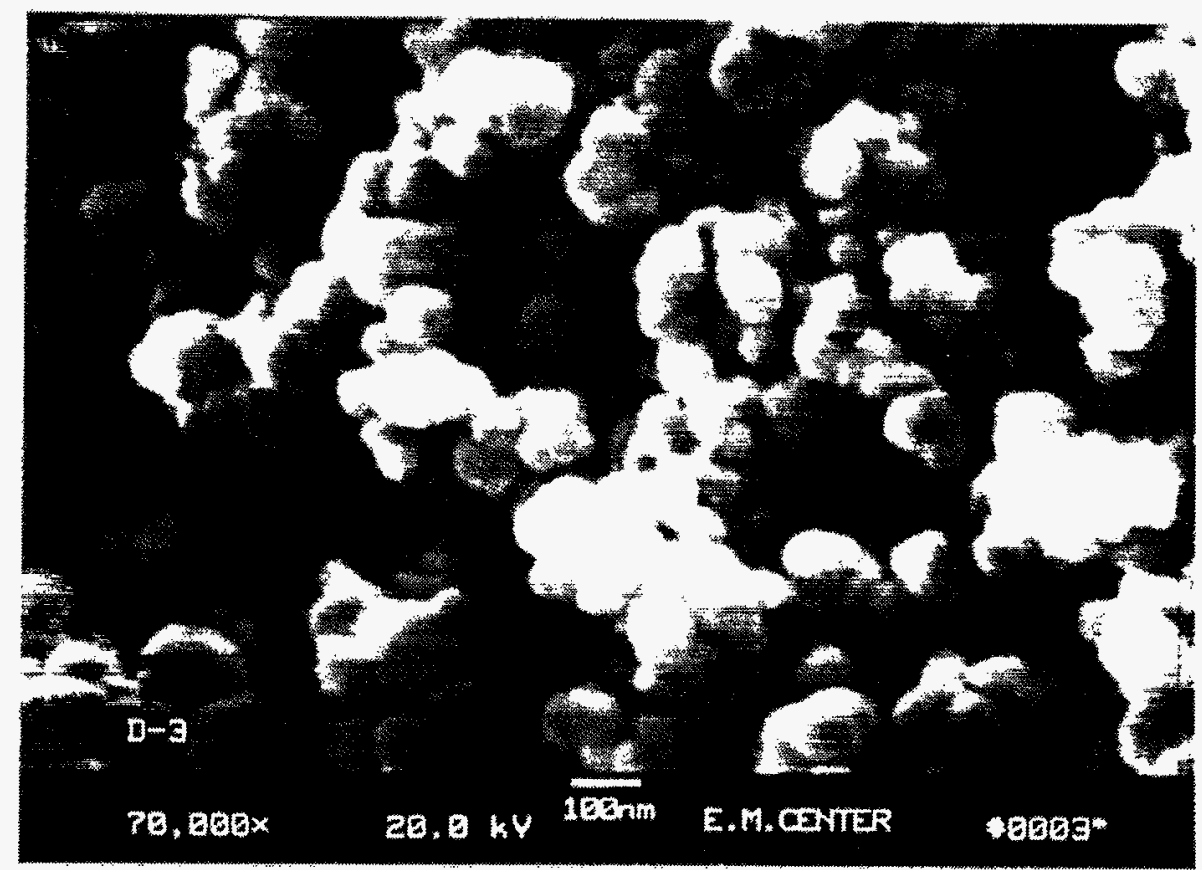

Figure 14. SEM micrograph of nickel powder produced.

The iron particles, after quenching, were collected from the different areas of the quench box and the filter. About 30\% were entrained in the gas leaving the quench box. Figure 15 shows the SEM micrograph for the powder collected from the quench box. The mean particle size in this micrograph is $48 \mathrm{~nm}$. The size distribution for this powder is shown in Figure 16.

Preliminary tests were done for the synthesis of nanosize intermetallics. For the synthesis of nickel aluminide, aluminum ( $-325 \mathrm{mesh})$ and nickel powder $(-325 \mathrm{mesh})$ were used as reactants. Both the powders were mixed in the powder feeder with a molar ratio of (1:1). The powder was fed into the reactor at a feed rate of $2.5 \mathrm{~g} / \mathrm{min}$. X-ray diffraction results on the quench box powder showed the presence of $\mathrm{Al}, \mathrm{Ni}$, and $\mathrm{NiAl}$ phases.

\section{Conclusions}

A novel thermal plasma reactor was designed and built. The reactor provides for the development of an extended plasma flame by utilizing a variable height transferred arc to a donutshaped electrode. Nanocrystalline metals are produced in the thermal plasma reactor. The reactor appears to be capable of producing sufficient quantities of nanosized materials for subsequent consolidation and analysis. 


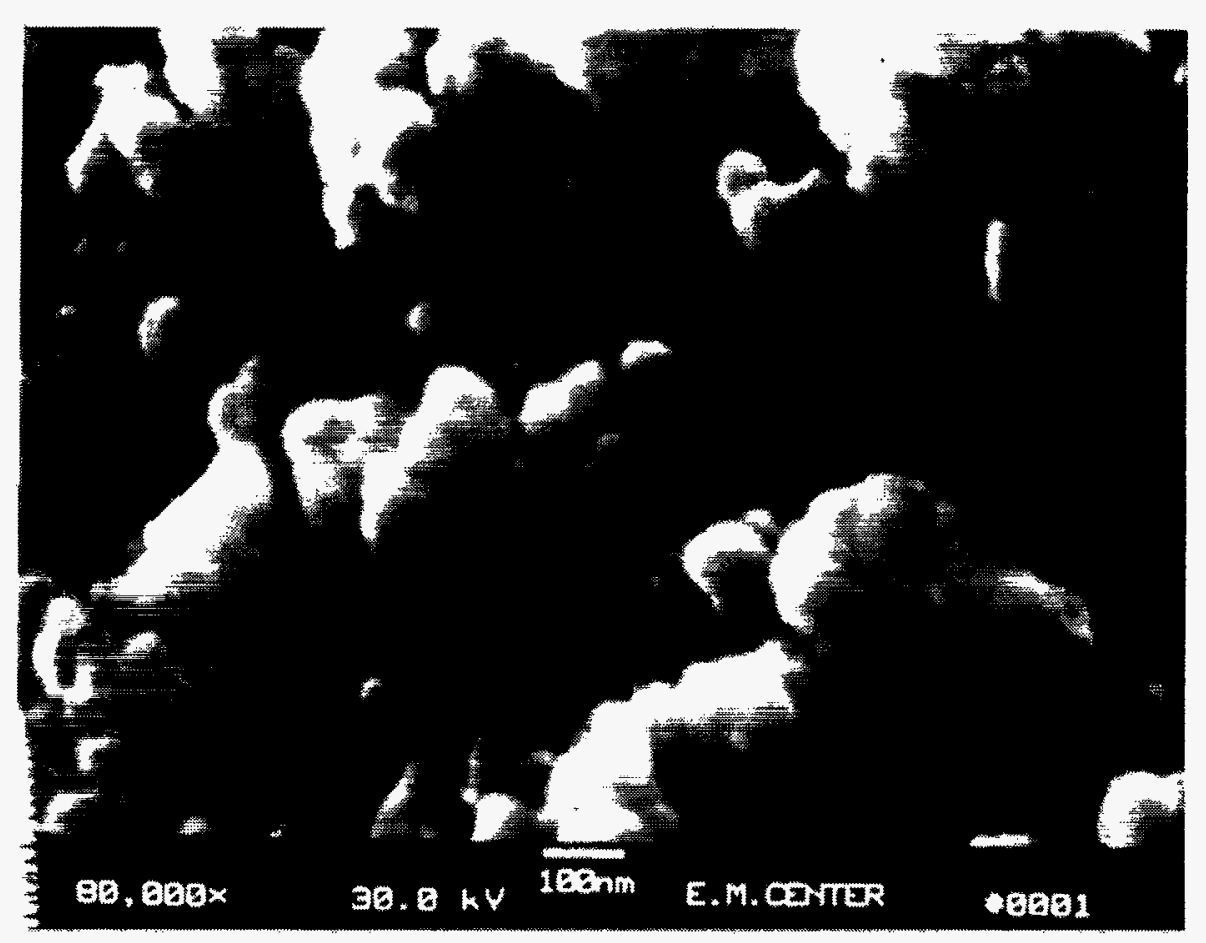

Figure 15. SEM micrograph of iron powder produced.

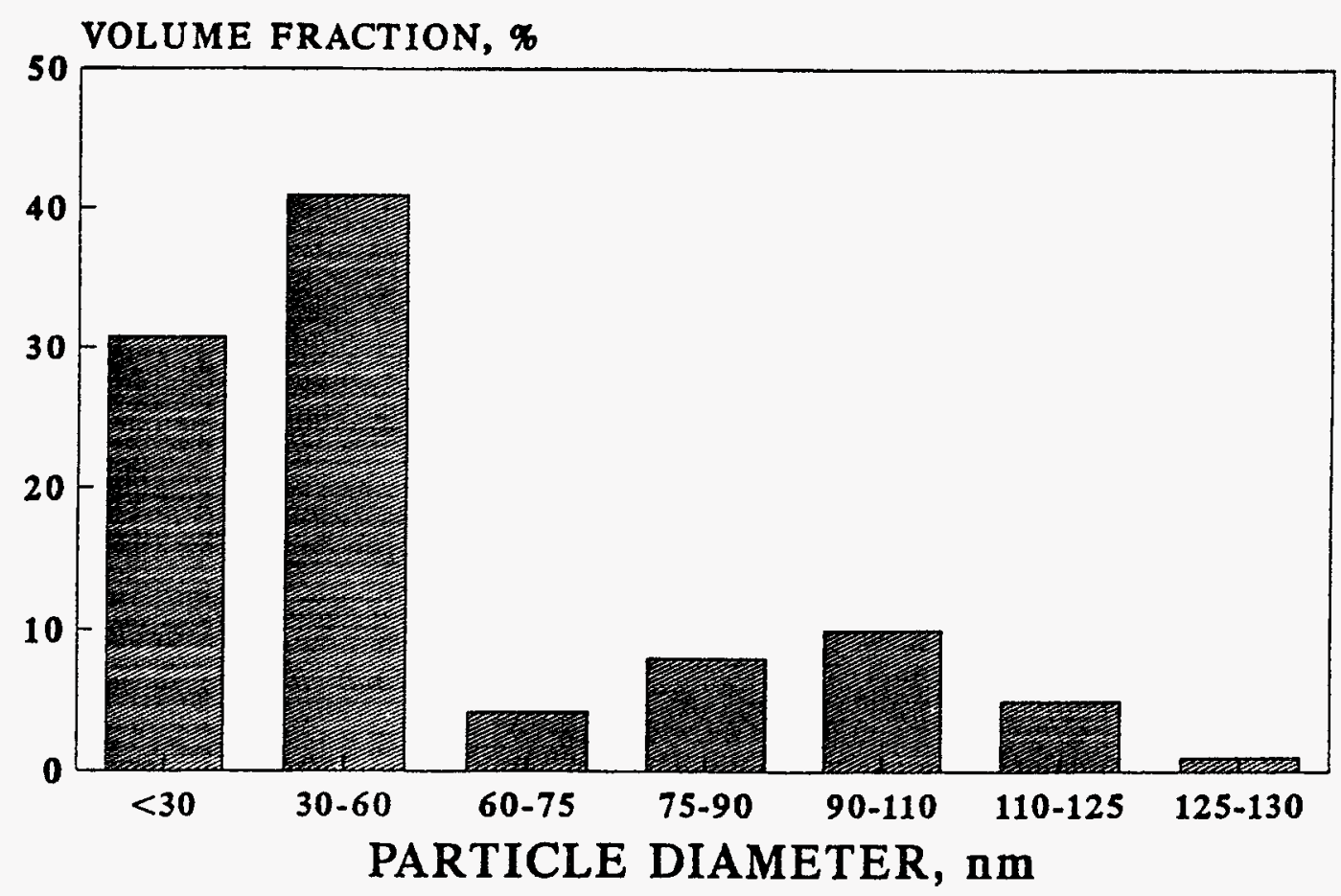

Figure 16. Size distribution of iron powder produced. 


\section{MECHANICAL ALLOYING}

\section{Personnel}

1. F.H. Froes

2. C. Suryanarayana

3. D.K. Mukhopadhyay

4. Guo-Hao Chen

5. Abdulbaset Frefer

6. Gary Cizmich

7. Gary E. Korth

\section{Introduction}

Mechanical alloying (MA) is a solid-state powder processing technique involving repeated welding, fracturing, and rewelding of powder particles in a dry, high-energy ball mill. ${ }^{14-16}$ Mechanical alloying has been shown to be a powerful technique in allowing even further excursions from equilibrium than Raman spectroscopy, in addition to its more traditional application to produce oxide-dispersion strengthened nickel- and iron-based alloys. ${ }^{15,16}$ The presence of these non-equilibrium phases allows greater flexibility and control of the final equilibrium microstructure, thereby producing materials with properties superior to those obtained by more conventional ingot metallurgy and casting techniques. The non-equilibrium phases synthesized by MA include supersaturated solid solutions, metastable crystalline or quasicrystalline intermediate (intermetallic) phases, and amorphous phases. ${ }^{16,17}$ Mechanical alloying also results in a highly refined microstructure with a grain size down to nanometer levels. ${ }^{18,19}$ The development of nanostructures through $\mathrm{MA}$ in the $\mathrm{Al}-\mathrm{Fe}, \mathrm{Ti}-\mathrm{Al}$, and $\mathrm{Ti}-\mathrm{Al}-\mathrm{Nb}$ systems is the major thrust of this program.

\section{Experimental Procedure}

Mechanical alloying was carried out at room temperature either in a SPEX 8000 mixer mill or a Szegvari $01-\mathrm{HD}$ attritor. Generally, about $10 \mathrm{~g}$ of the powder was produced at a time in the SPEX mill and about $100 \mathrm{~g}$ in the attritor. The grinding medium was 3/16-in. diameter hardened 52100 steel balls.

For MA in the SPEX mill, a ball-to-powder weight ratio of 10:1 (100 g of steel balls and $10 \mathrm{~g}$ of powder) was normally used. Occasionally, the ball-to-powder weight ratio was changed to different values (e.g., 2:1, 5:1, 20:1, 50:1, or 100:1) to investigate its impact on the powder constitution and the time taken to produce a specific phase in the powder mix. The ball-topowder weight ratio in the attritor was $20: 1$ or 30:1, and a continuous flow of argon was maintained to minimize/prevent powder oxidation. The loading and unloading of the powders for the SPEX milling was done inside an argon-filled glove box. Other atmospheres, such as air, nitrogen, and helium, were also employed to investigate the effect of atmosphere on the milling behavior. 
To minimize excessive cold welding of the powder particles amongst themselves and to the grinding medium and the container walls, about 1 to 2 wt.\% of a process control agent, generally stearic acid $\left(\mathrm{C}_{18} \mathrm{H}_{36} \mathrm{O}_{2}\right)$, was used. Further, to improve intimate mixing and to avoid formation of a thick crust at the bottom, the vial was rotated through $90^{\circ}$ every 30 minutes and was inverted (through $180^{\circ}$ ) every 2 hours.

Table 4 gives the purity and mesh size of the starting elemental powders. Prealloyed Ti$24 \mathrm{Al}-11 \mathrm{Nb}$ (at.\%) powder prepared by the plasma rotating electrode process was also used to evaluate the differences in the milling characteristics between the blended elemental and prealloyed powders, and their effect on the nanostructure formation.

Small quantities of the powder were withdrawn from the vials at regular time intervals inside an argon-filled glove box to follow the progress of alloying via $x$-ray diffraction (XRD), transmission electron microscopy (TEM), and scanning electron microscopy (SEM) techniques. The milled powders were heat-treated by sealing them in evacuated glass tubes to evaluate the stability of the phases formed.

Consolidation of MA powder was investigated by using three methods: hot isostatic pressing (HIP'ing), the Ceracon process, and dynamic compaction using explosives. These three methods are illustrated schematically in Figure 17. The difficulty in consolidating the MA powders is to achieve full density, metallurgical bonding of the powder particles, and still retain the metastable nanosized grains. Elevated temperature is required to obtain particle-to-particle bonding and pressure for densification, but elevated temperatures can also result in grain coarsening. Uniaxial hot pressing was tried earlier in the investigation, but the maximum pressure available with the apparatus was only $60 \mathrm{MPa}$, which was not sufficient to give high-density compacts without quite high temperatures that caused considerable coarsening of the nanostructure. HIP'ing represents a more conventional process, but requires a fairly long time (an hour or two) at temperature. The Ceracon process, which is capable of much higher pressures than HIP'ing also requires less time (of the order of a minute during actual consolidation), but a preheat is necessary, so the powder is at high temperature for several minutes. Dynamic or shock consolidation is a very highpressure technique in which the room temperature powder is exposed to a high-intensity compression wave for only a few microseconds. The very high strain rate densification results in localized heating of the particle surfaces, which bonds them together, and the bulk of the powder particle remains relatively cool.

Table 4. Purity and size of starting powders for ma.

\begin{tabular}{lcc}
\hline \multicolumn{1}{c}{ Powder } & Purity & Mesh Size \\
\hline Aluminum & $>99.7 \%$ & -100 \\
Iron & $>99.4 \%$ & -325 \\
Titanium & $>99.4 \%$ & -100 \\
Niobium & $>99 \%$ & -20 \\
\hline
\end{tabular}




\section{Consolidation Methods}

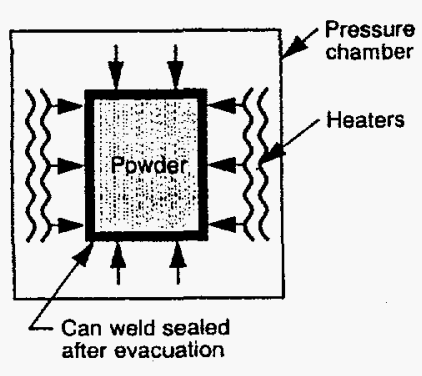

HIP

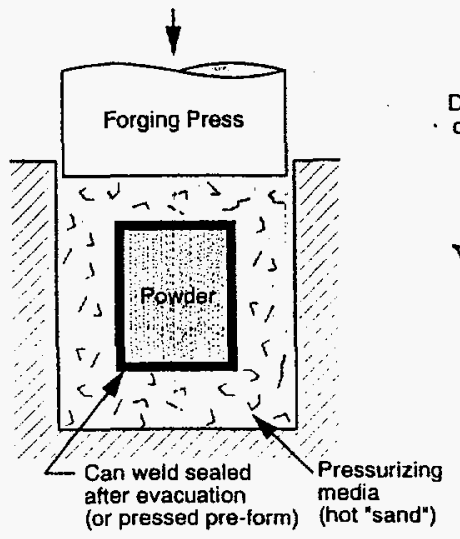

Ceracon

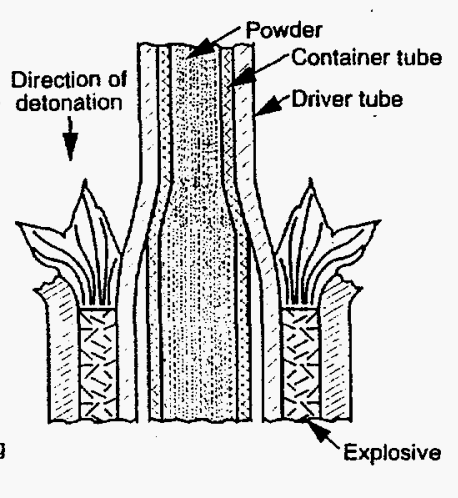

Dynamic

Figure 17. Schematic of the three consolidation methods used on the MA powder.

The consolidated compacts were again characterized using XRD, TEM, and SEM techniques. Additionally, microhardness measurements were made with a 50-g load on the consolidated $\mathrm{Ti}-\mathrm{Al}$ and $\mathrm{Ti}-\mathrm{Al}-\mathrm{Nb}$ compacts.

\section{Al-Fe System}

Five different alloys with different Fe contents (Table 5) were chosen to investigate the ability of MA to produce metastable effects (supersaturated solutions, intermediate phases, and amorphous phases) and, in particular, nanocrystalline structures.

Table 5. Compositions of Al-Fe alloys investigated.

\begin{tabular}{ccc}
\hline Alloy \# & at.\% Fe & wt.\% Fe \\
\hline 1 & 1 & 2 \\
2 & 4 & 8 \\
3 & 7.3 & 14 \\
4 & 10.7 & 20 \\
5 & 25 & 41 \\
\hline
\end{tabular}


In all the five alloys investigated, a decrease in the particle size was observed with increasing mill time. Figure 18 shows SEM micrographs of the Al-4 at.\% Fe powder in as-blended condition and after milling for 10 hours and 20 hours, indicating that the particle size decreases with increasing milling time. A similar situation was obtained in all the other compositions. A highmagnification SEM micrograph (Figure 19) showed that the particles are composite in nature and are made up of agglomerated nanometer-sized crystals; the crystals are $<100 \mathrm{~nm}$ in size in the Al10.7 at.\% Fe powder MA up to 30 hours.

The XRD patterns in each case showed that the $\mathrm{Al}(200)$ and $\mathrm{Al}(220)$ peaks overlap with $\mathrm{Fe}(110)$ and $\mathrm{Fe}(200)$ peaks, respectively, and only the $\mathrm{Al}(111)$ and $\mathrm{Al}(311)$ peaks are seen clearly and separately. Increasing milling time caused the peaks to broaden and decrease their intensities due to both the refinement of crystal size and introduction of strain during milling. In powders with high Fe contents, the $\mathrm{Al}(111)$ peak is found to have a lower intensity than the $\mathrm{Al}(200)$ peak, whereas at lower Fe contents, the $\mathrm{Al}(111)$ peak is more intense, as expected.

Figure 20 shows the XRD patterns of the Al-7.3 at.\% Fe powder as a function of milling time. With increasing milling time, the $\mathrm{Al}$ peaks shifted to higher angles, suggesting alloying of $\mathrm{Fe}$ with $\mathrm{Al}$, leading to formation of a solid solution. The lattice parameter of the $\mathrm{Al}$ solid solution, calculated from the position of the $\mathrm{Al}(311)$ peak, had decreased at 20 hours from the initial value of $0.40497 \mathrm{~nm}$ in the as-blended state to $0.4015 \mathrm{~nm}$ for the Al-7.3 at.\% Fe powder and to about $0.4022 \mathrm{~nm}$ for the Al-4 at.\% Fe powder. Thereafter, it remained constant, indicating that a steady-state condition has been reached. The steady-state lattice parameters in different powder compositions were used to calculate the solid solubility in each case using the master plot of lattice parameter versus $\mathrm{Fe}$ content. From this, it is clear that a maximum of 4.5 at.\% Fe can be dissolved in $\mathrm{Al}$ in the solid state by $\mathrm{MA}$.
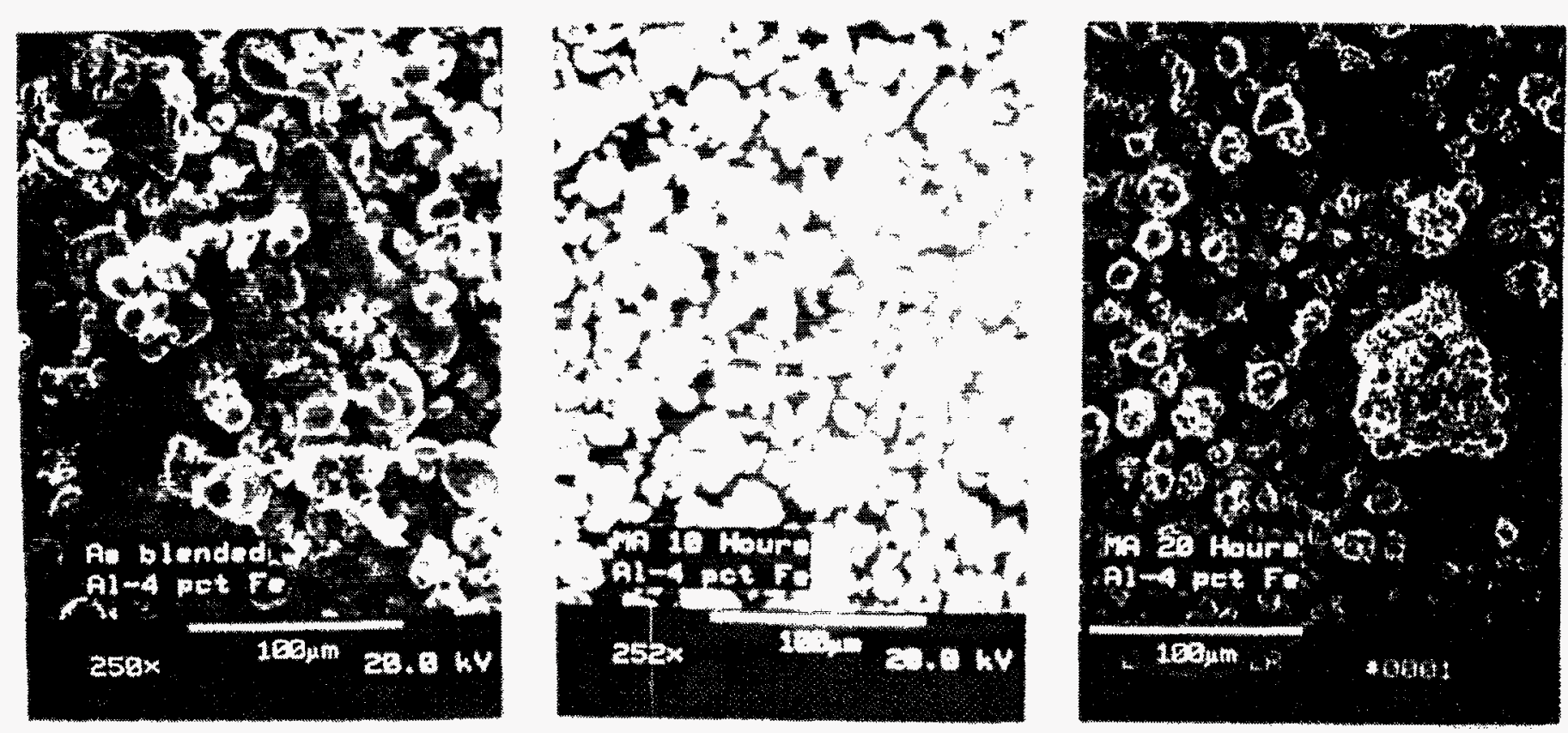

Figure 18. Scanning electron micrographs of the Al-4 at.\% Fe powder (a) as-blended, (b) milled for 10 hours, and (c) milled for 20 hours showing a decrease in the particle size with milling time. 


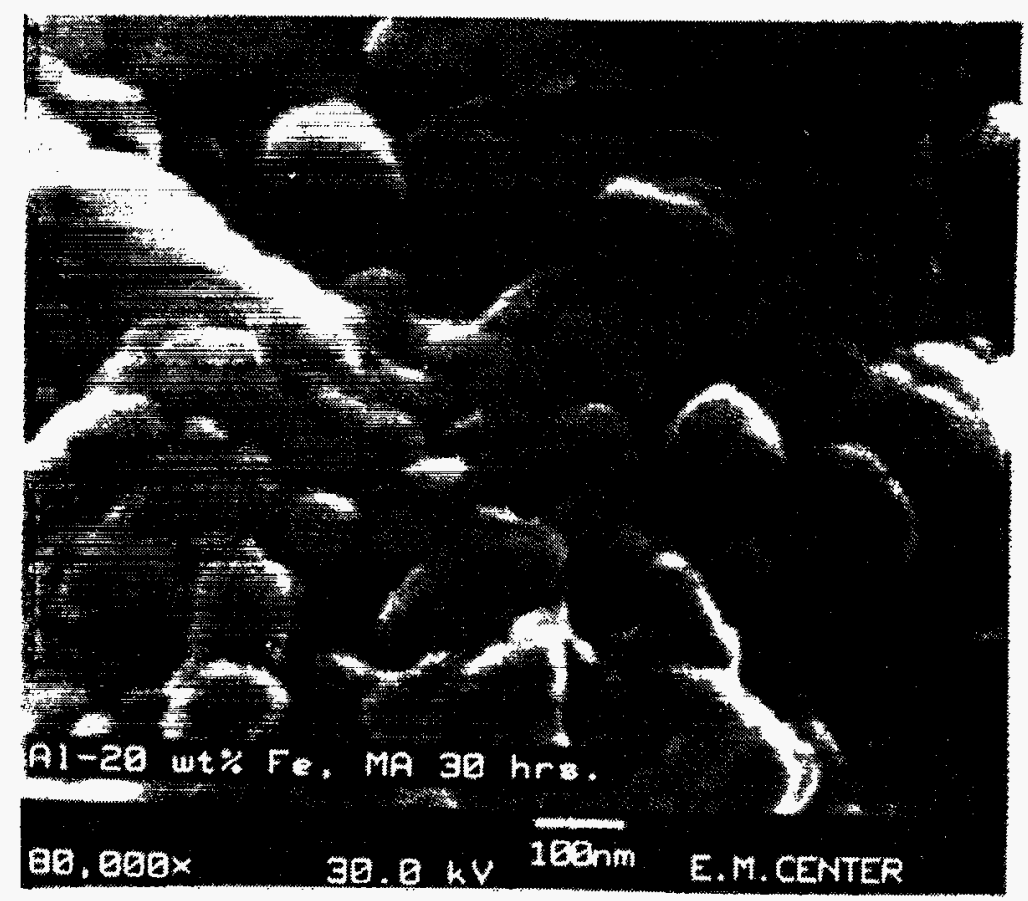

Figure 19. Scanning electron micrograph of the Al-10.7 at.\% Fe powder MA for 30 hours, showing the presence of nanometer sized crystals.

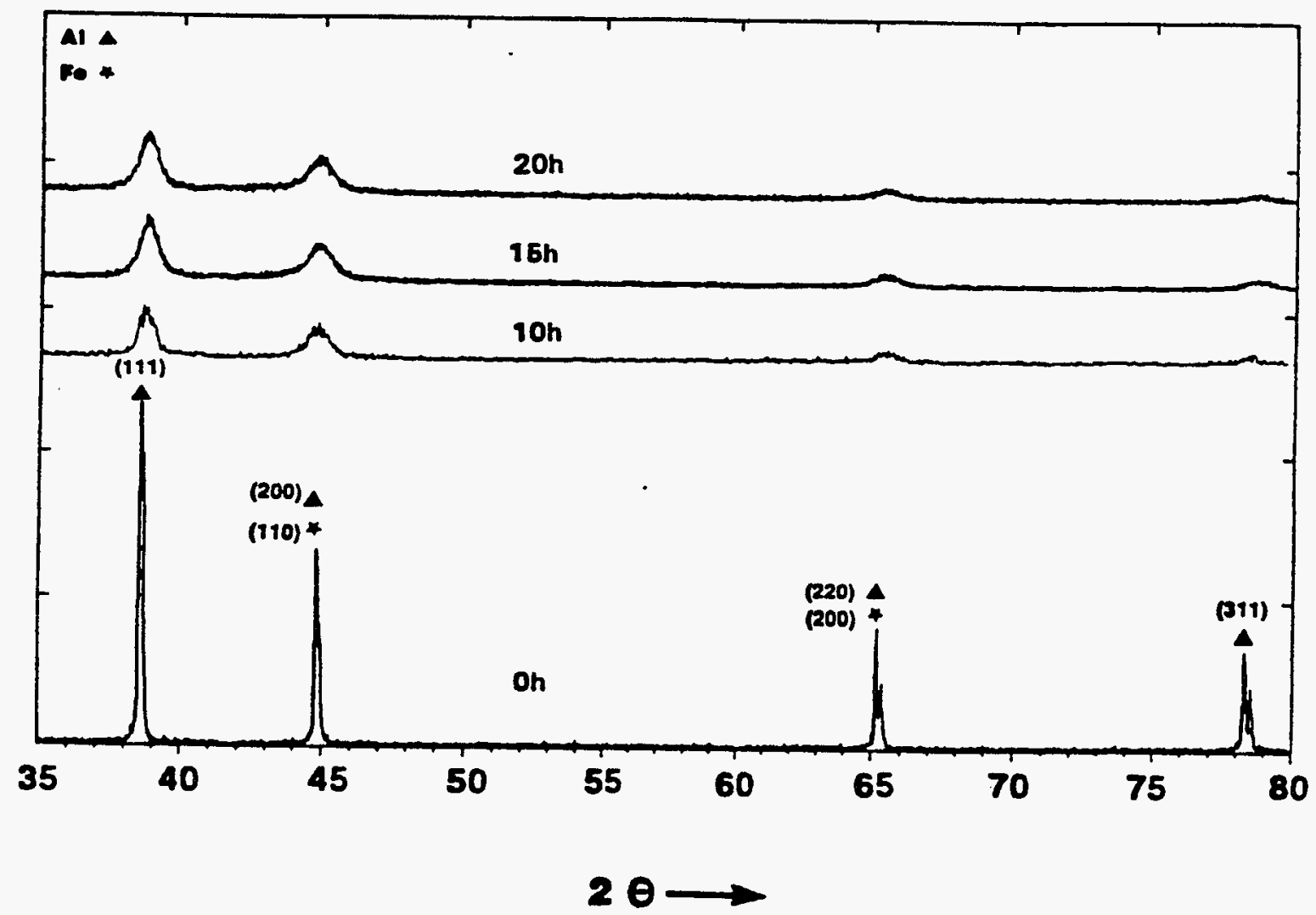

Figure 20. X-ray diffraction patterns of $\mathrm{Al}-7.3$ at.\% Fe powder as a function of MA time. 
Nanostructure formation was evaluated using the Scherrer formula, ${ }^{20} \mathrm{~d}=0.9 \lambda / \mathrm{B} \cos \theta$ where $\mathrm{d}$ is the crystal size, $\lambda$ is the $\mathrm{x}$-ray wavelength, $\mathrm{B}$ is the full width at half maximum peak height, and $\theta$ is the Bragg angle, and subtracting the strain and instrumental broadening effects. Nanometer-sized crystals are formed in all of the alloys after long MA times (Figure 21). Increasing the ball-to-powder weight ratio resulted in a faster rate of decrease of crystal size.

Synthesis of Al-rich Al-Fe intermetallics was attempted by MA of blended elemental powders in a SPEX mill. A mixture of Al-25 at.\% (41 wt.\%) Fe powders was milled in a SPEX mill, and the x-ray diffraction patterns recorded at different times of milling are shown in Figure 22. With increasing milling time, the peaks became broader and their intensities decreased (Figure 22b). After 15 hours of milling formation, a new phase is seen (Figure 22c). Formation of this new intermetallic phase, without any trace of either $\mathrm{Al}$ or $\mathrm{Fe}$, is complete on milling for 30 hours (Figure 22d), and the powder became amorphous after further milling (Figure 22e). The $x$-ray diffraction peaks from the new phase could be indexed as belonging to $\mathrm{Al}_{5} \mathrm{Fe}_{2}$ having an

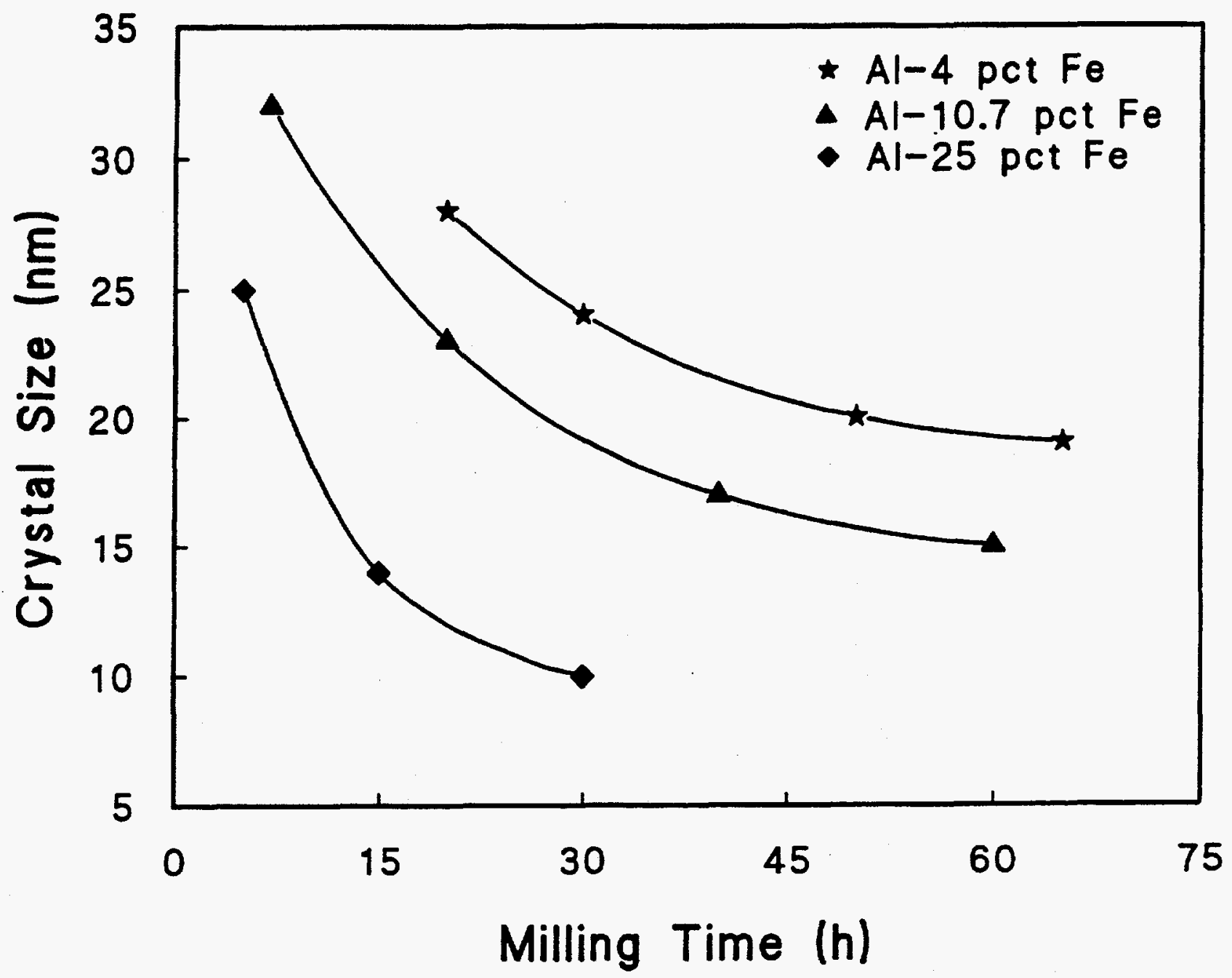

Figure 21. Plot showing the variation of crystal size with milling time in $\mathrm{Al}-4,10.7$ and 25 at.\% Fe powders. 


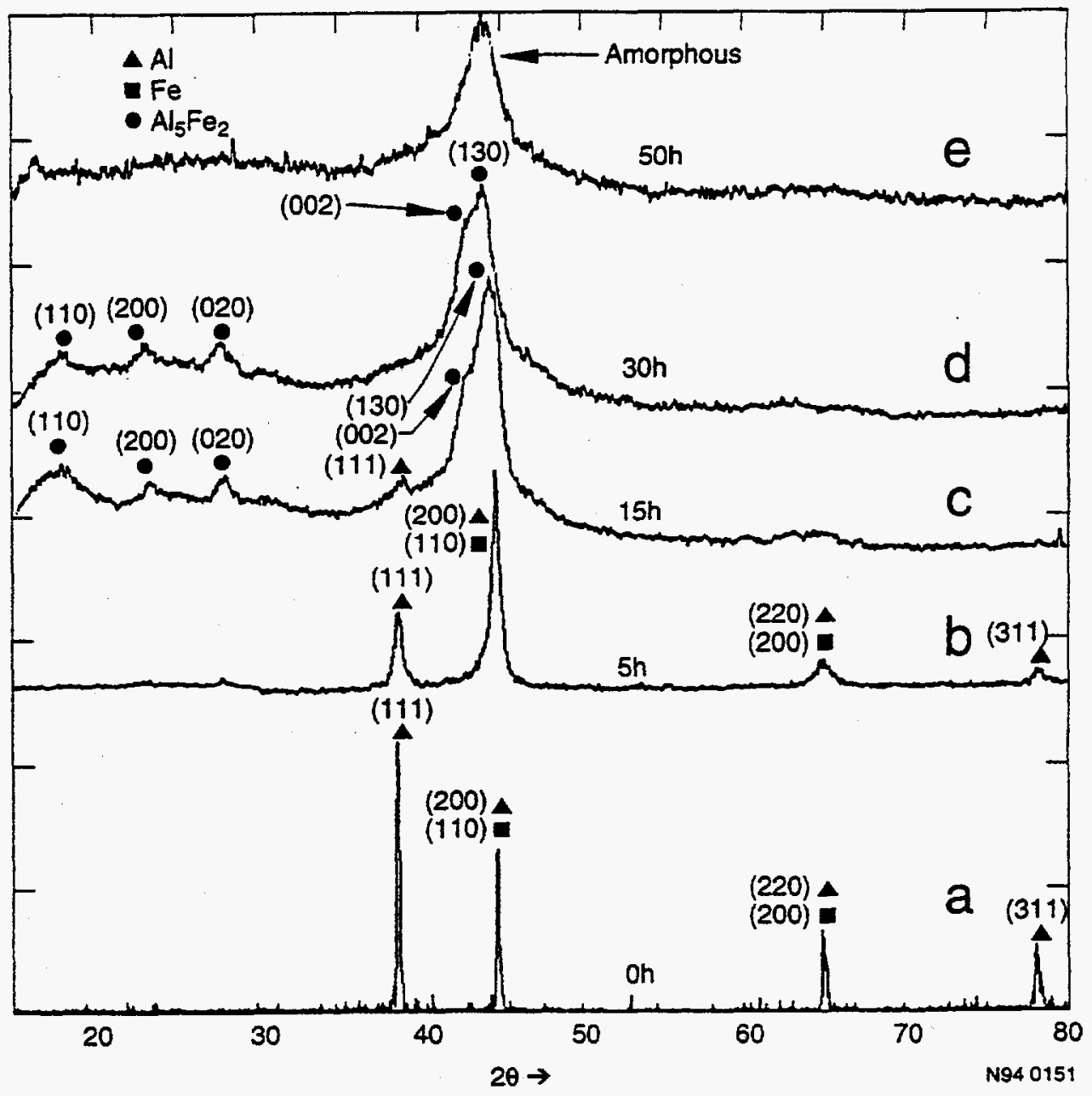

Figure 22. X-ray diffraction patterns of blended elemental nominal Al-25 at.\% Fe mechanically alloyed powders (a) as-mixed, (b) after milling for 5 hours, (c) 15 hours, (d) 30 hours, and (e) 50 hours.

orthorhombic structure with the lattice parameters $a=0.767 \mathrm{~nm}, \mathrm{~b}=0.64 \mathrm{~nm}$, and $c=0.42 \mathrm{~nm}$. Thus, the sequence of phase evolution with milling time in this powder mix is

$\mathrm{Al}+\mathrm{Fe} \stackrel{30 \mathrm{~h}}{\longrightarrow} \mathrm{Al}_{5} \mathrm{Fe}_{2} \stackrel{50 \mathrm{~h}}{\longrightarrow}$ Amorphous

Even though complete formation of the $\mathrm{Al}_{5} \mathrm{Fe}_{2}$ compound was observed after 30 hours of milling, the peaks are relatively broad due to the fine crystal size and the presence of strain in the powder. After the powder was milled for 30 hours, it was annealed at $625^{\circ} \mathrm{C}$ for 324 hours, resulting in sharp $\mathrm{x}$-ray diffraction lines (Figure 23 ), including a number with low intensities that did not show up in the as-milled powder. However, there is no difference either in the structure or the lattice parameters of this phase between the as-milled and annealed conditions. The sequence of reflections observed in the $x$-ray diffraction patterns and a calculation of the structure factors indicated that the $\mathrm{Al}_{5} \mathrm{Fe}_{2}$ phase is in the ordered state, although the degree of ordering is far from complete. 


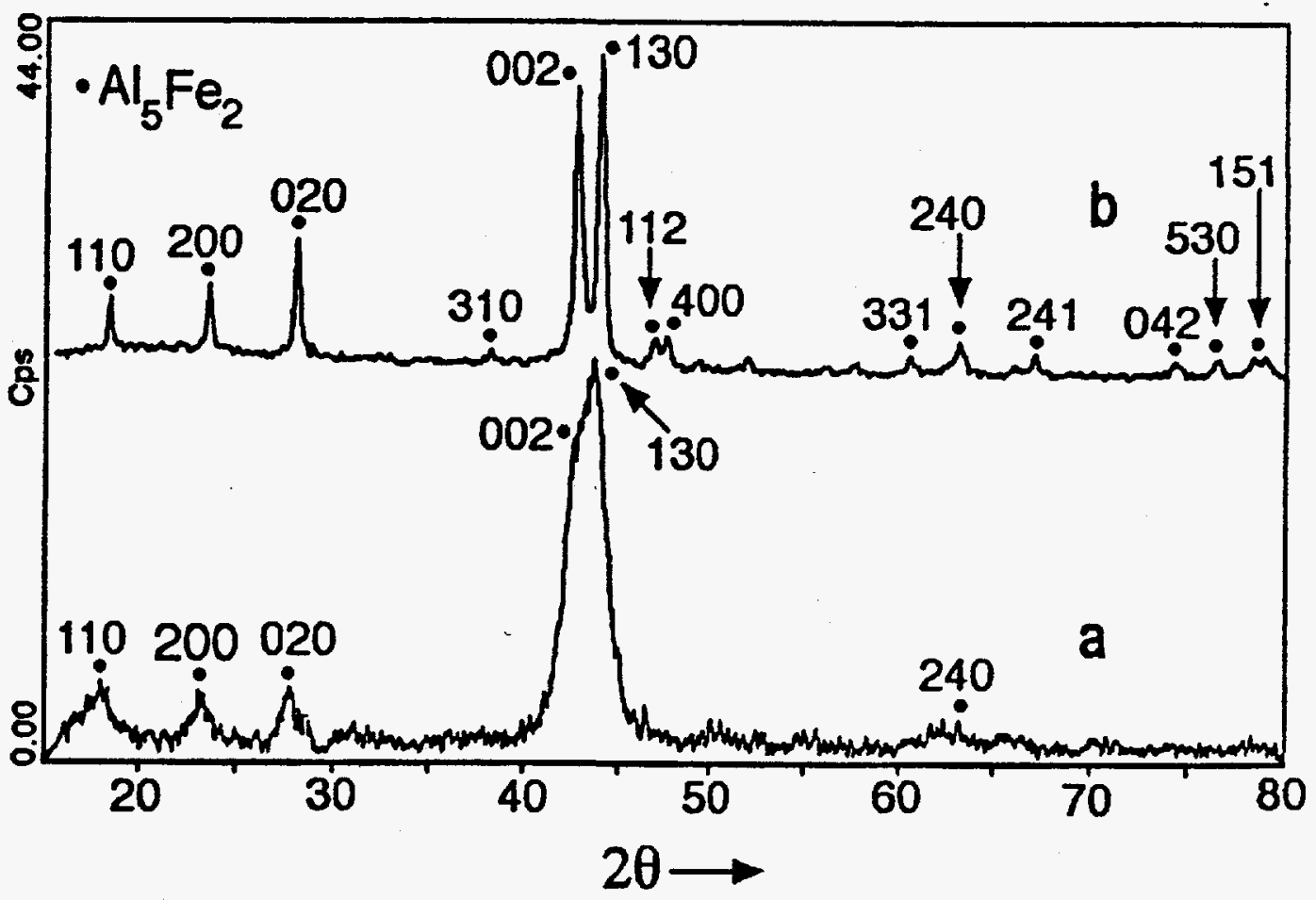

Figure 23. X-ray diffraction patterns of the Al-25 at.\% Fe powders, (a) mechanically alloyed for 30 hours, (b) mechanically alloyed for 30 hours and heat treated at $625^{\circ} \mathrm{C}$ for 324 hours.

Since the starting powder was of the overall $\mathrm{Al}_{3} \mathrm{Fe}$ composition, EDS analysis was conducted on the MA powders to check whether the composition has changed. The analysis indicated that the powder contains 73.5 at.\% $\mathrm{Al}$ and 26.5 at.\% Fe. This change in composition can be either due to loss of $\mathrm{Al}$ due to sticking of the powder on the container wall and to the grinding balls and/or due to a gain of $\mathrm{Fe}$ from the steel balls and container wall. Since the $\mathrm{Al}_{5} \mathrm{Fe}_{2}$ intermetallic forms under equilibrium conditions in the composition range of about 27 to 29 at. $\% \mathrm{Fe}^{21}$, it is not surprising that formation of homogeneous $\mathrm{Al}_{5} \mathrm{Fe}_{2}$ was observed in the present investigation at an Fe content of 26.5 at.\%. Similarly, Huang ${ }^{22}$ also observed the formation of the $\mathrm{Al}_{5} \mathrm{Fe}_{2}$ in nominally $\mathrm{Al}-24.4$ at.\% Fe powder heat-treated at $500^{\circ} \mathrm{C}$ after MA for 180 hours.

In the other compositions, however, formation of the intermetallic phases was not observed directly by milling; additional heat treatments were necessary.

The crystal size, as determined by x-ray diffraction line broadening technique is about $10 \mathrm{~nm}$ after milling for $\mathbf{3 0}$ hours. Transmission electron microscopy investigations on the shock consolidated powder also showed a similar crystal size (Figure 24).

To determine whether the $\mathrm{Al}_{3} \mathrm{Fe}$ intermetallic can be synthesized directly by MA after compensating for the loss of $\mathrm{Al}$, an extra amount of 1.5 at.\% Al was added to the nominal $\mathrm{Al}-25$ at.\% Fe powder mix prior to $\mathrm{MA}$. However, the $\mathrm{Al}_{3} \mathrm{Fe}$ intermetallic phase did not form; instead, a solid solution of $\mathrm{Fe}$ in $\mathrm{Al}$ formed at early milling times, and an amorphous phase formed after 50 hours. Although the enthalpy of formation of $\mathrm{Al}_{3} \mathrm{Fe}(28.1 \mathrm{~kJ} / \mathrm{g}$-atom) is very close to that of $\mathrm{Al}_{5} \mathrm{Fe}_{2}\left(28.3 \mathrm{~kJ} / \mathrm{g}\right.$-atom), $\mathrm{Al}_{3} \mathrm{Fe}$ could not be directly synthesized probably due to the complex crystal (monoclinic) structure and large size of the unit cell. The Miedema model ${ }^{23}$ 


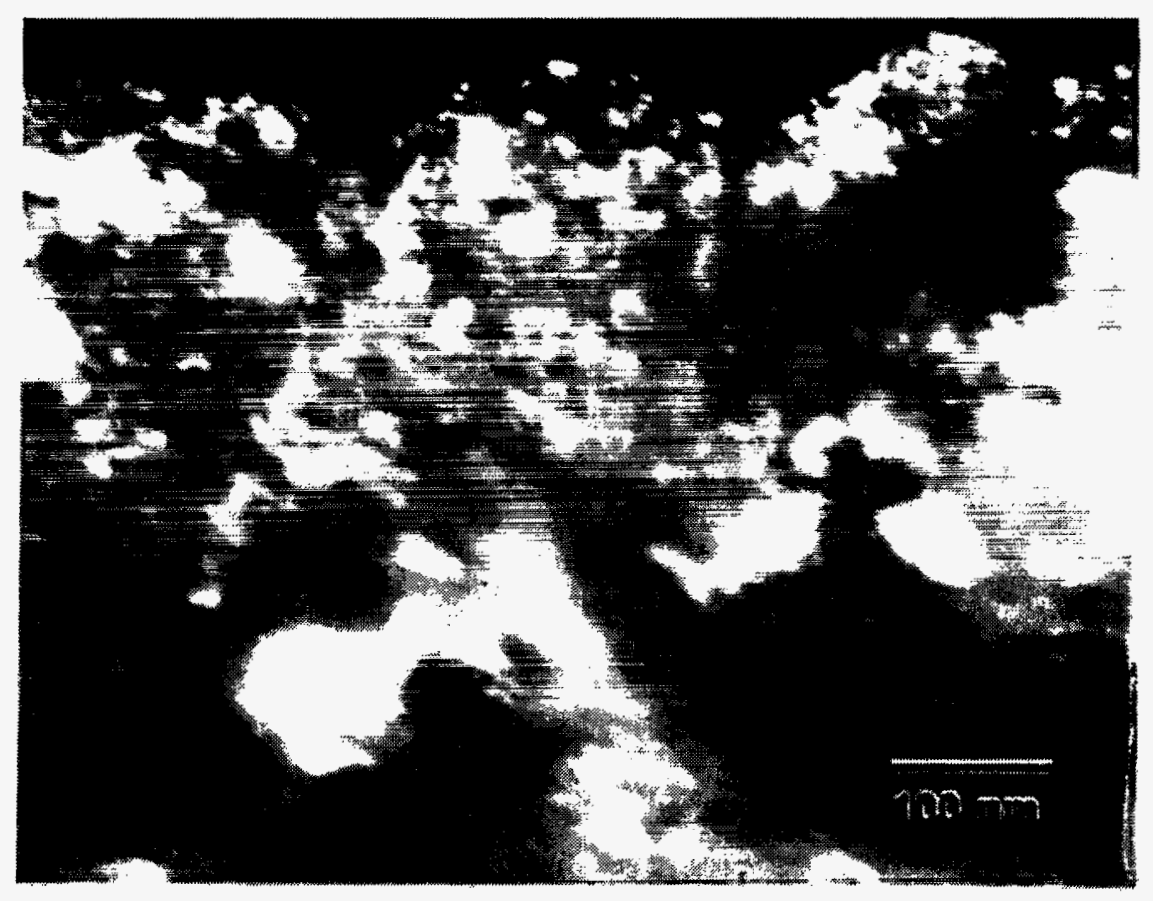

a.

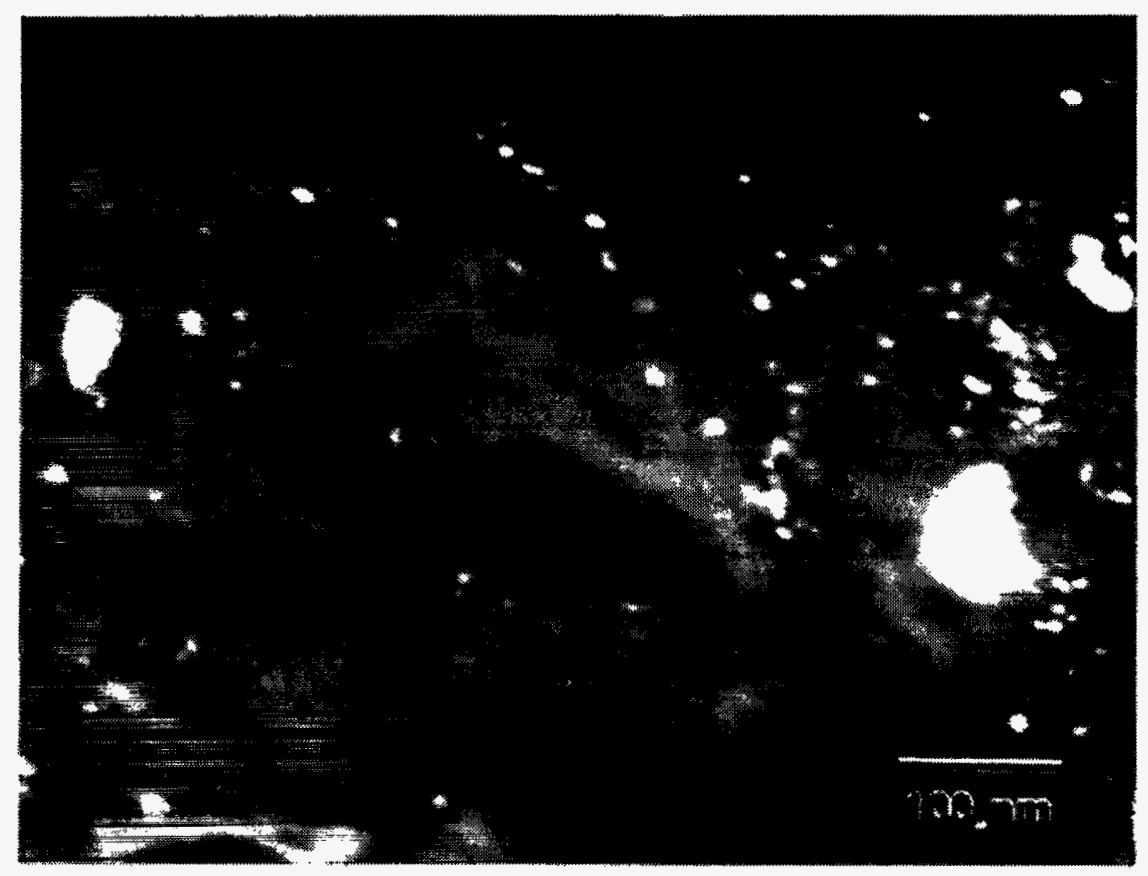

b.

Figure 24. Transmission electron micrographs of the shock-consolidated specimens of (a) Al-10.7 at.\% Fe powder MA for 65 hours and (b) Al-25 at.\% Fe powder MA for 15 hours showing the presence of 25- to 30-nm nanocrystals. 
predicts that an amorphous phase should form in the composition range 25 to 60 at.\% $\mathrm{Fe}$ in the Al-Fe system in agreement with the present work (Figure 25).

An amorphous phase was obtained after milling the Al-25 at.\% Fe powder for 50 hours. Electron diffraction techniques confirm the formation of the amorphous phase in the powder (Figure 26). However, only partial amorphization was observed in the Al-10.7 at.\% Fe powder after 50 hours of milling. Amorphization was not observed in $\mathrm{Al}-1,4$, and 7.3 at.\% Fe compositions.

The mechanically alloyed $\mathrm{Al}-10.7$ and 25 at.\% Fe powders were cold-compacted at $167 \mathrm{MPa}$. The pressure was later increased to $333 \mathrm{MPa}$, yielding densities of 61.6 and $63.7 \%$ of the theoretical values. Subsequent hot compaction of these cold-pressed samples at $550^{\circ} \mathrm{C}$ and 20 $\mathrm{MPa}$ increased the density only slightly, to 64.3 and $65.9 \%$ of the theoretical values for the 10.7 and 25 at.\% Fe alloys, respectively. Dynamic consolidation of these powders was not satisfactory either. A combustion synthesis reaction occurred during consolidation, which may have led to considerable grain coarsening in these powders.

In conformity with the results for the heat-treated powders, XRD patterns of the compacted $\mathrm{Al}-10.7$ and 25 at.\% $\mathrm{Fe}$ powders showed the presence of the $\mathrm{Al}_{3} \mathrm{Fe}$ and $\mathrm{Al}_{5} \mathrm{Fe}_{2}$ phases, respectively.

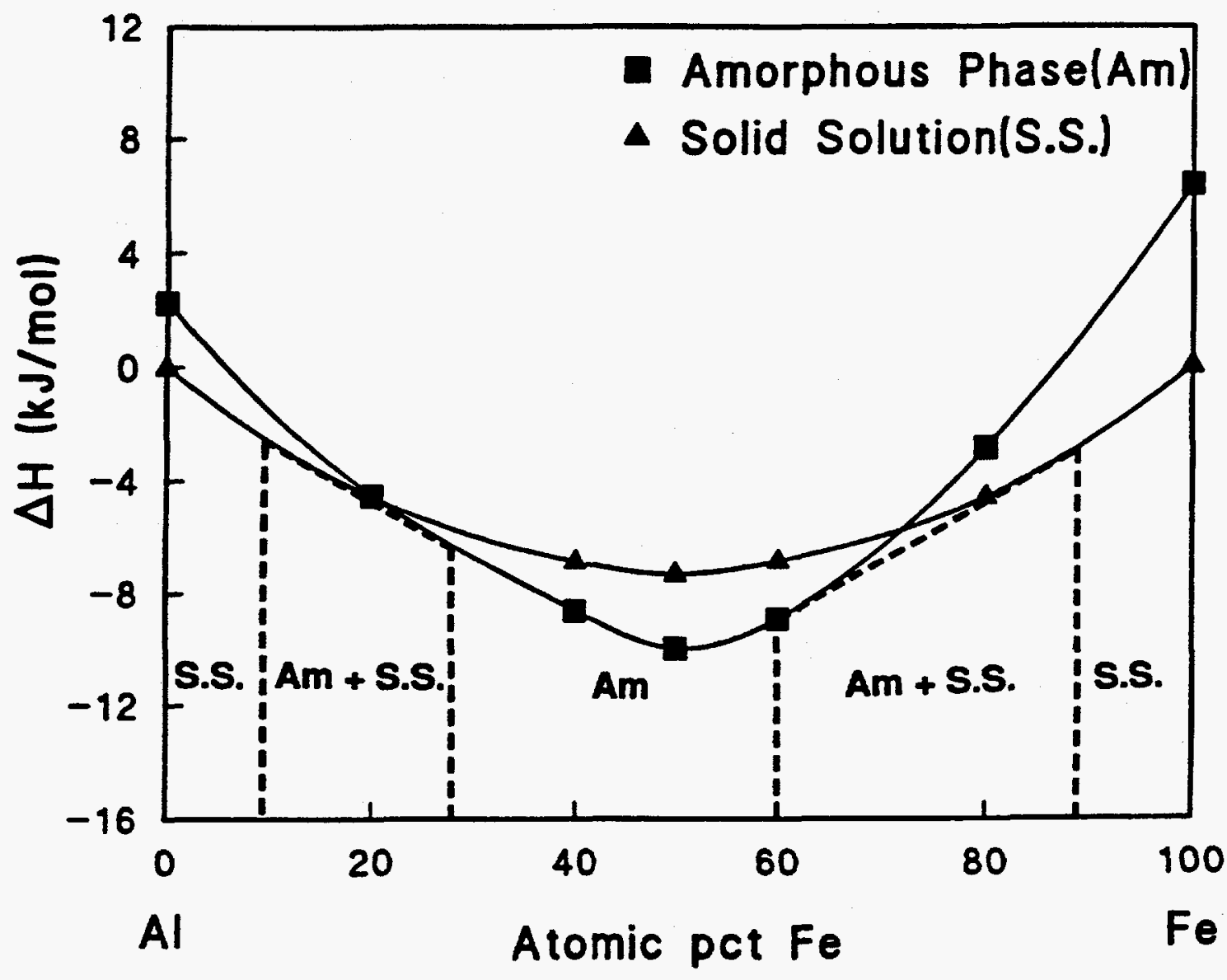

Figure 25. Calculated enthalpy versus composition diagram for the Al-Fe system using the Miedema model. 


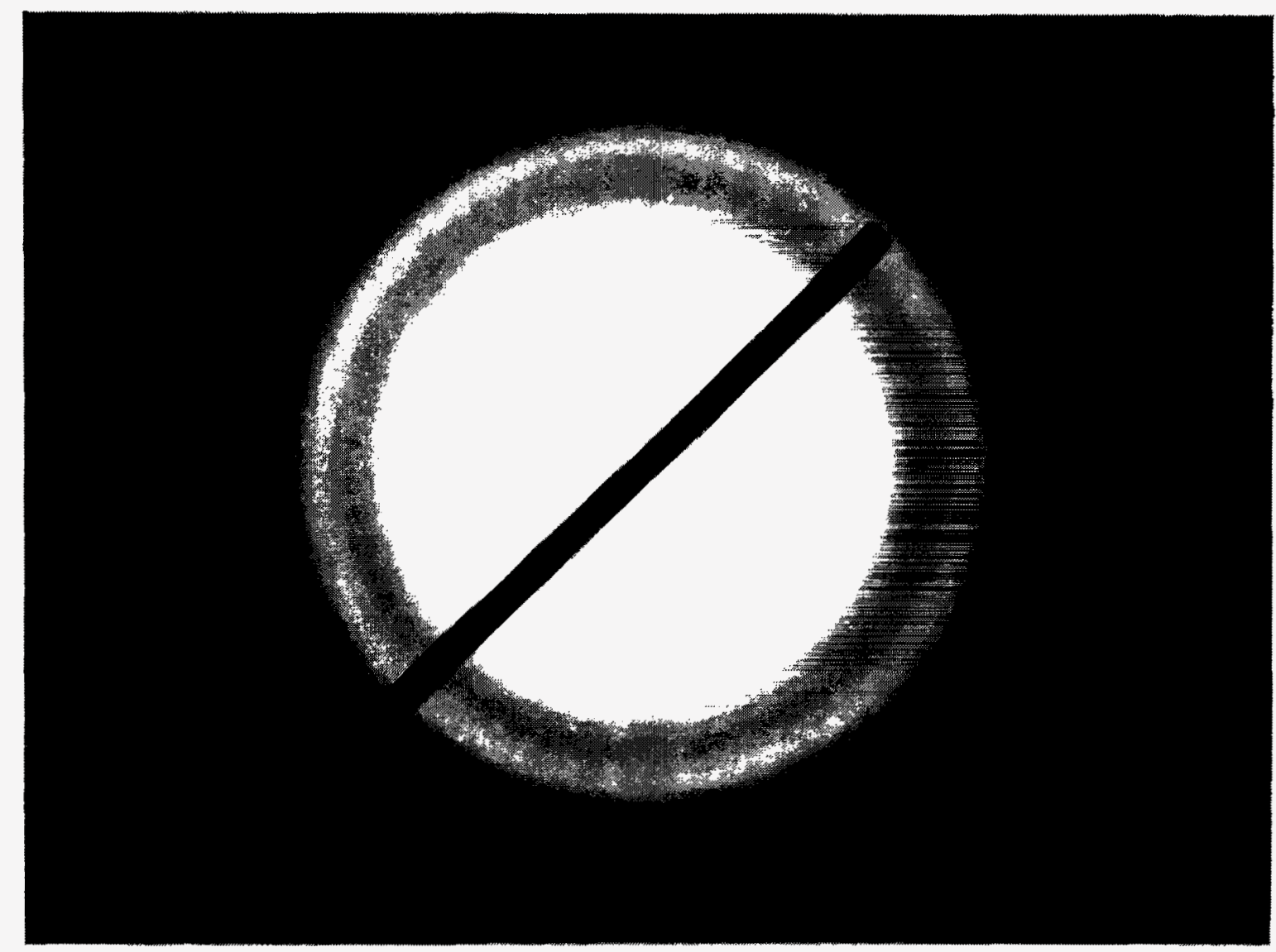

Figure 26. Electron diffraction pattern of $\mathrm{Al}-25$ at.\% Fe powder MA for 50 hours showing full amorphization.

\section{Conclusions}

Based on the results obtained on the mechanical alloying of Al-Fe alloys with 1, 4, 7.3, 10.7, and 25 at.\% $\mathrm{Fe}$, the following conclusions can be drawn:

1. Refinement of the crystal size to the nanometer dimensions was observed in all the compositions studies. Increasing the ball-to-powder weight ratio resulted in faster rate of decrease of crystal size.

2. A maximum extension of solid solubility of 4.5 at.\% $\mathrm{Fe}$ in $\mathrm{Al}$ was observed. The extension of solubility is at least as much as the maximum extension observed by the Raman spectroscopy technique, and can be rationalized on the basis of equilibrium between the supersaturated solid solution and the amorphous phase.

3. The $\mathrm{Al}_{5} \mathrm{Fe}_{2}$ intermetallic could be synthesized directly by $\mathrm{MA}$ in $\mathrm{Al}-25$ at. $\% \mathrm{Fe}$ composition. The formation of intermetallic compound directly by MA was not observed in the other compositions (4, 7.3, and 10.7 at.\% Fe). Here, heat treatment of the milled powders was necessary to synthesize the intermetallic $\mathrm{Al}_{3} \mathrm{Fe}$ compound. 
4. A fully amorphous phase was observed in the $\mathrm{Al}-25$ at.\% Fe powder after 50 hours of milling. A mixture of an amorphous phase and solid solution was observed in the Al10.7 at.\% Fe composition. A thermodynamic analysis based on Miedema's model predicts that full amorphization should be observed in powders from 25 to 60 at. $\% \mathrm{Fe}$; thus, the results of the present investigation fit this prediction.

5. Shock consolidation of $\mathrm{Al}-10.7$ and 25 at.\% Fe powders MA for 65 hours and 15 hours produced near $100 \%$ dense compacts. TEM studies of the shock-consolidated material showed retention of nanometer-sized grains of 25 to $30 \mathrm{~nm}$ in both the Al-10.7 and 25 at.\% Fe powder compacts.

\section{Ti-Al System}

In spite of several attractive properties such as low density, high-temperature strength, creep resistance, and acceptable oxidation resistance, the titanium aluminide intermetallics $\alpha_{2}\left(\mathrm{Ti}_{3} \mathrm{Al}\right)$ and $\gamma(\mathrm{TiAl})$ have yet to find extensive applications in the industry due to their low ductility at ambient temperatures. ${ }^{24-26}$ This problem is most serious in the $\gamma$-TiAl compositions where the room temperature ductility is generally only 1 to $2 \%{ }^{27}$ Since nanostructured materials are expected to show improved ductility over their conventional coarse-grain-sized counterparts, ${ }^{28}$ several Ti-Al powder mixtures (Table 6) were mechanically alloyed either in a SPEX mill or a Szegvari attritor to produce them in a nanocrystalline state to increase their ductility. Attention was focussed only on the Ti-55 at.\% Al composition in the present program for detailed investigations.

Mechanical alloying was conducted either in a SPEX mill or in an attritor. X-ray line broadening studies indicated that the crystal size decreased with milling time in all the cases and reached about $10 \mathrm{~nm}$ in 5 hours milling time (Figure 27). Figure 28 shows the x-ray diffraction patterns of the blended elemental Ti-24 at.\% Al powder mix as a function of milling time. Sequentially, a solid solution of $\mathrm{Al}$ in Ti, an amorphous phase, and an f.c.c. phase formed. Thus, the phase formation sequence in Ti-24 at.\% Al can be represented as

$$
\begin{aligned}
(\mathrm{Ti}+\mathrm{Al}) & \frac{3 \mathrm{~h}}{11 \mathrm{~h}} \mathrm{Ti}(\mathrm{Al}) \text { solid solution } \\
& \frac{11 \mathrm{~h}}{\mathrm{Ti}(\mathrm{Al}) \text { solid solution + Amorphous + f.c.c. }} \text { f.c.c. }
\end{aligned}
$$

Table 6. Compositions of binary Ti-Al powders investigated.

\begin{tabular}{ccc}
\hline Alloy \# & Ti (at.\%) & Al (at.\%) \\
\hline 1 & 76 & 24 \\
2 & 67 & 33 \\
3 & 52 & 48 \\
4 & 50 & 50 \\
5 & 45 & 55 \\
6 & 40 & 60 \\
\hline
\end{tabular}




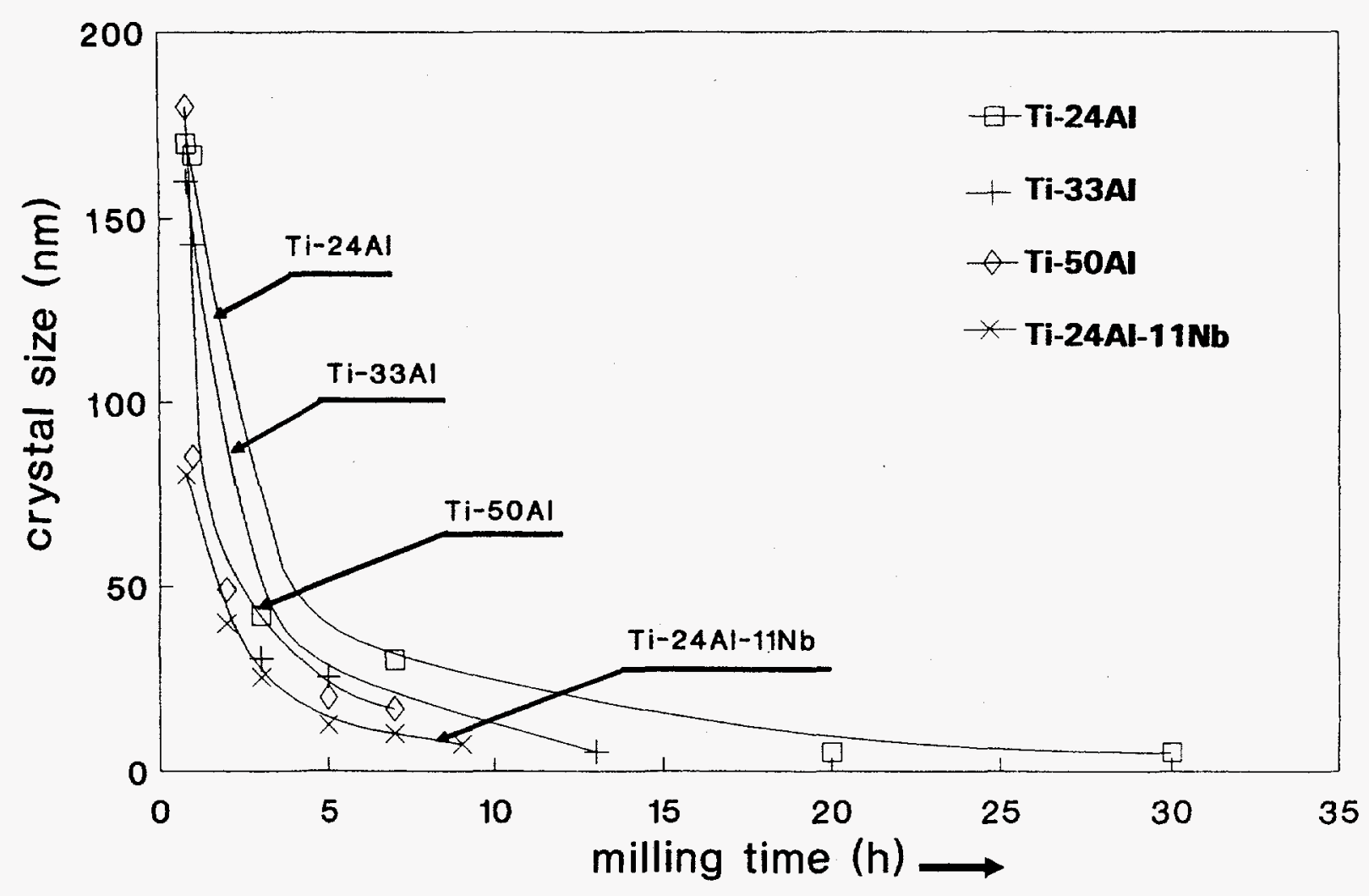

Figure 27. Crystal size as a function of milling time in binary Ti-Al powder mixes.

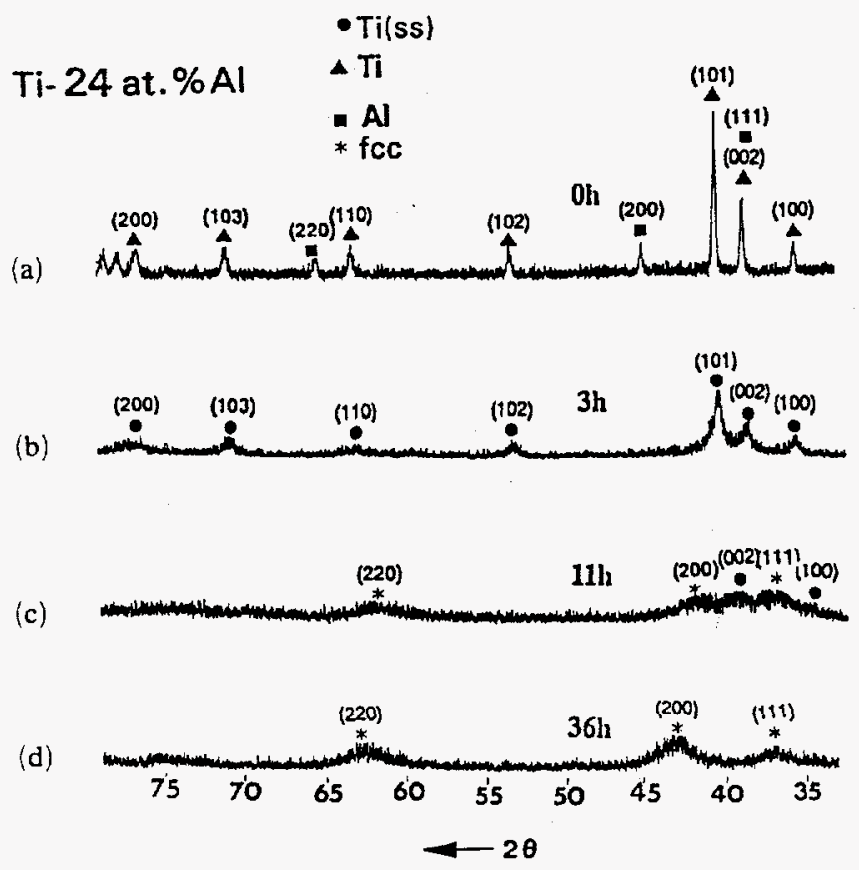

Figure 28. X-ray diffraction patterns of Ti-24 at.\% $\mathrm{Al}$ powder as a function of milling time: (a) as-mixed, 0 hours, and MA for (b) 3 hours, (c) 11 hours, and (d) 36 hours. 
A similar sequence was observed in the Ti-55 at.\% $\mathrm{Al}$ powder mix also (Figure 29), and the phase formation sequence can be represented as

$$
\begin{aligned}
(\mathrm{Ti}+\mathrm{Al}) & \frac{5 \mathrm{~h}}{9 \mathrm{~h}} \mathrm{Ti}(\mathrm{Al}) \text { solid solution }+\mathrm{Al} \\
& \underline{\underline{30 \mathrm{~h}}} \text { Amorphous } \\
& \text { f.c.c. }
\end{aligned}
$$

In general, for all the binary Ti-Al powder mixes, the sequence of phase formation is

$(\mathrm{Ti}+\mathrm{Al}) \rightarrow \mathrm{Ti}(\mathrm{Al})$ solid solution $\rightarrow$ Amorphous $\rightarrow$ f.c.c.

noting that the times for the formation of the different phases are different for different alloy compositions.

Figure 30 shows the electron diffraction patterns confirming formation of the amorphous phase, and Figure 31 shows the f.c.c. phase in the Ti-55 at.\% Al powder mix.

The times required for the formation of different phases during milling were evaluated by varying the ball-to-powder weight ratios from 10:1 to 100:1 during milling of a Ti-33 at.\% Al

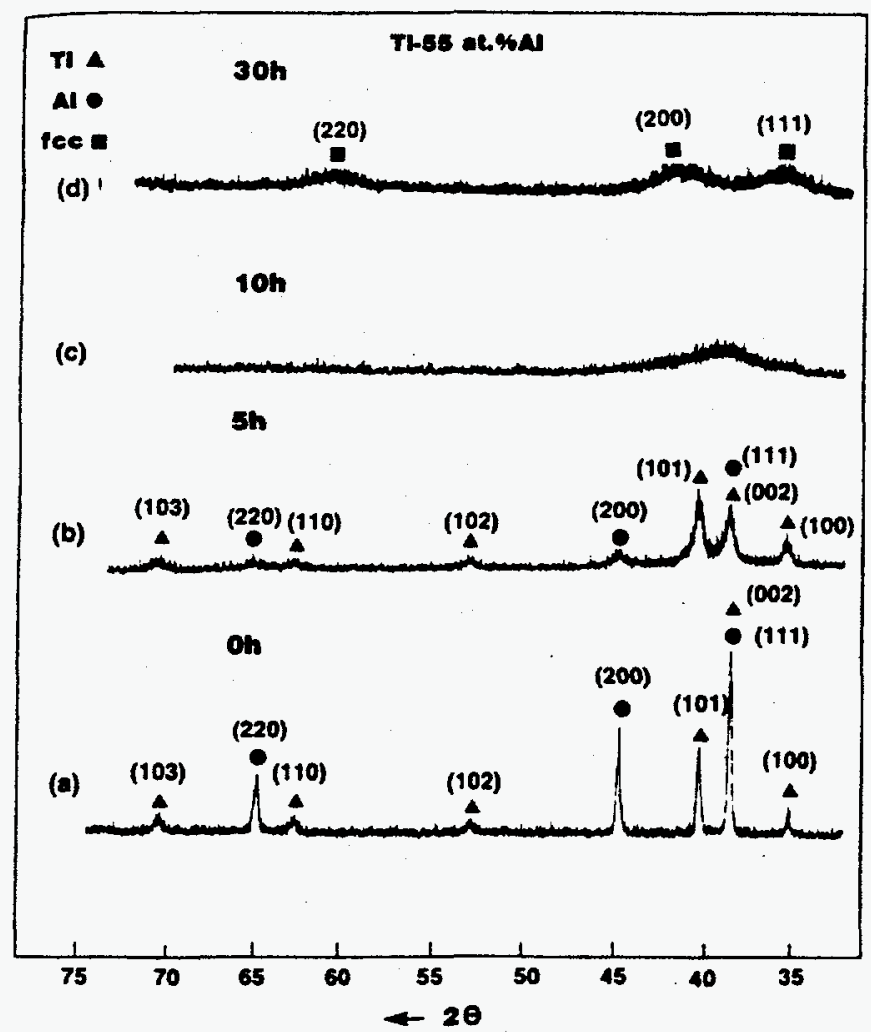

Figure 29. X-ray diffraction patterns of Ti-55 at.\% $\mathrm{Al}$ powder as a function of milling time: (a) as-mixed, 0 hours, and MA for (b) 5 hours, (c) 10 hours, and (d) 30 hours. 


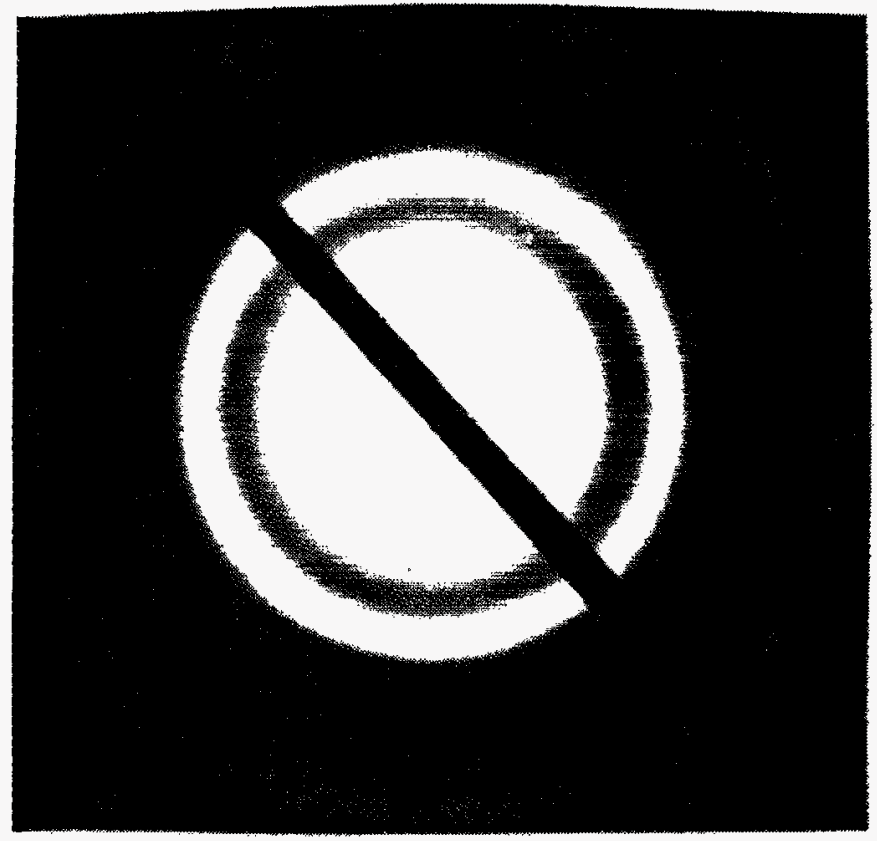

Figure 30. Electron diffraction pattern of Ti-55 at.\% $\mathrm{Al}$ powder MA for 10 hours showing the formation of an amorphous phase.
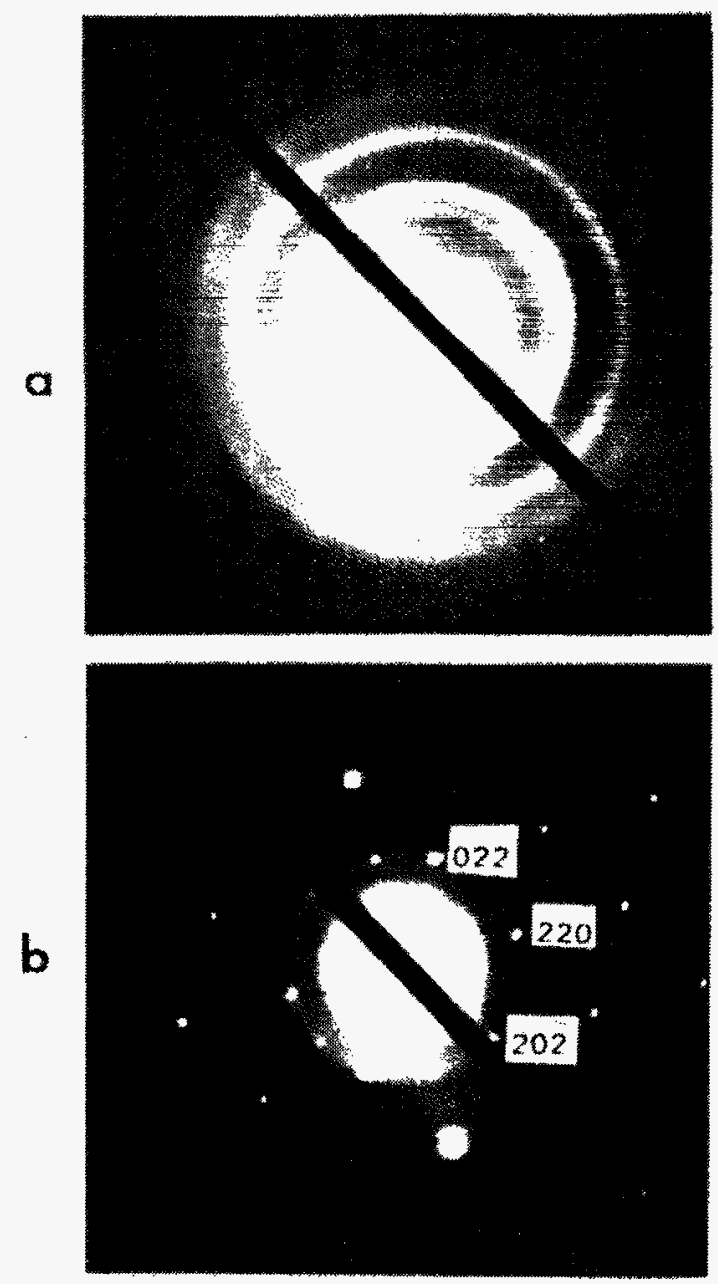

Figure 31. Electron diffraction patterns of Ti-55 at.\% Al powder MA for 30 hours showing the formation of an f.c.c. phase. 
powder mix. The milling times required were much shorter at higher ratios than at smaller ratios and, using this information, a "milling map" was constructed (Figure 32). From this map, it is possible to quickly identify the phases present at any milling time for a specified ball-to-powder ratio and define the final phases produced by the MA process.

In order to evaluate the mechanical properties of the binary Ti-55 at.\% $\mathrm{Al}$ composition, a large quantity $(\sim 100 \mathrm{~g})$ of the blended elemental powder was mechanically alloyed in a Szegvari attritor with a ball-to-powder weight ratio of 20:1. X-ray diffraction patterns clearly indicated that the material is in an amorphous state in the as-milled condition after milling for 115 hours in the attritor (Figure 33a).

The mechanically alloyed powders were consolidated into bulk shapes by four different methods: hot pressing, hot isostatic pressing, shock consolidation, and Ceracon processing.

Table 7 gives the consolidation parameters for the different methods.

Figure $33 \mathrm{~b}$ shows the $\mathrm{x}$-ray diffraction pattern of the Ti-55 at.\% $\mathrm{Al}$ powder HIP'ed at $975^{\circ} \mathrm{C}$. The starting amorphous phase has completely crystallized to a mixture of the $\gamma-\mathrm{TiAl}$ and $\alpha_{2}-\mathrm{Ti}_{3} \mathrm{Al}$ phases, with calculated lattice parameters similar to those reported in the literature.

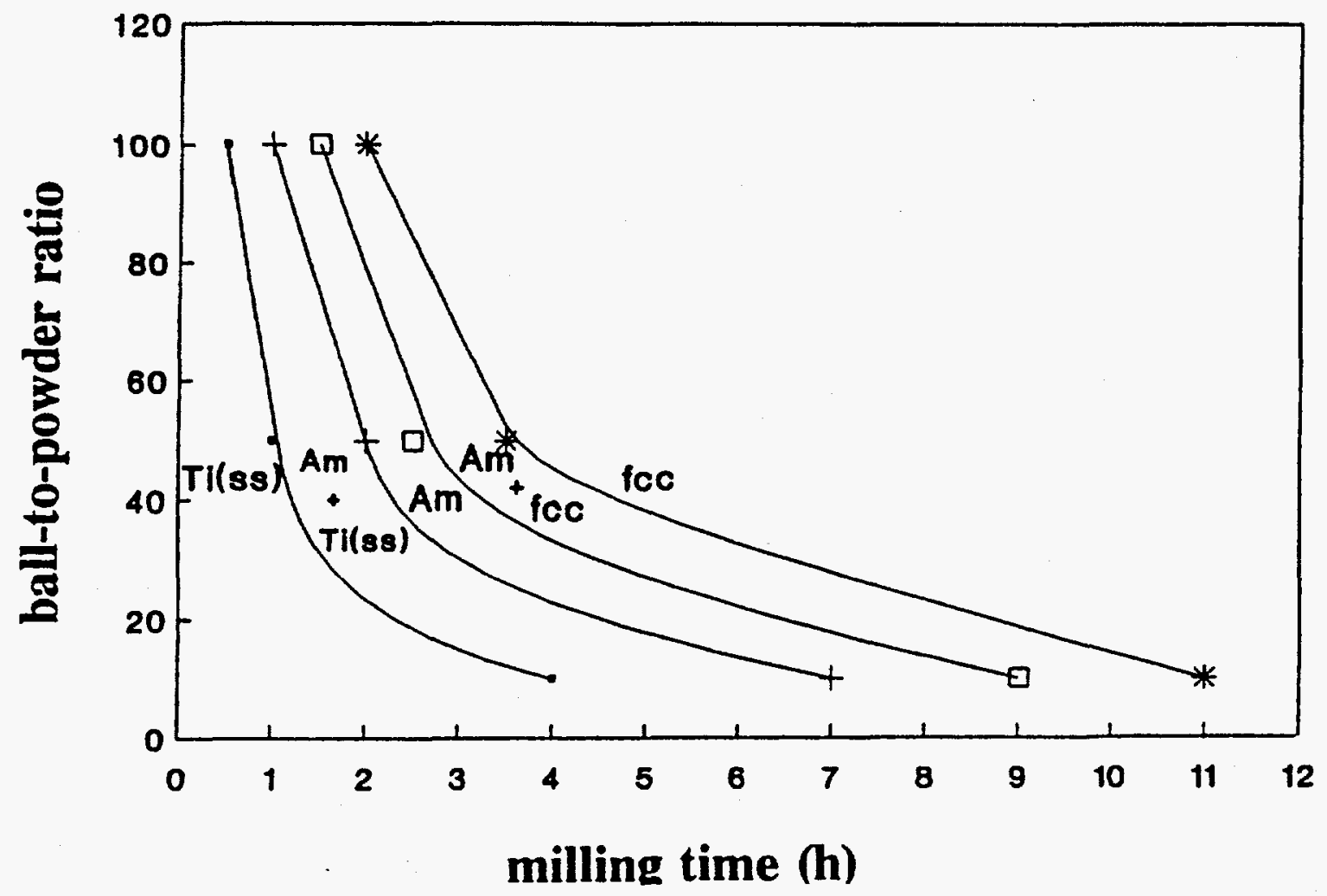

Figure 32 Milling map for a Ti-33 at.\% $\mathrm{Al}$ alloy powder relating the ball-to-powder ratio and milling time to the phases present. 


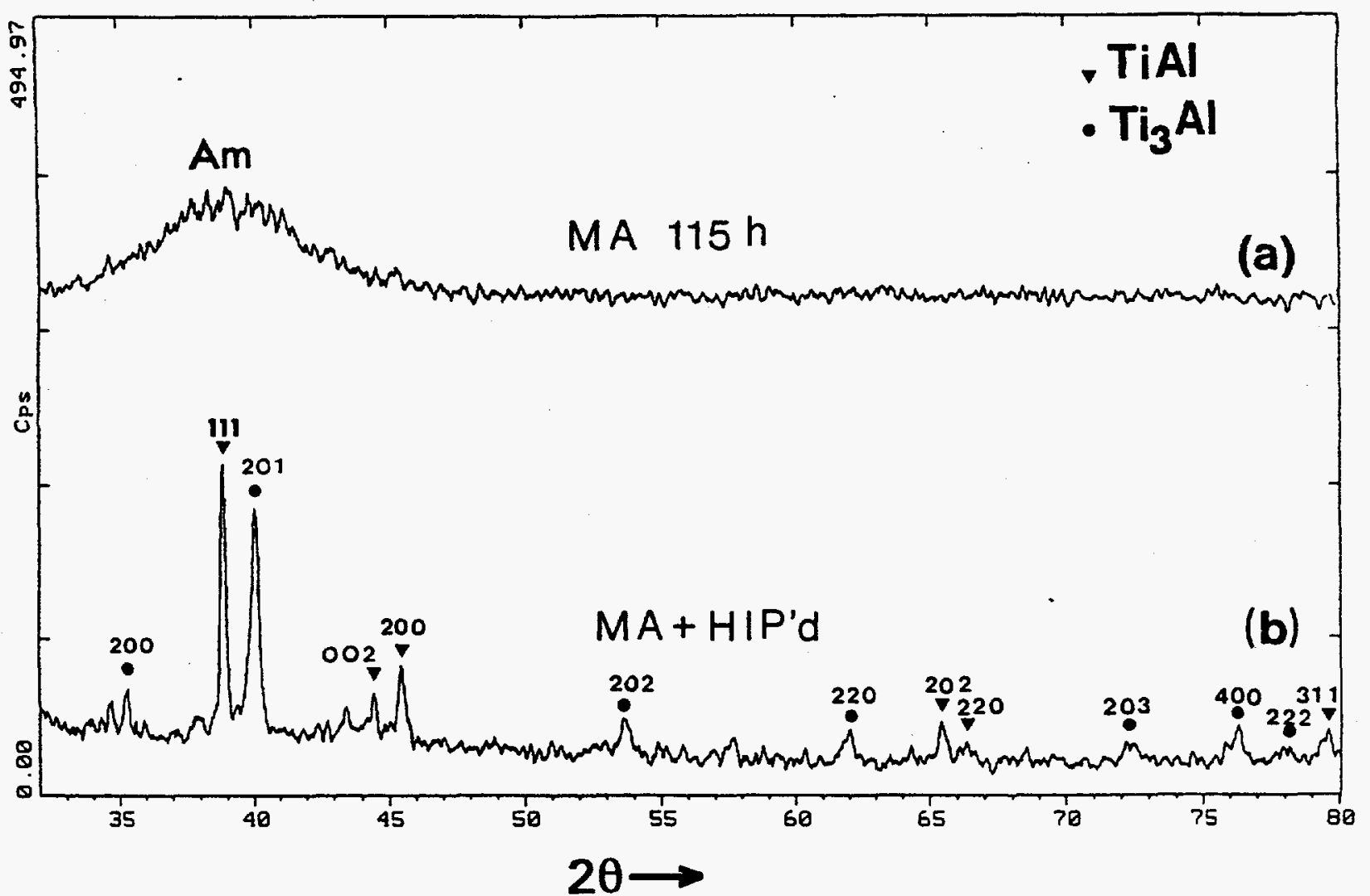

Figure 33. X-ray diffraction patterns of Ti-55 at.\% $\mathrm{Al}$ powder (a) milled for 115 hours in the attritor showing the amorphous phase, and (b) HIP'ed at $975^{\circ} \mathrm{C}, 207 \mathrm{MPa}$ for 2 hours showing a mixture of the $\mathrm{TiAl}$ and $\mathrm{Ti}_{3} \mathrm{Al}$ phases.

The microstructural features of the samples HIP'ed at 800,900 , and $975^{\circ} \mathrm{C}$ were characterized. The amorphous phase in the as-milled powder crystallized into a mixture of two phases on HIP'ing at all of the temperatures investigated. Typical electron micrographs are shown in Figure 34. There is a bimodal distribution of the grain sizes, and the grain size increases with increasing HIP temperature. One of the phases, identified as TiAl on the basis of x-ray diffraction (Figure 33b), electron diffraction, and dark field microscopy results, had a smaller grain

Table 7. Consolidation parameters for the mechanically alloyed Ti-55 at.\% Al powders.

\begin{tabular}{lccc}
\hline Method & Pressure $(\mathrm{MPa})$ & Temperature $\left({ }^{\circ} \mathrm{C}\right)$ & Time $(\mathrm{h})$ \\
\hline Hot Pressing & 60 & 975 & 0.5 \\
Hot Isostatic Pressing & 207 & 800 & 2 \\
& 207 & 900 & 2 \\
Shock Consolidation & 207 & 975 & 2 \\
Ceracon Processing & $-15,000$ & Room & A few $\mu \mathrm{s}$ \\
\hline
\end{tabular}



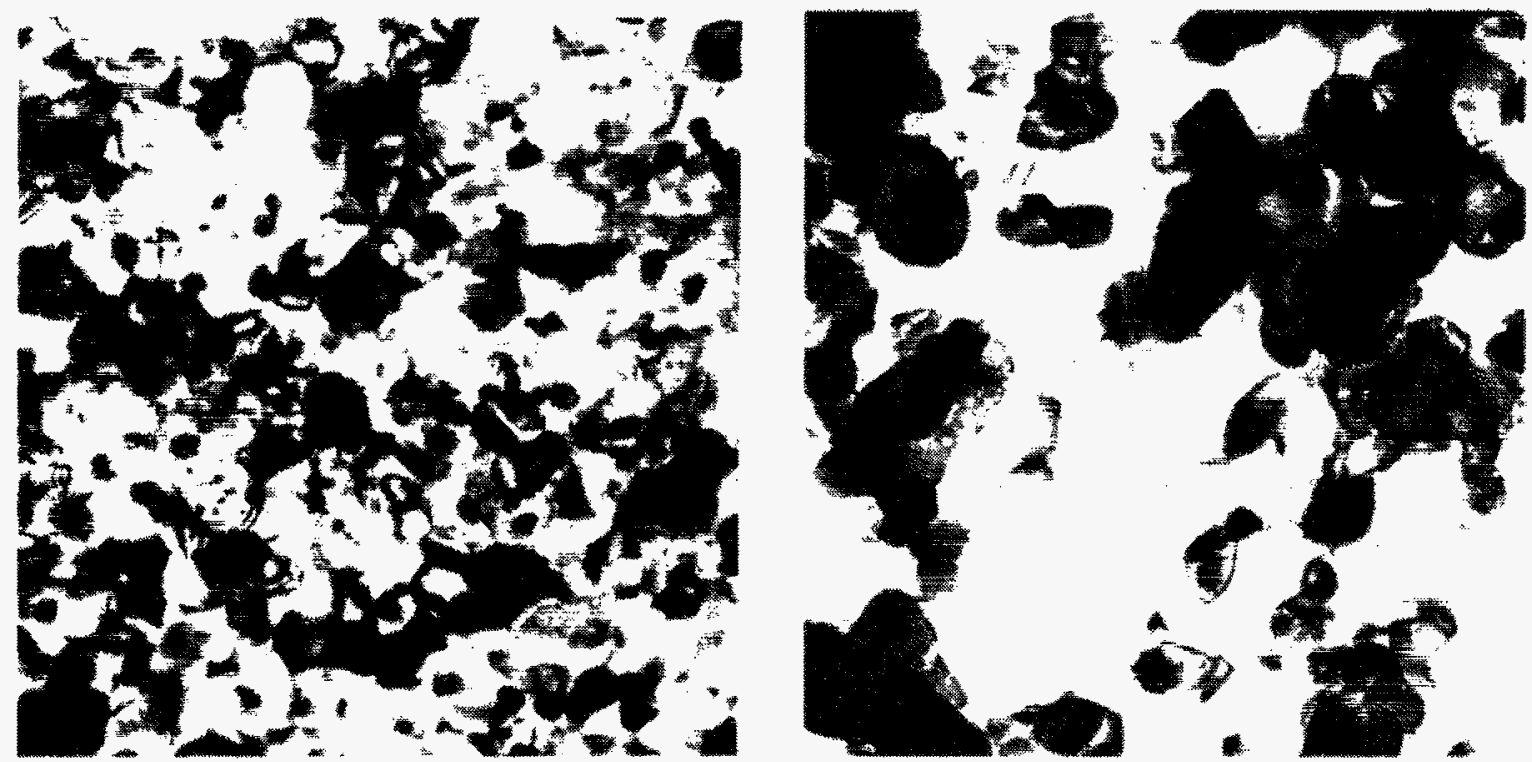

เ. $8000^{\prime \prime} C^{\circ}$

b. 900 "

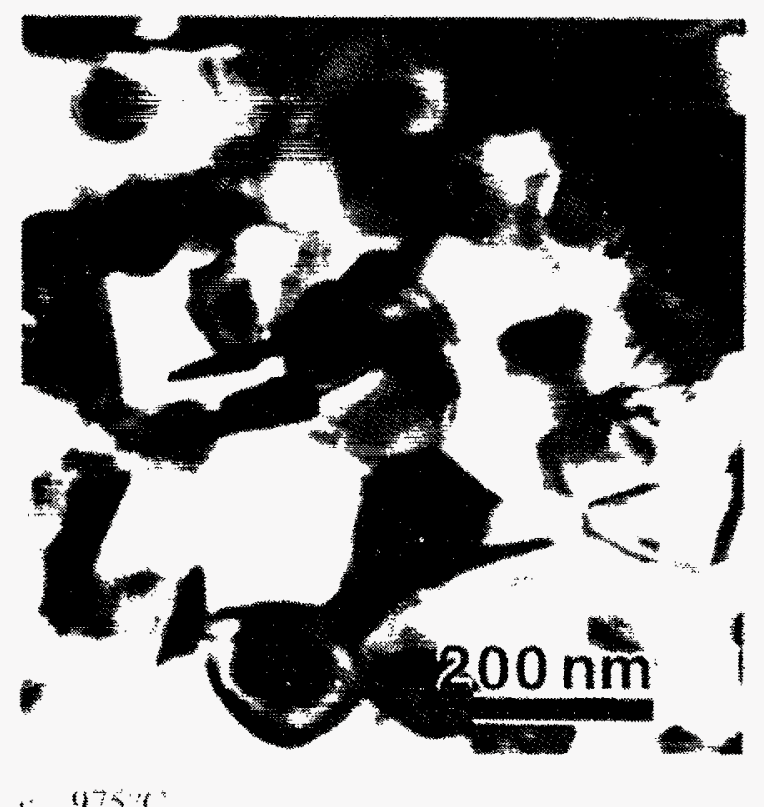

Figure 34. Transmission electron micrographs of the MA Ti-55 at.\% Al powder HIP'ed for 2 hours at $207 \mathrm{MPa}$ pressure and at (a) $800^{\circ} \mathrm{C}$, (b) $900^{\circ} \mathrm{C}$, and (c) $975^{\circ} \mathrm{C}$.

size. This ranged from about $8 \mathrm{~nm}$ on HIP'ing at $800^{\circ} \mathrm{C}$ to $85 \mathrm{~nm}$ on HIP'ing at $975^{\circ} \mathrm{C}$. The EDS analysis confirmed the chemical composition expected of the TiAl phase.

The phase with the larger grain size (ranging from $90 \mathrm{~nm}$ at $800^{\circ} \mathrm{C}$ to $220 \mathrm{~nm}$ at $975^{\circ} \mathrm{C}$ ) had a chemical analysis of 63 at.\% $\mathrm{Al}$ and 37 at.\% $\mathrm{Ti}$, suggesting that this phase is aluminum-rich and approaching the $\mathrm{Al}_{3} \mathrm{Ti}$ composition (though still away from the exact stoichiometry). 
High-resolution TEM investigations have been carried out on the samples HIP'ed at $900^{\circ} \mathrm{C}$ (Figure 35). The grain boundaries and grain interiors are clean and devoid of any contaminants (e.g., due to the use of stearic acid as a process control agent).

Table 8 summarizes the consolidation parameters and the grain sizes as determined by the TEM techniques.

Optical microscopy shows that the hot-pressed and HIP'ed material is no longer amorphous but has undergone the development of two phases, one as the matrix and the other appearing as a fine precipitate. Due to the fine dispersion, microhardness was not possible on both phases of the HIP'ed material. The dynamically consolidated material appeared homogeneous and evidently did not transform into the two crystalline phases. The amorphous or "near amorphous" state of the dynamically consolidated material, even with the shock-hardening normally expected, is comparable to the hardness of the powders consolidated by HIP'ing or Ceracon consolidation.

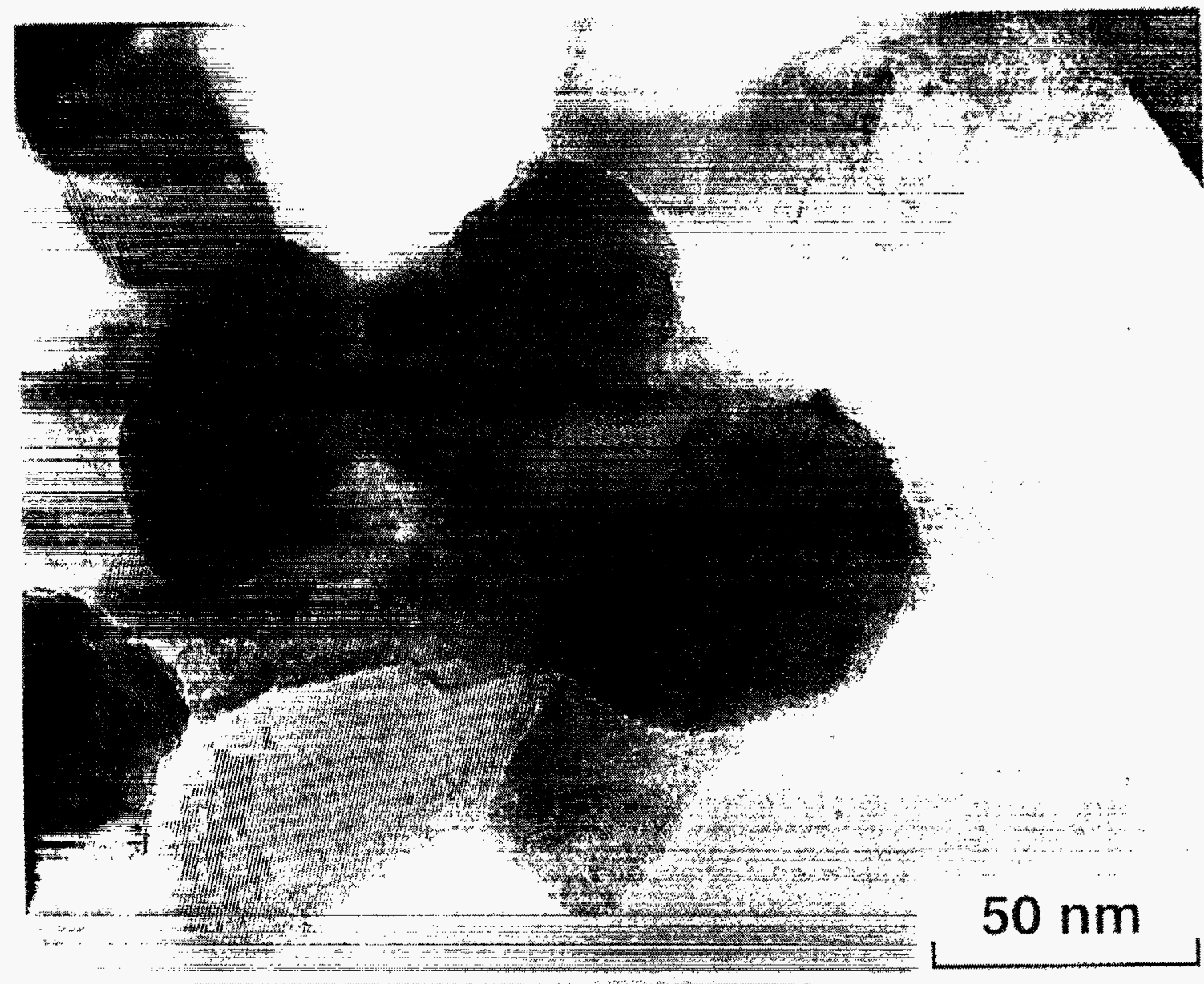

Figure 35. High-resolution electron micrograph of MA blended elemental Ti-55 at.\% $\mathrm{Al}$ powder HIP'ed at $900^{\circ} \mathrm{C} / 207 \mathrm{MPa} / 2$ hours. 
Table 8. Summary of results on consolidated Ti-55 at.\% $\mathrm{Al}$ powder mechanically alloyed for 35 hours in a Szegvari 01-HD attritor under argon with a 20:1 ball-to-powder ratio.

\begin{tabular}{|c|c|c|c|}
\hline $\begin{array}{l}\text { Consolidation } \\
\text { Method }\end{array}$ & $\begin{array}{l}\text { Consolidation Parameters } \\
\left(^{(T e m p / P r e s s / T i m e}\right)^{\mathrm{a}}\end{array}$ & $\begin{array}{c}\text { Grain Size, } \\
\text { by TEM (nm) }\end{array}$ & $\begin{array}{l}\text { Microhardness } \\
\text { (DPH) }\end{array}$ \\
\hline As-Milled & --- & Amorphous & 645 \\
\hline HIP & $800 / 207 / 120$ & $8-90$ & 980 \\
\hline HIP & $900 / 207 / 120$ & $30-140$ & 940 \\
\hline HIP & $975 / 207 / 120$ & $\begin{array}{c}85 \mathrm{TiAl} \\
220 \mathrm{Ti}_{3} \mathrm{Al}\end{array}$ & 835 \\
\hline Dynamic & Shot \#280 & $5-15$ & 960 \\
\hline Ceracon & $950 / 1240 / 1$ & $\begin{array}{c}60 \mathrm{TiAl} \\
120 \mathrm{Ti}_{3} \mathrm{Al}\end{array}$ & 960 \\
\hline
\end{tabular}

After dynamic consolidation, the material appears to be in the early stages of crystallization; a significant amount of the compact is in a near-amorphous state as demonstrated by the TEM examination (Figure 36).

Microcracks were present in compacts from all consolidation processes, rendering the material unsuitable for mechanical property tests. The hardness of the samples was very high (in the range of low grades of tungsten carbide), due to the retention of nanometer-sized grains that may result in low ductility. These values also are presented in Table 8.

The variation of hardness with grain size can be represented by the Hall-Petch equation

$\mathbf{H}=\mathrm{H}_{\mathrm{o}}+\mathrm{Kd}^{-1 / 2}$

where $\mathrm{H}$ is the hardness, $\mathrm{H}_{\mathrm{o}}$ is the hardness at extremely large grain sizes, and $\mathrm{d}$ is the grain size. The hardness variation with grain size (determined by TEM) for the HIP'ed Ti-55 at.\% Al compacts is shown in Figure 37. The hardness increases with decreasing grain size when one considers only the HIP compacts. However, when the hardness of the as-milled powder also is considered, an inverse Hall-Petch relationship (decreasing hardness with decreasing grain size) is observed. The reasons for this behavior are not clear at present. Further, both the constants $H_{0}$ and $\mathrm{K}$ in the Hall-Petch equation are substantially different from the ingot-metallurgy values ${ }^{29}$, as listed in Table 9. 

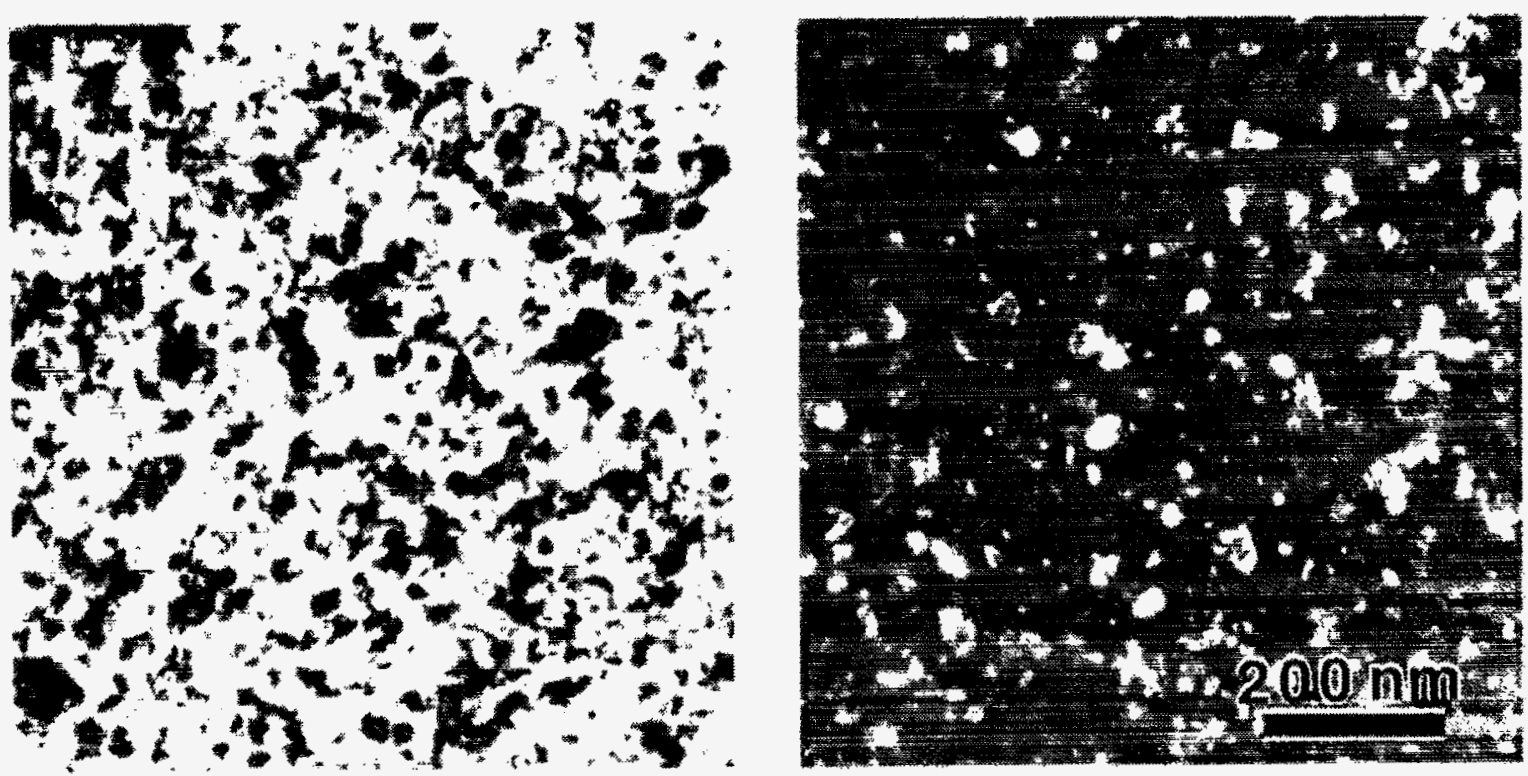

a. Brigh-fied micropraph

b. Darkticld micrograph

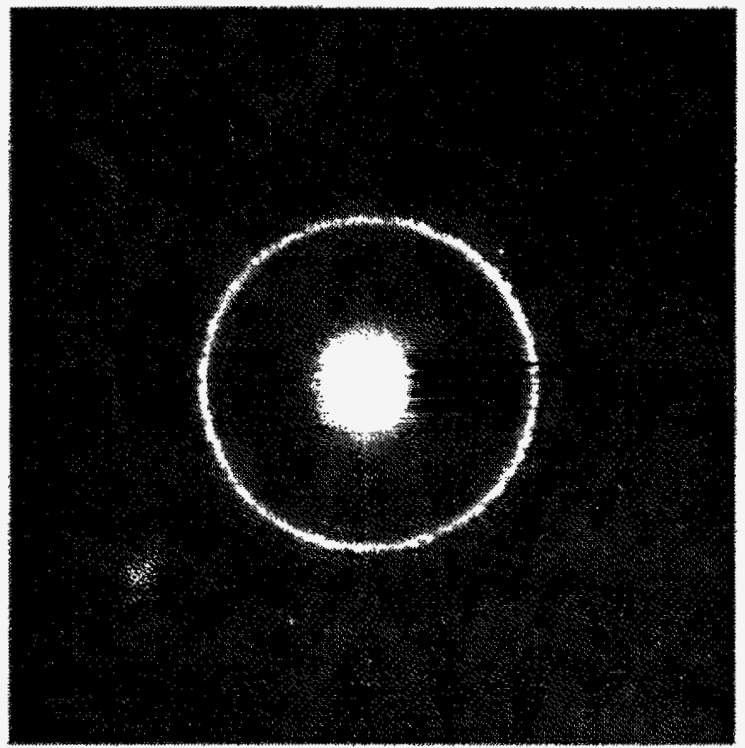

\& Dimastion patern

Figure 36. Transmission electron micrographs and diffraction patterns of shock-consolidated Ti-55 at.\% $\mathrm{Al}$ powder compact: (a) bright-field micrograph, (b) dark-field micrograph, and (c) diffraction pattern. 


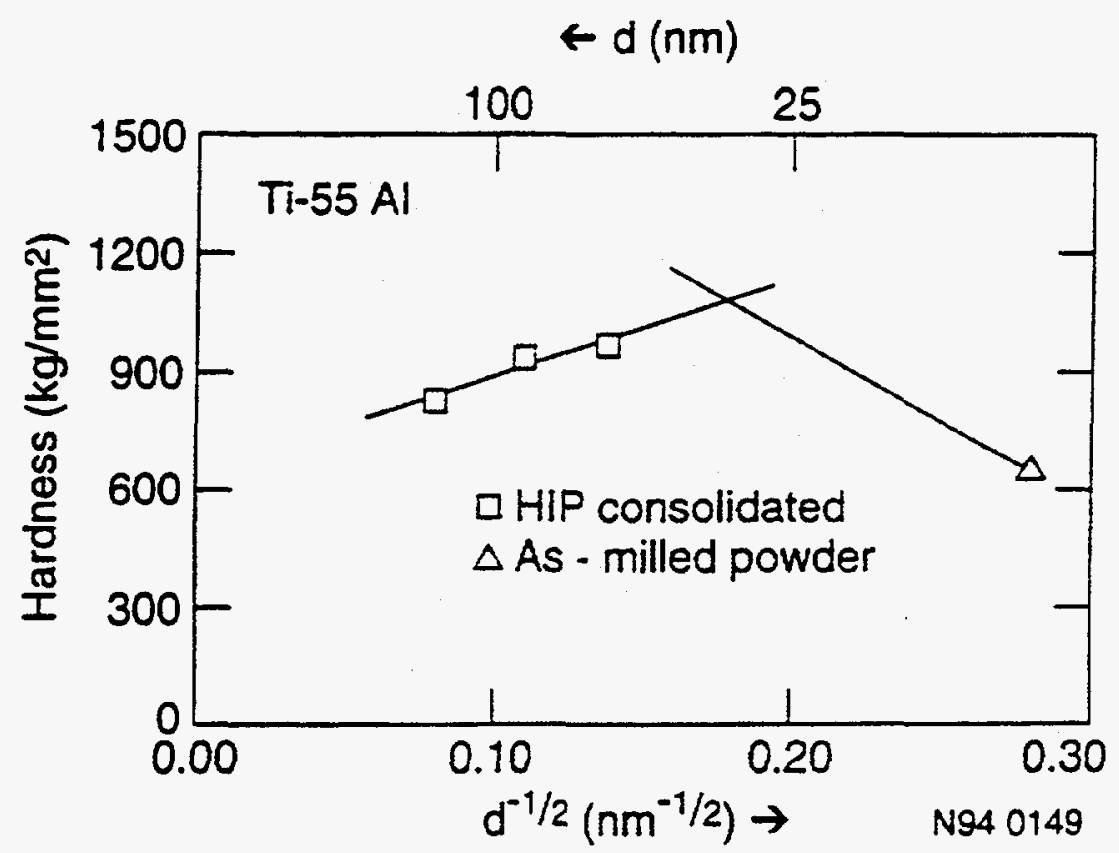

Figure 37. Hall-Petch plot for the Ti-55 at.\% $\mathrm{Al}$ as-milled powder HIP-consolidated compacts.

\section{The F.C.C. Phase}

The f.c.c. phase in all the compositions investigated was found to form after the formation of the amorphous phase. Although it is generally accepted that the amorphous phase is farthest from equilibrium, some investigators earlier reported that the MA process does not always end in an amorphous state, but, depending on kinetic constraints, the powder can transform into other phases. ${ }^{30-33}$ However, it was noted that the Ti-55 at.\% Al powder milled for 35 hours in the attritor contained $1.8 \mathrm{wt} . \%$ nitrogen and $3.2 \mathrm{wt} . \%$ oxygen. Similar high interstitial contents were also noted in other powders; generally, however, the nitrogen content is higher than the oxygen content when the powders were milled in the SPEX mill. This powder contamination could be due to some leakage of atmospheric air into the milling container. Further, using spectroscopic techniques like $\mathrm{x}$-ray photoelectron spectroscopy and laser Raman spectroscopy, it could be concluded that the f.c.c. phase observed in these powders is TiN. Attempts were later successfully made to reduce/minimize the nitrogen and oxygen contents in the powders.

Table 9. $\mathrm{H}_{\mathrm{o}}$ and $\mathrm{K}$ values in the Hall-Petch equation.

\begin{tabular}{lccc}
\hline Material & Condition & $\mathrm{H}_{\mathrm{o}}(\mathrm{MPa})$ & $\mathrm{K}(\mathrm{MPa} \sqrt{\mathrm{m}})$ \\
\hline Ti-55 at.\% Al & $\mathrm{MA}$ & 1,950 & 0.75 \\
Ti-54 at.\% Al & Ingot Metallurgy & 450 & 1.1 \\
Ti-24Al-11Nb (at.\%) & $\mathrm{MA}$ & 1,670 & 1.02 \\
\hline
\end{tabular}




\section{Conclusions}

Based on the results presented above, the following conclusions can be drawn:

1. Mechanical alloying of blended elemental Ti-Al powders in the range of 24 to 60 at.\% Al led sequentially to formation of a $\mathrm{Ti}(\mathrm{Al})$ h.c.p. solid solution, an amorphous phase, and at the longest times investigated, an f.c.c. phase.

2. The grain size of the solid solution phase decreased with increasing MA time and reached about $10 \mathrm{~nm}$ after milling the powder for about 7 hours.

3. Consolidation of the milled Ti-55 at.\% $\mathrm{Al}$ amorphous powder by shock consolidation, HIP'ing, and Ceracon processing led to crystallization, resulting in the formation of $\gamma$-TiAl and $\alpha-\mathrm{Ti}_{3} \mathrm{Al}$ phases.

4. Near-nanometer-sized grains were retained after consolidation by all the above methods.

5. The hardness of the HIP'ed Ti-55 at.\% Al compacts increased with a decreasing grain size and reached a value of $980 \mathrm{~kg} / \mathrm{mm}^{2}$ for a grain size of $40 \mathrm{~nm}$.

6. Ductility evaluations could not be made because of the presence of micro-cracking in the consolidated specimens.

\section{Ti-Al-Nb System}

As mentioned earlier, both $\alpha_{2}-\mathrm{Ti}_{3} \mathrm{Al}$ and $\gamma$-TiAl alloys have low ductilities. Addition of 12 to 22 at.\% Nb to $\mathrm{Ti}_{3} \mathrm{Al}$ stabilizes the $\mathrm{B} 2$ (the ordered $\mathrm{CsCl}$-type b.c.c.) structure at temperatures above $850^{\circ} \mathrm{C} ;{ }^{34}$ this transforms to the ordered orthorhombic ("O") phase at lower temperatures. ${ }^{35,36}$ The two-phase $\alpha_{2}+\mathrm{B} 2$ alloys and those containing "O" phase have been shown to be stronger, more ductile, and exhibit a higher fracture toughness than alloys with lower niobium content. ${ }^{37}$ It is expected that the ductility of these titanium alloys will be maximized by producing them with a fine grain size. MA is known to produce a disordered structure in intermetallics ${ }^{38}$ and refine the grain size down to nanometer levels. The synergistic effect of all these factors-fine grain size, disordering, and formation of a cubic phase-is expected to result in ductile titanium aluminides. Thus, mechanical alloying was conducted on several compositions in the Ti-Al-Nb system (Table 10). Additionally, prealloyed Ti-24Al-11Nb (at.\%) powder obtained by the plasma rotating electrode process was also milled to compare its characteristics with those obtained from the blended elemental powders.

All the above powders were mechanically alloyed in both the SPEX mill and the attritor. These powders were consolidated using the same methods described above for the Ti-55at.\% Al powder.

The results obtained on all four ternary compositions are similar except that the times required for the formation of the different phases were different. Further, since it was decided to emphasize the Ti-24Al-11Nb (at.\%) composition in this program, and for brevity, detailed results 
Table 10. Compositions of $\mathrm{Ti}-\mathrm{Al}-\mathrm{Nb}$ powders investigated.

\begin{tabular}{ccll}
\hline & Alloy \# & Condition $^{\text {a }}$ & \multicolumn{1}{c}{$\begin{array}{c}\text { Compositions } \\
(\text { at.\% })\end{array}$} \\
\hline 1 & BE & Ti-24Al-11Nb \\
2 & PA & Ti-24Al-11Nb \\
3 & BE & Ti-25Al-25Nb \\
4 & BE & Ti-37.5Al-12.5Nb \\
& 5 & BE & Ti-28.5Al-23.9Nb \\
a. BE = blended elemental; PA = pre-alloyed. & \\
\hline
\end{tabular}

of only the Ti-24Al-11Nb (at.\%) powder mix will be presented here. The other compositions will be referred to only when there are significant differences to report.

Figure 38 shows the $\mathrm{x}$-ray diffraction patterns of blended elemental $\mathrm{Ti}-24 \mathrm{Al}-11 \mathrm{Nb}$ powders. The as-mixed powders show the presence of the three expected phases: $\alpha$-Ti (hcp) with a $=$ $0.294 \mathrm{~nm}$ and $\mathrm{c}=0.467 \mathrm{~nm}, \mathrm{Al}$ (f.c.c.) with $\mathrm{a}=0.404 \mathrm{~nm}$ and $\mathrm{Nb}$ (b.c.c.) with $\mathrm{a}=0.330 \mathrm{~nm}$. With increasing milling time, $x$-ray diffraction peaks become broader and their intensities decrease. Formation of a solid solution of $\mathrm{Al}$ and $\mathrm{Nb}$ in $\mathrm{Ti}\left[\mathrm{Ti}(\mathrm{ss})_{\text {hep }}\right.$ ] with the lattice parameters $\mathrm{a}=0.294 \mathrm{~nm}, \mathrm{c}=0.467 \mathrm{~nm}$, and a B2/b.c.c. ${ }^{\mathrm{a}}$ phase with $\mathrm{a}=0.330 \mathrm{~nm}$, were observed after 3 hours milling Figure $38 \mathrm{~b}$. On continued milling to 10 hours, the formation of a mixture of B2 and f.c.c. phases with Ti(ss) $)_{\text {hcp }}$ solid solution can be clearly seen in Figure 38c. With further milling to 14 hours, the amorphous and f.c.c. phases were formed. Formation of the amorphous phase was also confirmed by electron diffraction. At a still longer milling time, up to 23 hours, only the f.c.c. phase with $\mathrm{a}=\mathbf{0 . 4 2} \mathrm{nm}$ was present. In general, for all the binary Ti-Al powder mixes, the sequence of phase formation is

$$
\begin{aligned}
& \begin{array}{lll}
(\mathrm{Ti}+\mathrm{Al}+\mathrm{Nb}) & \frac{3 \mathrm{~h}}{10 \mathrm{~h}} & \mathrm{Ti}(\mathrm{ss})_{\mathrm{hcp}}+\mathrm{B} 2 \\
& \stackrel{\mathrm{14h}}{\mathrm{Ti}(s s)_{\mathrm{hcp}}+\mathrm{B} 2+\text { f.c.c. }} \mathrm{Am}+\text { f.c.c. }
\end{array} \\
& \stackrel{23 \mathrm{~h}}{\longrightarrow} \text { f.c.c. }
\end{aligned}
$$

The prealloyed Ti-24Al-11Nb (at.\%) alloy powder, which had the B2 phase in the as-rapidlysolidified condition, transformed directly to the amorphous phase and then fully to an f.c.c. structure (Figure 39). The times required for the formation of these phases in different alloy compositions are presented schematically in Figure 40 .

a. The $x$-ray diffraction technique cannot differentiate between the disordered (b.c.c.) and ordered (B2) structures of the ternary Ti-Al-Nb alloys. Therefore, throughout the text, we use the terminology B2/b.c.c. whenever we are uncertain of the nature of ordering. 


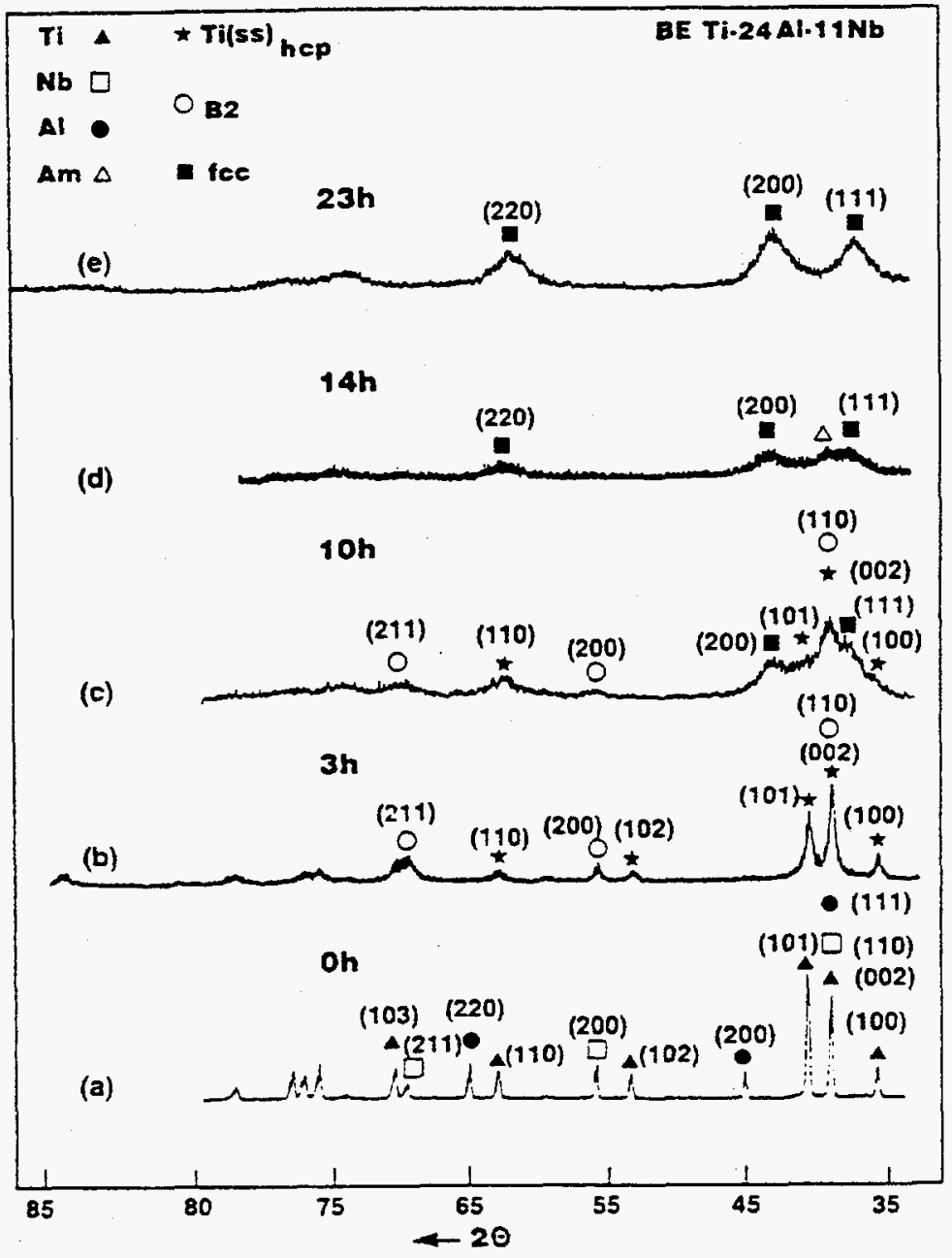

Figure 38. X-ray diffraction patterns of blended elemental Ti-24Al-11Nb (at.\%) powders as a function of milling time.

To determine the effect of nominal milling atmosphere on the times required for phase formation, to understand the reasons for the formation and stability of the f.c.c. phase in these ternary $\mathrm{Ti}-\mathrm{Al}-\mathrm{Nb}$ alloys, and also to determine whether the f.c.c. phase results from contamination, milling of the blended elemental $\mathrm{Ti}-25 \mathrm{Al}-25 \mathrm{Nb}$ (at.\%) alloy powders was carried out in nominally four different atmospheres: air, argon, helium, and nitrogen. The sequence of phase formation was similar in all the cases, but the times required for the formation of different phases varied (Figure 41). For example, the times for the B2/b.c.c. phase formation were a little longer in argon ( 8 hours) than in air ( 5 hours). Further, the time for the f.c.c. phase formation was shorter when the powder was milled in air or nitrogen atmospheres (about 20 hours), longer in an argon atmosphere ( 30 hours), and even longer in a helium atmosphere ( 35 hours), suggesting that contamination from air and/or nitrogen may be responsible for the formation of the f.c.c. phase.

When the blended elemental Ti-24Al-11Nb powder was milled in air, the B2/b.c.c. phase coexisted with either the Ti solid solution or the f.c.c. phase. However, when the powder was milled for 10 hours under a nominally protective argon atmosphere, $100 \%$ of the B2/b.c.c. phase formed. 


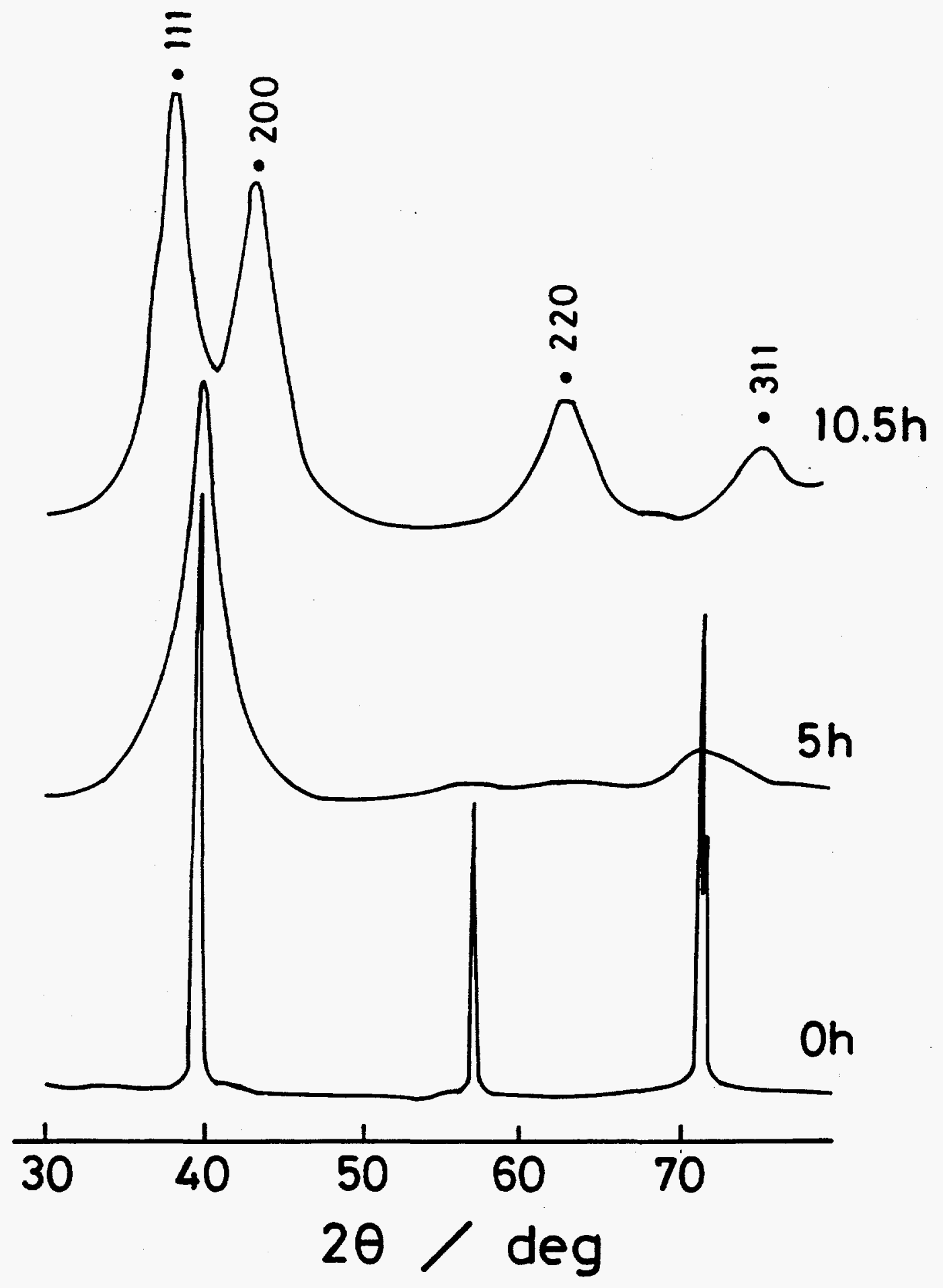

Figure 39. X-ray diffraction patterns of PA Ti-24Al-11Nb powder as a function of milling time. 
composition

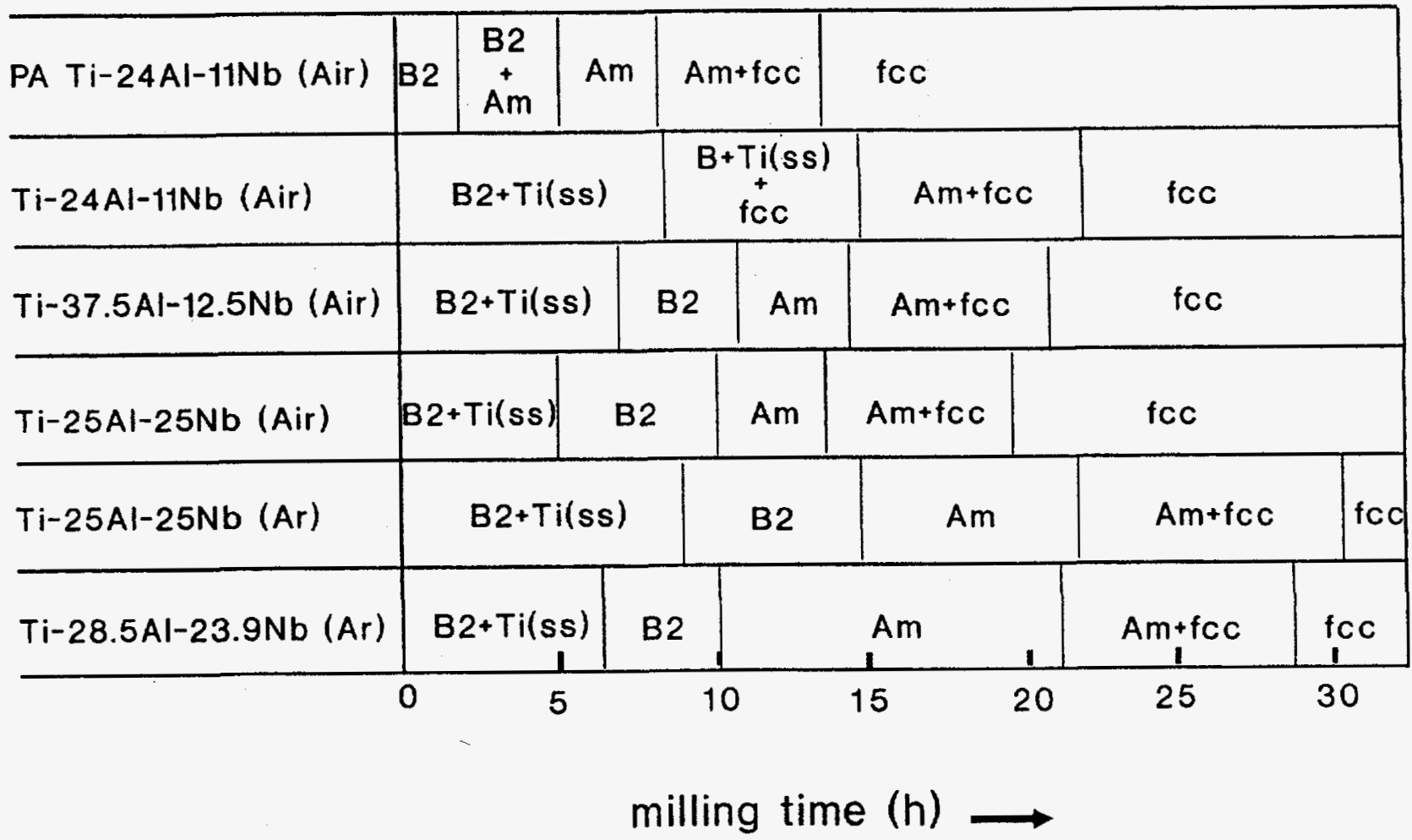

Figure 40. Schematic representation of phases present in different $\mathrm{Ti}-\mathrm{Al}-\mathrm{Nb}$ alloys as a function of milling time.

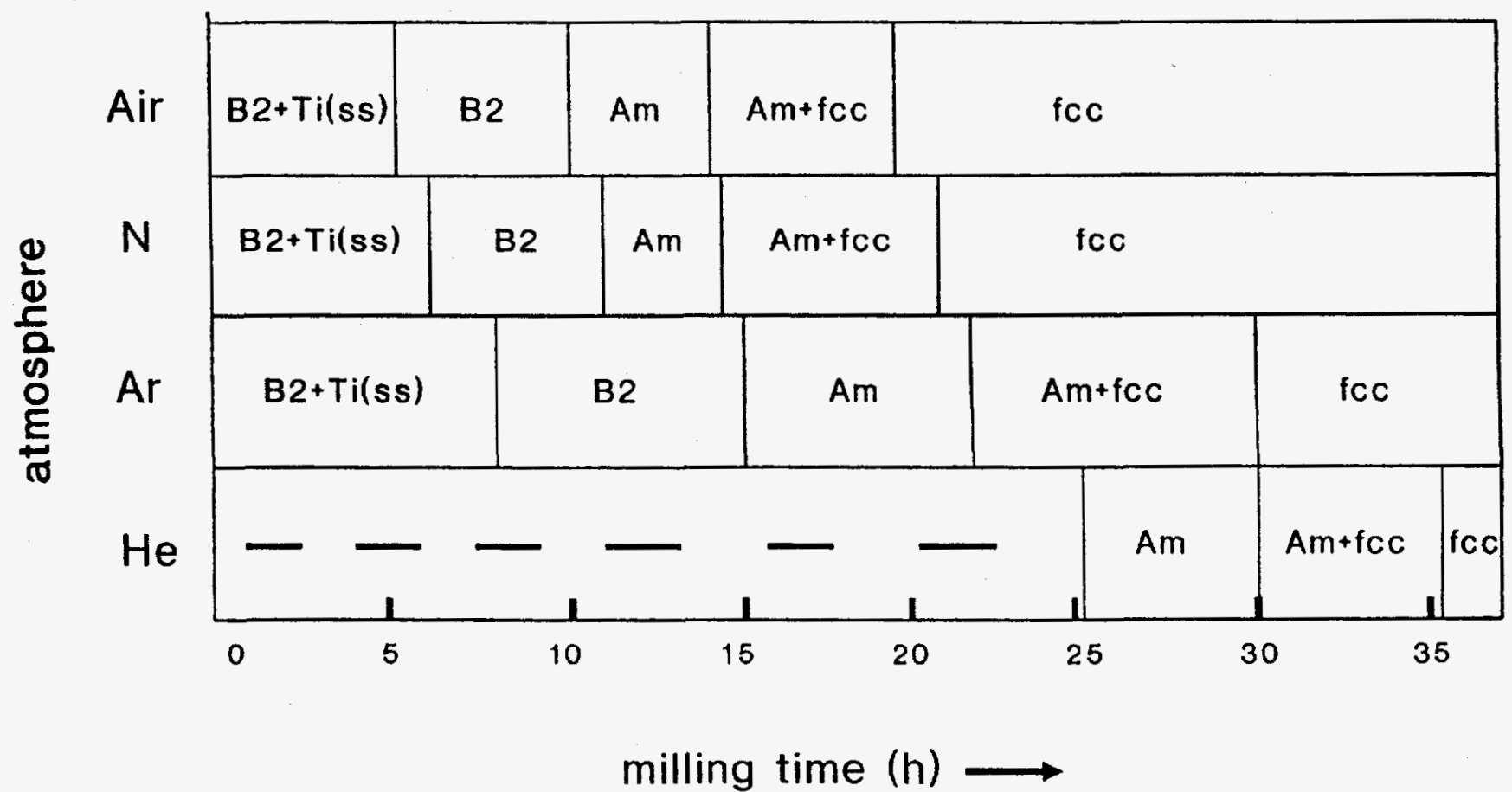

Figure 41. Schematic representation of phases present in the Ti-25Al-25Nb powder as a function of milling time in different atmospheres. 
The crystal size of the MA powders, determined from the width of the $\mathrm{x}$-ray diffraction lines, decreased exponentially with milling time and reached nanometer levels in about 5 hours for the blended elemental Ti-24Al-11Nb powder. The rate of decrease is faster in the prealloyed powder than in the blended elemental powder, presumably because homogenization must first occur in the latter material. Figure 42 shows a plot of the crystal size as a function of milling time for the several ternary $\mathrm{Ti}-\mathrm{Al}-\mathrm{Nb}$ compositions investigated. Transmission electron micrographs from the milled powders confirm the formation of nanocrystals (Figure 43).

The mechanically alloyed Ti-24Al-11Nb (at.\%) powder was consolidated by different methods to produce bulk material for mechanical property characterization. First, they were coldcompacted at $334 \mathrm{MPa}$, reaching only $58.8 \%$ of the theoretical density. Increasing the pressure to $500 \mathrm{MPa}, 62.0 \%$ of the theoretical density was achieved. Subsequent hot compaction at $750^{\circ} \mathrm{C}$ and $20 \mathrm{MPa}$ increased the density slightly, to $65.9 \%$. Secondly, dynamic consolidation was performed. The mechanically alloyed material was loaded into the fixtures and cold-pressed in small increments ( -1 to $2 \mathrm{~g}$ ) to achieve the desired density. Two $\mathrm{M} / \mathrm{C}$ ratios ( $\mathrm{M}$ is the unit mass of the driver tube and $C$ is the unit mass of the explosive charge), 0.85 and 0.61 , were used to achieve different consolidations. In both cases, a large number of cracks were observed in the samples, thus making it difficult to characterize their mechanical properties.

Scanning electron microscopy revealed three distinct areas in the dynamically consolidated specimen (Figure 44). Area 1 is within the circle of melt pores where the titanium aluminide apparently melted, Area 2 just outside the melt area, and Area 3 near the outside radius of the

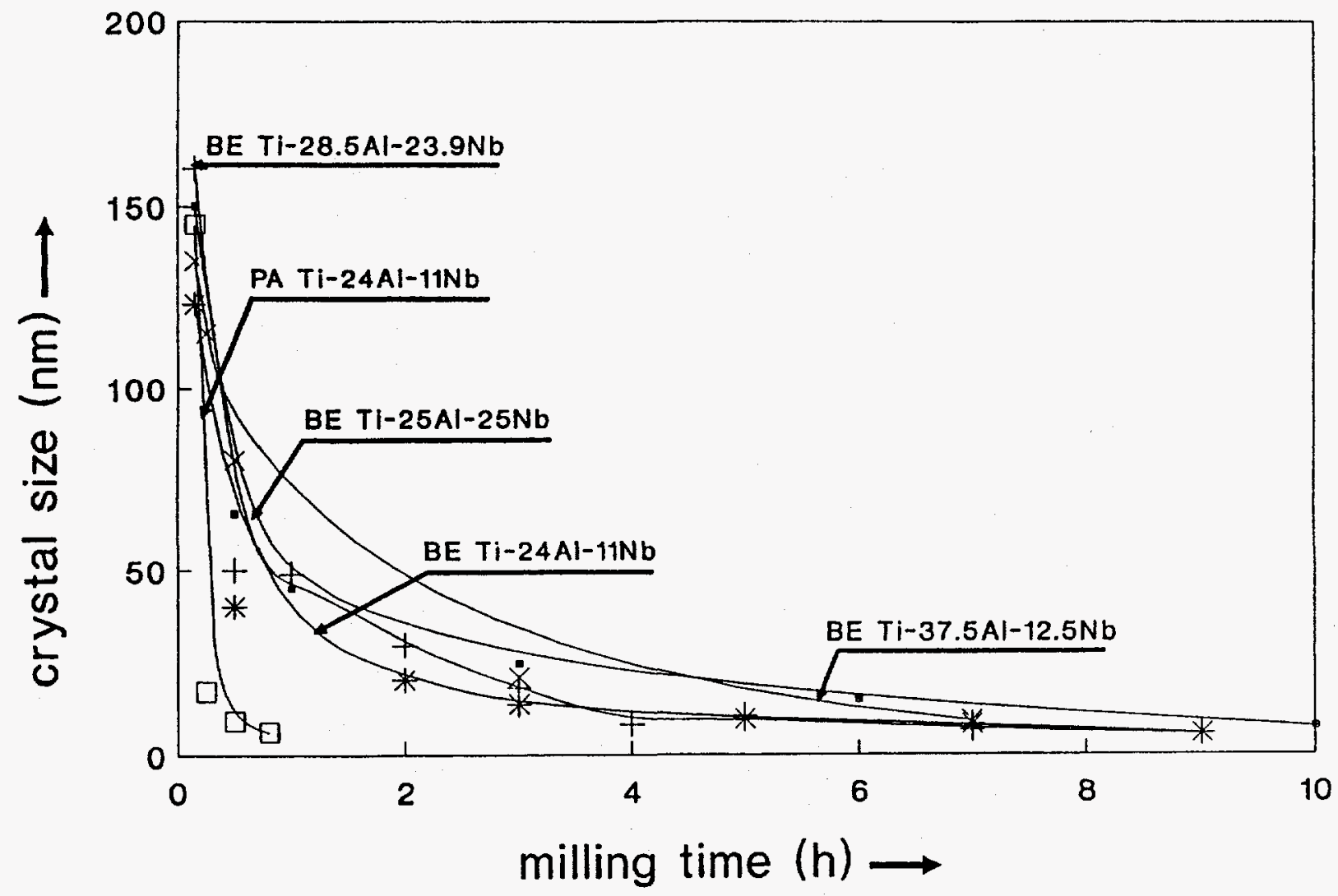

Figure 42. Crystal size as a function of milling time in ternary Ti-Al-Nb powder mixtures. 


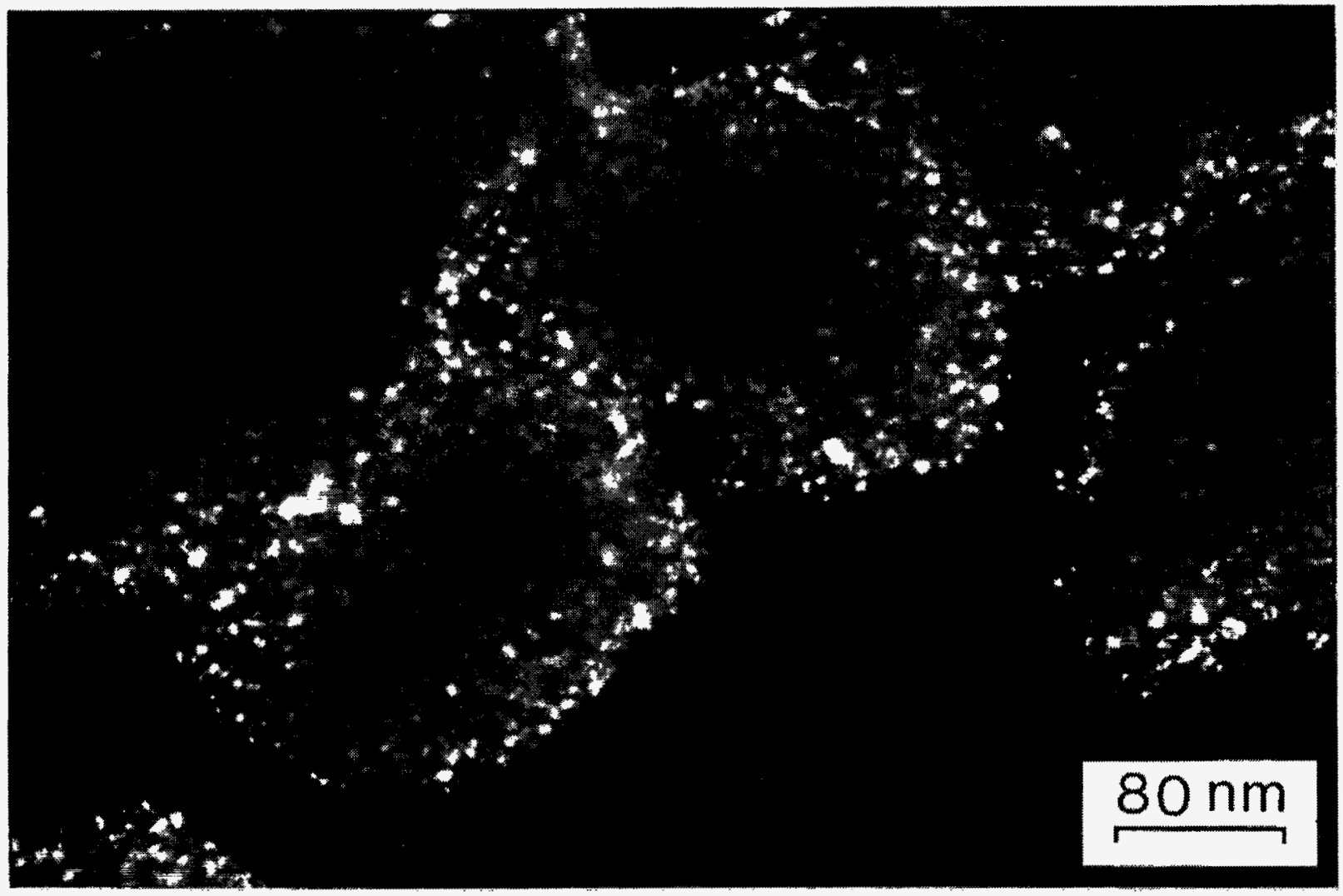

Figure 43. Transmission electron micrograph showing $15-\mathrm{nm}$ size crystals in BE Ti-24Al-11-Nb (at.\%) after MA for 14 hours.

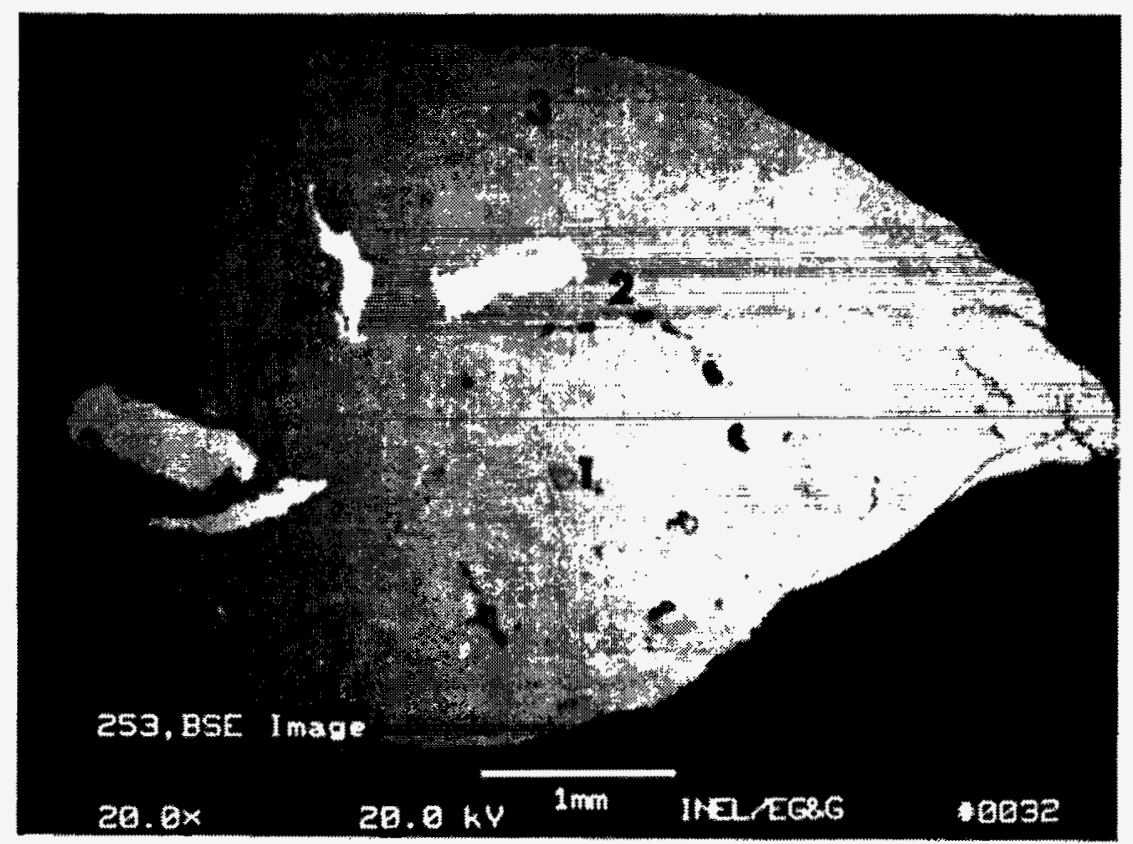

Figure 44. Scanning electron micrograph showing transverse cross-section of cylindrical sample of Ti-24Al-11Nb (at.\%) powder that was dynamically consolidated (shot \#253). 
consolidated sample. The large white islands shown in Figure 44 are pure $\mathrm{Nb}$ particles. Areas 1 , 2 , and 3 have DPH hardness values of 600,690 , and 775, respectively, while the $\mathrm{Nb}$ particles have a hardness of only 103. Thus, the intermetallic formed appears to be very hard (and strong), which could be the reason the specimen cracked during dynamic consolidation. Figure 45 shows a pair of bright-field and dark-field electron micrographs of the dynamically consolidated Ti-24Al$11 \mathrm{Nb}($ at.\%) samples and confirm the retention of grains from 15 to $25 \mathrm{~nm}$.

TEM investigations were conducted on the HIP'ed samples. While the transmission electron micrographs of the HIP'ed samples showed the presence of the B2 phase with a grain size of $2.5 \mu \mathrm{m}(2,500 \mathrm{~nm})$ in the non-mechanically alloyed plasma rotating electrode process powder, the $\mathrm{B} 2$ phase in the as-milled powders had partially transformed to the orthorhombic " $\mathrm{O}$ " phase, and thus all the HIP'ed samples showed a mixture of the B2 and orthorhombic phases; this was shown both by $\mathrm{x}$-ray (Figure 46 ) and electron diffraction techniques. As in the Ti-Al samples, these two phases had widely different grain sizes, the B2 phase showing the finer grain size. The grain size of the B2 phase ranged from about $40 \mathrm{~nm}$ on HIP'ing at $800^{\circ} \mathrm{C}$ to about $125 \mathrm{~nm}$ on HIP'ing at $975^{\circ} \mathrm{C}$. The chemical compositions of the grains derived from the EDS analysis indicated that the faulted grains have the average composition of the alloy. The individual compositions of the two phases could not, however, be determined because of inadequate resolution in the system. Typical electron micrographs from the HIP'ed sample are shown in Figure 47.

A high resolution TEM micrograph from the Ti-24Al-11Nb (at.\%) sample HIP'ed at $900^{\circ} \mathrm{C}$ (Figure 48) shows that the grain interiors and grain boundaries are devoid of any contaminant. Clear lattice fringes can be seen up to the grain boundary.

Table 11 summarizes the consolidation parameters and the grain sizes as determined by the TEM techniques.

Microcracks were present in compacts from all consolidation processes, rendering the material unsuitable for mechanical property tests. The hardness of the samples was very high (Table 11). As in the Ti-Al samples, the hardness variation with grain size can be fitted to the Hall-Petch relationship

$\mathrm{H}=\mathrm{H}_{\mathbf{O}}+\mathrm{Kd}^{-1 / 2}$

with $\mathrm{K}$ and $\mathrm{H}_{\mathrm{o}}$ having values of $1.02 \mathrm{MPa} \sqrt{\mathrm{m}}$ and 1,670 MPa, respectively. An inverse Hall-Petch relationship was observed, including the hardness of the as-milled powder (Figure 49).

To compare the levels of hardness achieved in the blended elemental powders with those of the prealloyed powders, the prealloyed powders were milled for various times to obtain different grain sizes. For example, the powders were milled for 2 and 5 hours, HIP'ed at $800^{\circ} \mathrm{C} / 207 \mathrm{MPa} / 2$ hours, and their hardness values were measured. Here the data can again be fitted to the HallPetch equation, but with different $\mathrm{H}_{\mathrm{o}}$ and $\mathrm{K}$ values; $\mathrm{K}$ appears to be much higher.

Microstructural evaluation of the prealloyed Ti-24Al-11Nb (at.\%) compacts showed that 2 hours of MA was insufficient to produce a uniform structure. A significant portion of the large grains persisted from the as-received condition, with refined grains at the interfaces between the particles (Figure 50). With increasing milling time ( 5 hours), the substructure became more uniform. 

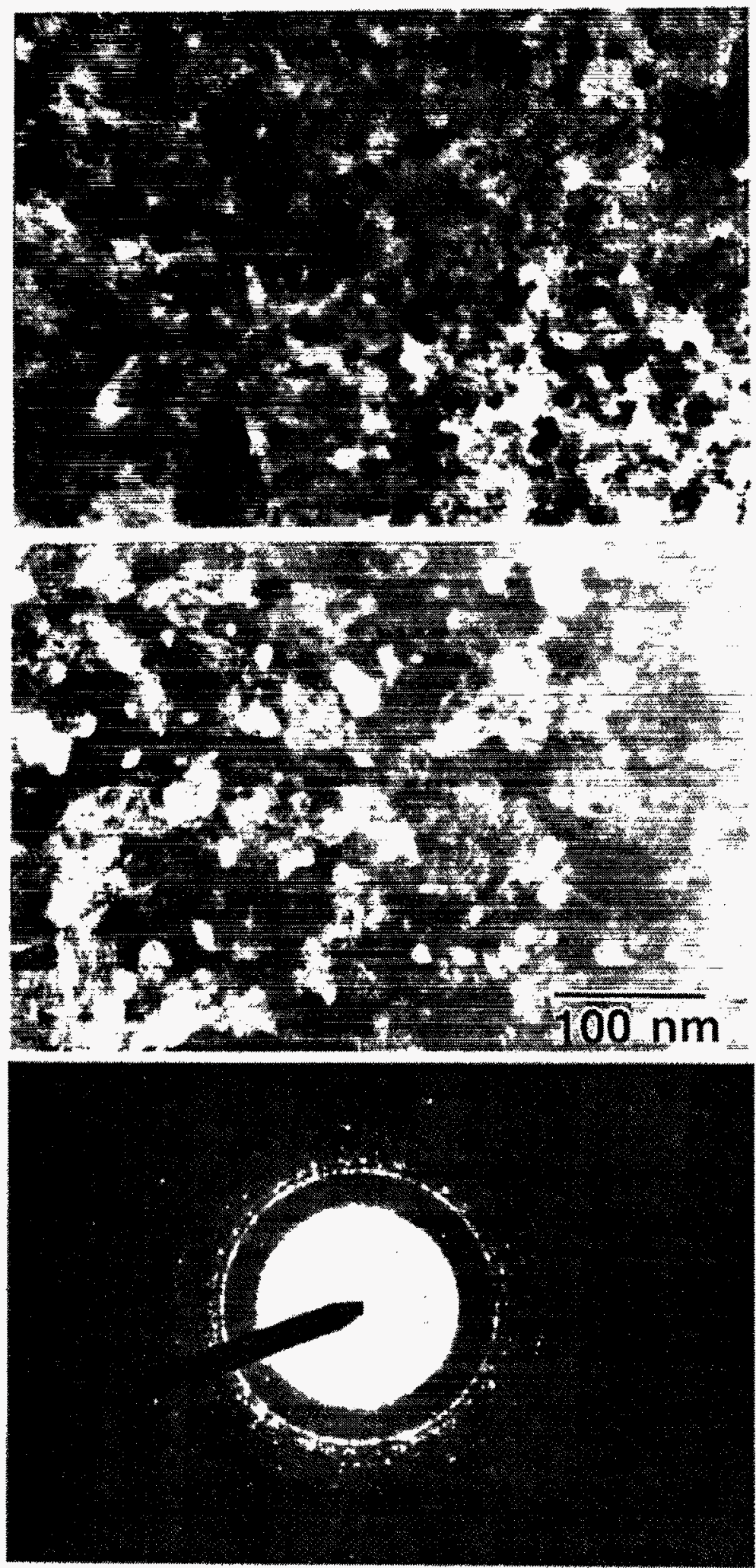

Figure 45. Transmission electron micrographs and diffraction pattern of dynamically consolidated Ti-24Al-Nb (at.\%) powder (shot \#253). 


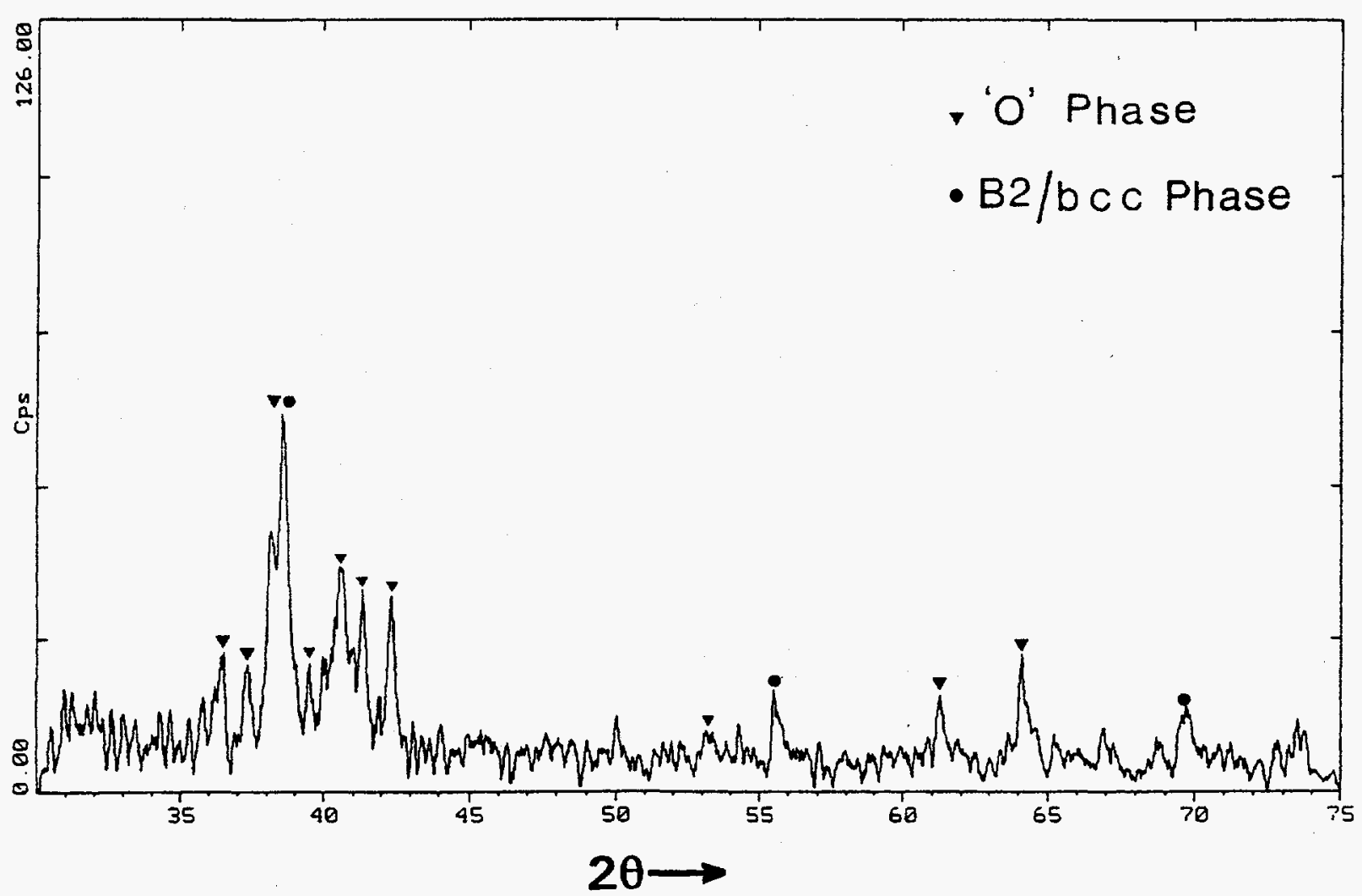

Figure 46. X-ray diffraction pattern of the Ti-24Al-11Nb (at.\%) MA powder HIP'ed at $975^{\circ} \mathrm{C} / 207 \mathrm{MPa} / 2$ hours showing the presence of the B2/b.c.c. and orthorhombic phases. 

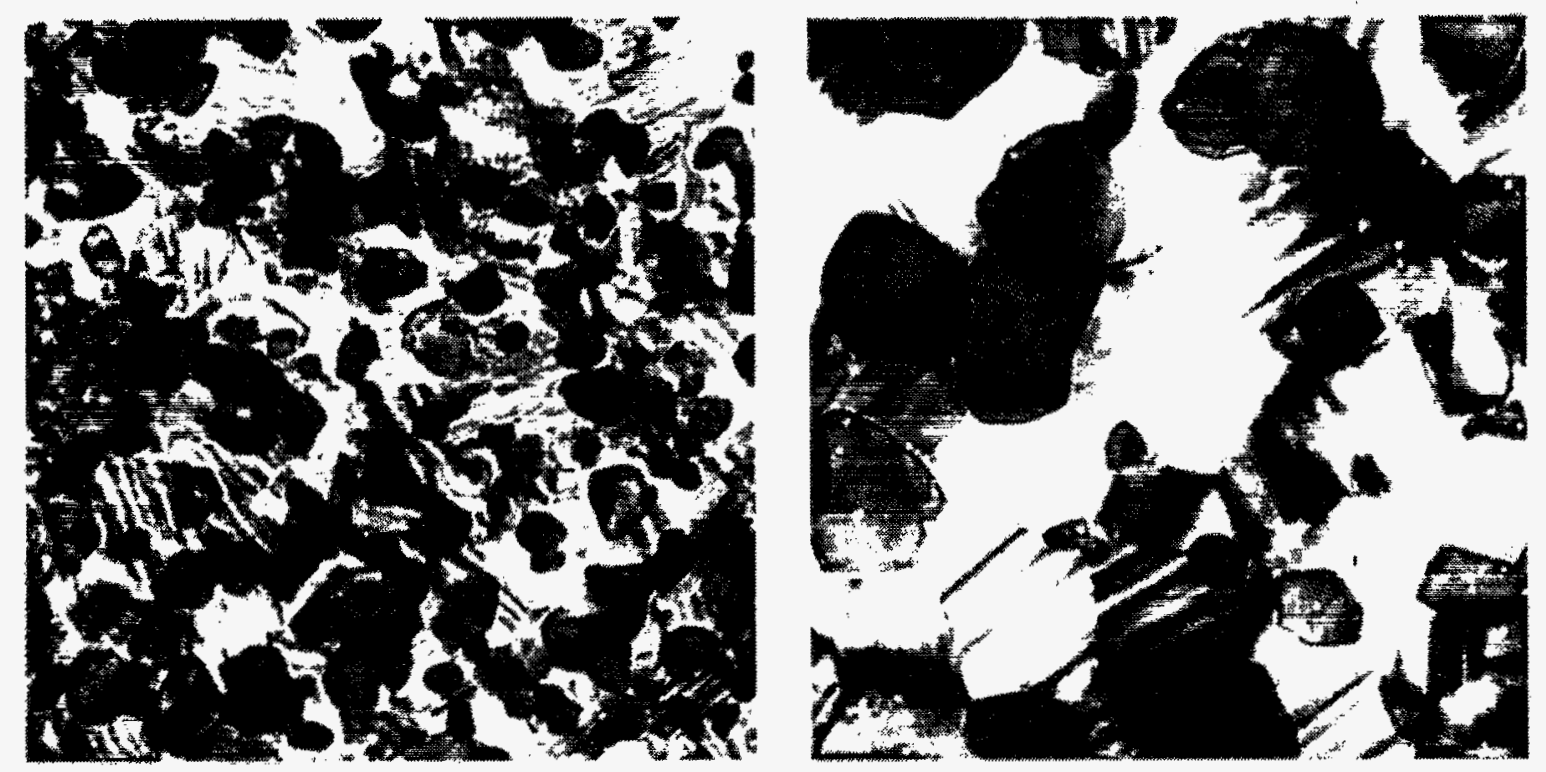

i. 800 " $\mathrm{C}$

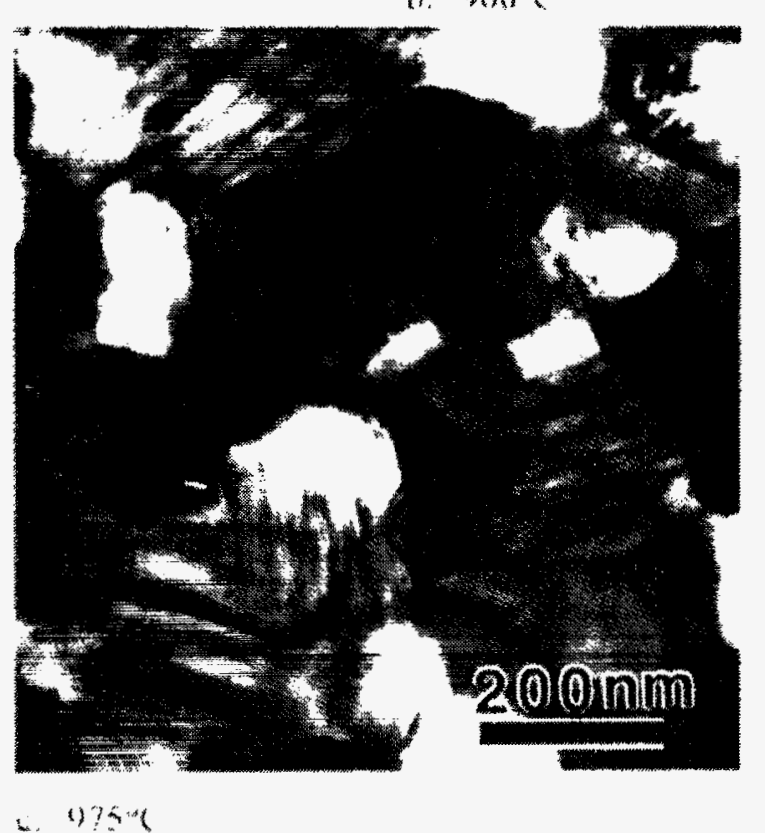

(201) 1111

b. $200 \%$ . 


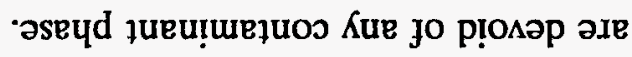

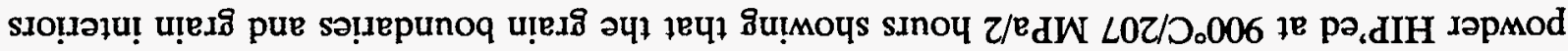

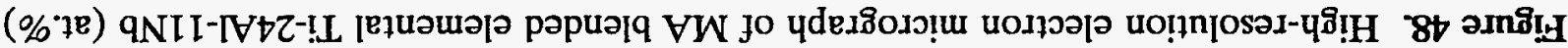

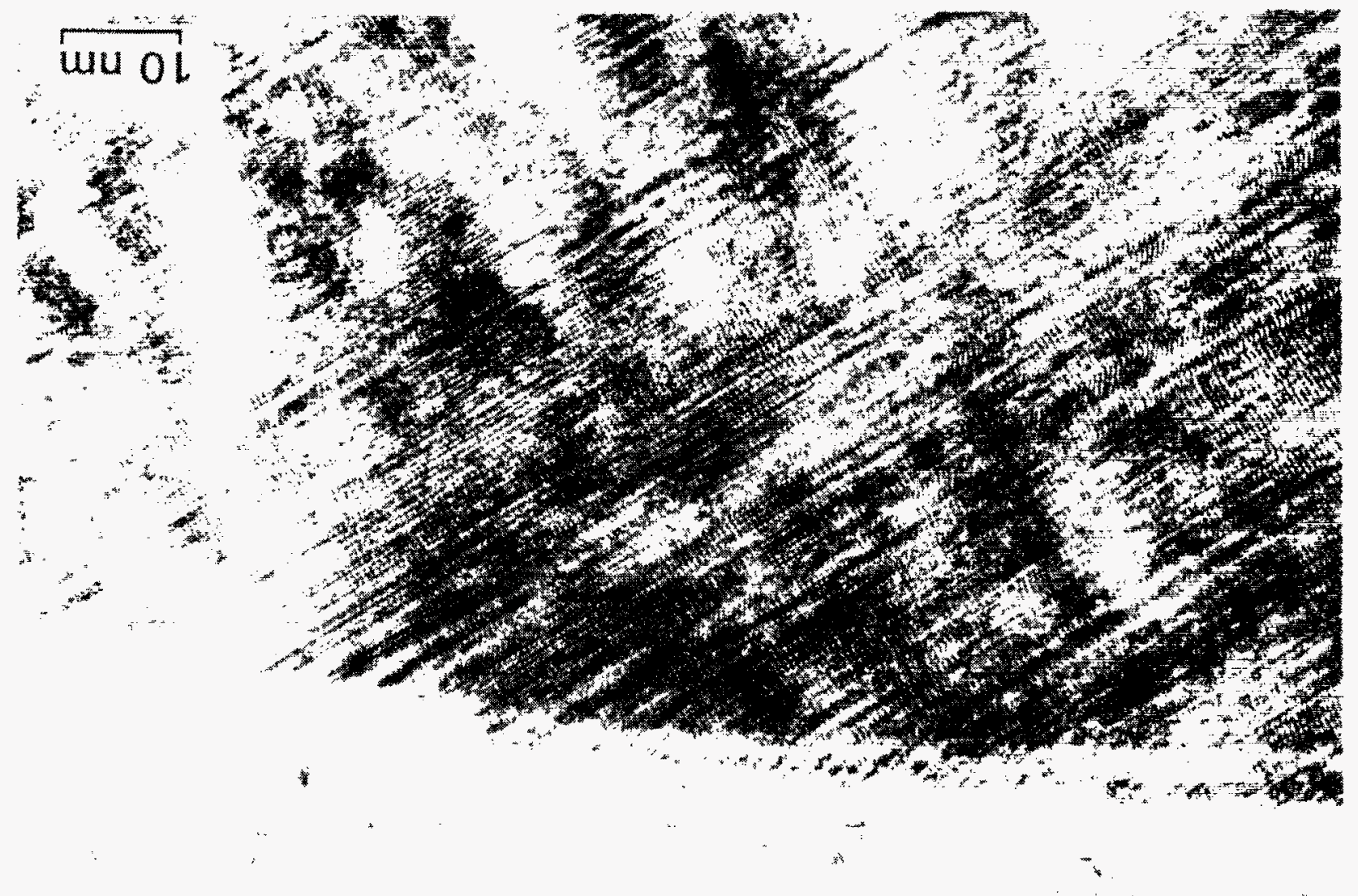


Table 11. Grain size and microhardness values of the Ti-24Al-11Nb (at.\%) samples.

\begin{tabular}{|c|c|c|c|c|c|}
\hline $\begin{array}{c}\text { Alloy } \\
\text { Sample }\end{array}$ & $\begin{array}{c}\text { Milling } \\
\text { Conditions }\end{array}$ & $\begin{array}{l}\text { Consolidation } \\
\text { Method }\end{array}$ & $\begin{array}{l}\text { Consolidation } \\
\text { Parameters }\end{array}$ & $\begin{array}{l}\text { Grain Size } \\
(\mathrm{nm})\end{array}$ & $\begin{array}{l}\text { Microhardness } \\
\text { (DPH) }\end{array}$ \\
\hline \multirow[t]{6}{*}{ Prealloyed } & Not milled & HIP & $900^{\circ} \mathrm{C} / 207 \mathrm{MPa} / 2 \mathrm{~h}$ & 2500 & 250 \\
\hline & Not milled & Hot Pressing & $\begin{array}{c}975^{\circ} \mathrm{C} 207 \mathrm{MPa} 30 \\
\mathrm{~min}\end{array}$ & $\cdots$ & 220 \\
\hline & Not milled & Dynamic & shot \#267 & -- & 385 \\
\hline & SPEX $2 \mathrm{~h}$ & HIP & $800^{\circ} \mathrm{C} / 207 \mathrm{MPa} / 2 \mathrm{~h}$ & $\begin{array}{l}80-120 \mathrm{~B} 2 \\
200-300 \text { "O" }\end{array}$ & Interface 910 \\
\hline & SPEX $2 \mathrm{~h}$ & HIP & $900^{\circ} \mathrm{C} / 207 \mathrm{MPa} / 2 \mathrm{~h}$ & $\begin{array}{l}-- \\
--\end{array}$ & $\begin{array}{c}\text { Interface } 875 \\
\text { Large particles } 315\end{array}$ \\
\hline & SPEX $5 \mathrm{~h}$ & HIP & $800^{\circ} \mathrm{C} / 207 \mathrm{MPa} / 2 \mathrm{~h}$ & -- & $\begin{array}{c}\text { Interface } 980 \\
\text { Large particles } 630\end{array}$ \\
\hline \multirow{7}{*}{$\begin{array}{l}\text { Blended } \\
\text { Elemental }\end{array}$} & As-milled ${ }^{\mathrm{a}}$ & -- & -- & $8-15$ & 560 \\
\hline & Milled $^{\mathrm{a}}$ & HIP & $800^{\circ} \mathrm{C} / 207 \mathrm{MPa} / 2 \mathrm{~h}$ & $\begin{array}{l}20-60 \mathrm{~B} 2 \\
65-140 \text { "O" }\end{array}$ & 975 \\
\hline & Milled $^{\mathrm{a}}$ & HIP & $900^{\circ} \mathrm{C} / 207 \mathrm{MPa} / 2 \mathrm{~h}$ & $\begin{array}{l}45-180 \mathrm{~B} 2 \text {, } \\
115-300 \text { "O" }\end{array}$ & 915 \\
\hline & Milled $^{\mathrm{a}}$ & HIP & $975^{\circ} \mathrm{C} / 207 \mathrm{MPa} / 2 \mathrm{~h}$ & $\begin{array}{l}125 \mathrm{~B} 2 \\
260 \text { "O" }\end{array}$ & 825 \\
\hline & Milled $^{a}$ & Dynamic & shot \#280 & $8-25$ & 920 \\
\hline & Milled $^{\mathrm{a}}$ & Ceracon & $\begin{array}{c}\text { 900\% } \\
\text { min }\end{array}$ & $\begin{array}{l}40-150 \mathrm{~B} 2 \\
125-330 \text { "O" }\end{array}$ & 860 \\
\hline & Milled $^{\mathrm{a}}$ & Hot Pressing & $975^{\circ} \mathrm{C} 60 \mathrm{MPa} 30 \mathrm{~min}$ & --. & 1000 \\
\hline
\end{tabular}

a. MA either 10 to 12 hours in a SPEX 8000 mixer mill under argon with a 10:1 ball-to-powder weight ratio or 28 hours in a Szegvari 01-HD attritor under Ar with a 25:1 ball-to-powder weight ratio. 


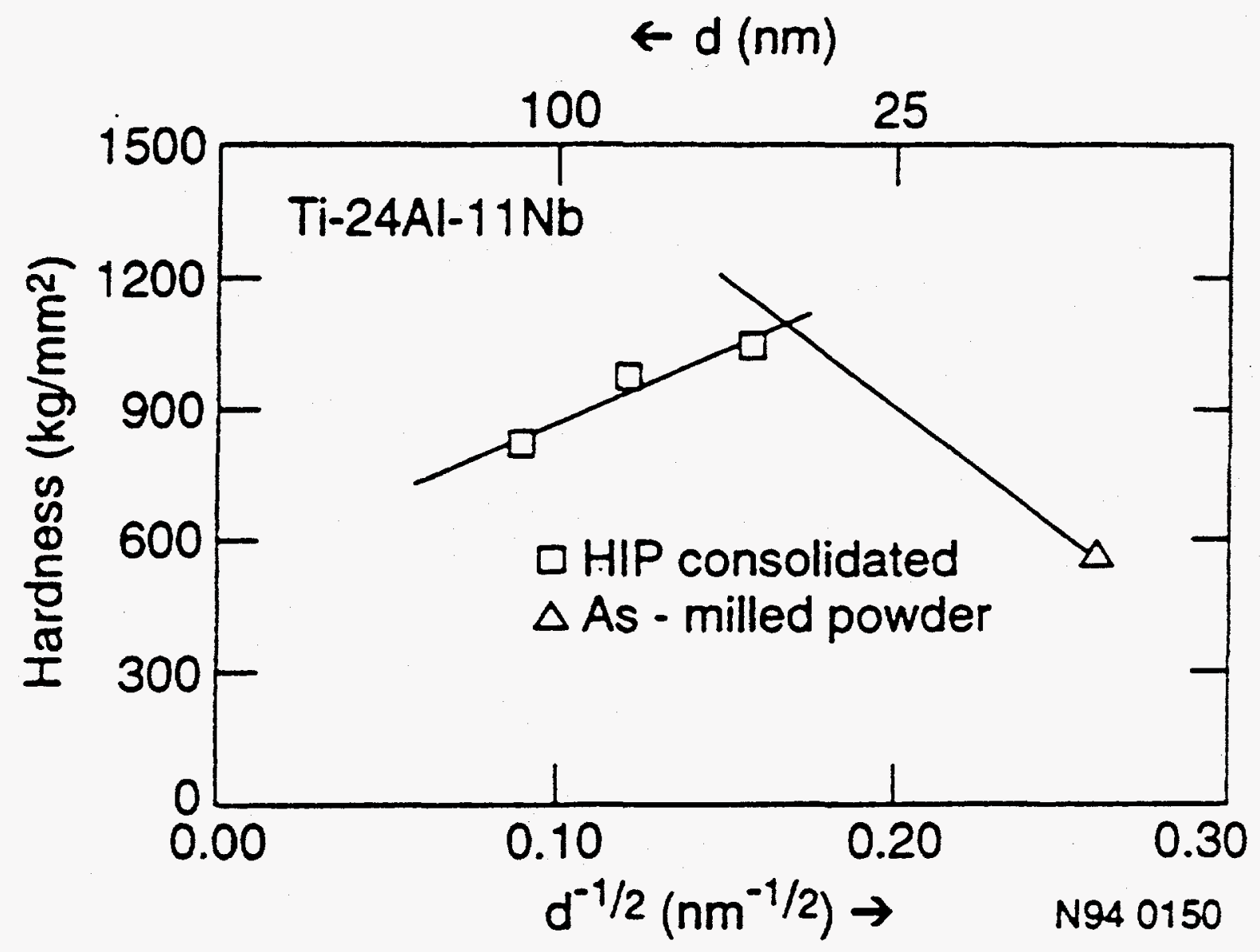

Figure 49. Hall-Petch plot for the blended elemental Ti-24Al-11Nb (at.\%) as-milled powder and HIP-consolidated compacts. 


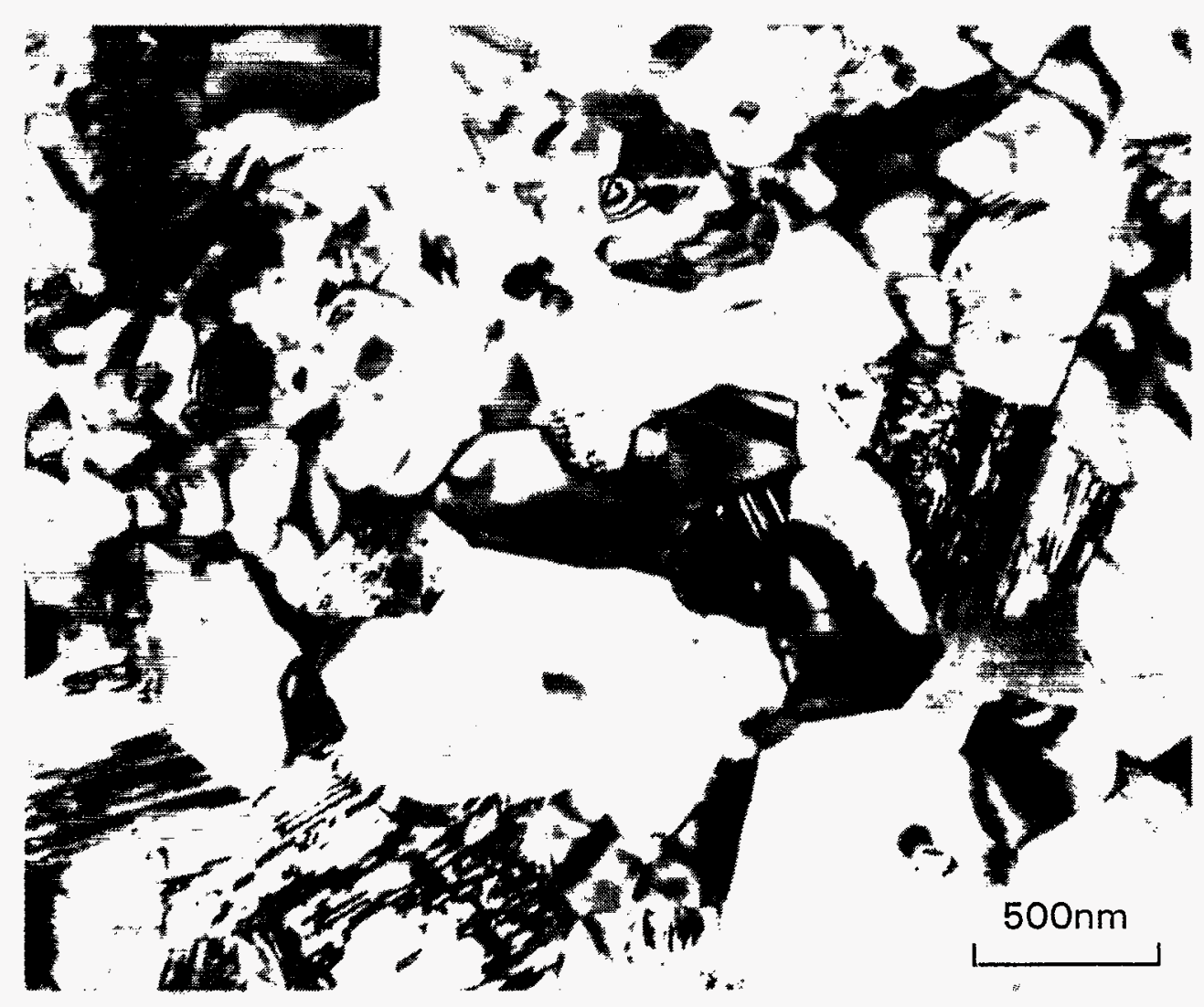

Figure 50. Transmission electron micrograph of the PA Ti-24Al-11Nb (at.\%) powder milled for 2 hours and HIP'ed at $800^{\circ} \mathrm{C} / 207 \mathrm{MPa} / 2$ hours. Note the bimodal distribution of grain sizes. 


\section{The F.C.C. Phase}

The powder containing the f.c.c. phase was chemically analyzed for interstitial contamination. The blended elemental powder milled for 28 hours in the attritor at a ball-to-powder weight ratio of $25: 1$ contained 0.99 wt.\% nitrogen and $1.4 \mathrm{wt} \%$ oxygen. Like in the Ti-55Al powder, this powder also was characterized using $x$-ray photoelectron spectroscopy (XPS) and laser Raman spectroscopy techniques. The Raman peak intensities indicated that the amount of the f.c.c. phase formed during milling increased with increasing milling time. Further, the XPS spectra showed that the nitrogen atoms have a basically nitride-like interaction with the titanium atoms, while the aluminum atoms are in a metal-like configuration. It is possible that by judicious use of TiN-perhaps embedded in a titanium aluminide matrix - a usable elevated temperature material can be synthesized.

High-temperature heat treatment of the powder containing the f.c.c. phase at $1,050^{\circ} \mathrm{C}$ for 144 hours resulted in the decomposition of the f.c.c. phase. In the binary Ti- $\mathrm{Al}$ alloy, the decomposition products were $\mathrm{TiN}$ and $\mathrm{Ti}_{2} \mathrm{AlN}$, while in the ternary alloy, they were the $\mathrm{TiN}$ and $\mathrm{Nb}_{2} \mathrm{Al}$ phases. These results suggest that the final product after MA is not just TiN, but a mixture of the TiN and an amorphous phase. The amorphous phase crystallized to another phase after the high-temperature heat treatment.

\section{Conclusions}

Based on the above results, the following conclusions can be drawn:

1. Mechanical alloying of blended elemental Ti-Al-Nb powders of different compositions led sequentially to the formation of an hcp solid solution, a B2/b.c.c. phase, and amorphous phase, and at the longest times investigated, an f.c.c. phase.

2. In the prealloyed Ti-24Al-11Nb (at.\%) powder (which contained the B2 phase in the as-received condition), an amorphous phase and an f.c.c. phase formed with increasing milling time.

3. The B2/b.c.c. phase powder has a nanostructure on mechanically alloying for 5 hours in all the compositions.

4. On HIP consolidation, the B2/b.c.c. phase has partially transformed to the orthorhombic "O" phase. The grain size is large at higher HIP temperatures. For example, the B2 phase has a grain size of $40 \mathrm{~nm}$ on HIP'ing at $800^{\circ} \mathrm{C}$ and $125 \mathrm{~nm}$ at $975^{\circ} \mathrm{C}$.

5. The hardness of the HIP'ed Ti-24Al-11Nb compacts increased with a decreasing grain size (Hall-Petch behavior).

6. Ductility evaluations could not be made because of the presence of microcracking in the consolidated specimens. 


\section{REFERENCES}

1. A.R.C. Westwood, Metall. Trans., 19A (1988) 749-758.

2. F.H. Froes, in Advanced Materials-Outlook and Information Requirements, L.J. Sousa, C.A. Sorell, and others (eds.), U.S. Bureau of Mines Information Circular IC 9274 (1990) 41-48.

3. F.H. Froes, J.J. deBarbadillo, and C. Suryanarayana, in Structural Applications of Mechanical Alloying, F.H. Froes and J.J. deBarbadillo (eds.), ASM International, Materials Park, $\mathrm{OH}$ (1990) 1-14.

4. F.H. Froes, C. Suryanarayana, K.C. Russell, and C.M. Ward-Close, in Proc. Internat. Conf. on Novel Techniques in Synthesis and Processing of Advanced Materials, J. Singh and S.M. Copley (eds.), TMS, Warrendale, PA (1995).

5. H. Gleiter, Prog. Mater. Sci., 33 (1989) 223-315.

6. F.H. Froes and C. Suryanarayana, JOM, 41, 6 (1989) 12-17.

7. R.L. Bickerdike, D. Clark, J.N. Easterbrook, G. Hughes, W.N. Mair, P.G. Partridge, and H.C. Ransom, Internat. J. Rapid Solidification, 1 (1984-85) 305-325.

8. $\quad$ R.M. Young and E. Pfender, Plasma Chem. \& Plasma Proc., 5 (1985) 1-37.

9. P.C. Kong and Y.C. Lau, Pure and Appl. Chem., 62 (1990) 1809-1816.

10. P.R. Taylor and S.A. Pirzada, in Thermal Plasma Applications in Materials and Metallurgical Processes, N. El-Kaddah (ed.), TMS, Warrendale, PA (1992) 249-268.

11. D. Girardin and M. Maurer, Mater. Res. Bull., 25 (1990) 119-127.

12. C.H. Chou and J. Phillips, J. Mater. Res., 7 (1992) 2107-2113.

13. M.I. Boulos, P. Fauchais, and E. Pfender, in Plasma Technology in Metallurgical Processing, J. Feinman (ed.), Iron \& Steel Society, Inc, Warrendale, PA (1987) 49-63.

14. R. Sundaresan and F.H. Froes, J. Metals, 39, 8 (1987) 22-27.

15. J.S. Benjamin, Metall. Trans., 1 (1970) 2943-2951.

16. C.C. Koch in Processing of Metals and Alloys, vol. 15 of Materials Science and Engineering-A Comprehensive Treatment, R.W. Cahn (ed.), VCH Verlagsgesellschaft, Weinheim, F.R. Germany (1991) 193-245.

17. C. Suryanarayana and F.H. Froes, Mater. Sci. Forum, 88-90 (1992) 445-452.

18. C. Suryanarayana and F.H. Froes, Metall. Trans., A23 (1992) 1071-1081. 
19. C.C. Koch, Nanostructured Mater., 2 (1993) 109-129.

20. B.D. Cullity, Elements of X-Ray Diffraction, Addison-Wesley Pub. Co., Redding, MA (1976).

21. T.B. Massalski, Binary Alloy Phase Diagrams, ASM International, Vol. 1, Metals Park, OH (1986) 147-149.

22. B. Huang, Non-Equilibrium Structures in Al-Fe Alloys by Mechanical Alloying, Ph.D. Thesis, Kyoto University, Japan (1990).

23. A.K. Niessen, F.R. de Boer, R. Boom, P.F. de Chatel, W.C.M. Mattens, and A.R. Miedemma, CALPHAD, 7 (1983) 51.

24. F.H. Froes, C. Suryanarayana, and D. Eliezer, J. Mater Sci., 27 (1992) 5113-5140.

25. C.H. Ward, Internat. Mater. Rev., 38 (1993) 79-101.

26. F.H. Froes and C. Suryanarayana, in Physical Metallurgy and Processing of Intermetallic Compounds, N.S. Stoloff and V.K. Sikka (eds.), Chapman \& Hall, New York, NY (1994) 297-350.

27. Y.-W. Kim, JOM, 46, 7 (1994) 30-39.

28. J. Karch, R. Birringer, and H. Gleiter, Nature, 330 (1987) 556-558.

29. C. Koeppe, A. Bartels, J. Seeger, and H. Mecking, Metall. Trans., 24A (1993) 1795-1806.

30. F. Petzoldt, B. Scholz, and H.D. Kunze, in New Materials by Mechanical Alloying Techniques," E. Arzt and L. Schultz (eds.), DGM, Oberursel, Germany (1989) 111-118.

31. P.I. Loeff and H. Bakker, Europhys. Lett., 8 (1989) 35-40.

32. U. Mizutani and C.H. Lee, J. Mater. Sci., 25 (1990) 399-406.

33. H.J. Fecht, G. Han, Z. Fu, and W.L. Johnson, J. Appl. Phys., 67 (1990) 1744-1748.

34. R. Strychor, J.C. Williams, and W.A. Saffa, Metall. Trans., A19 (1988) 225-234.

35. D. Banerjee, A.K. Gogia, T.K. Nandy, and V.A. Joshi, Acta Metall., 36 (1988) 871-882.

36. L.A. Bendersky, W.J. Boettinger, B.P. Burton, F.S. Biancaniello, and C.B. Shoemaker, Acta Metall. Mater., 38 (1990) 931-943.

37. R.G. Rowe, in High Temperature Aluminides and Intermetallics, S.H. Whang, C.T. Liu, D.P. Pope and J.O. Stiegler (eds.), TMS, Warrendale, PA (1990) 375-401.

38. J.S.C. Jang and C.C. Koch, J. Mater. Sci., 5 (1990) 498-510. 


\section{RESEARCH PAPERS PUBLISHED}

1. Guo-Hao Chen, C. Suryanarayana, and F.H. Froes, "Synthesis of B2 Phase in Ti-Al-Nb Alloys by Mechanical Alloying," Scripta Metall. Mater., 25 (1991) 2537-2540.

2. F.H. Froes, C. Suryanarayana, Guo-Hao Chen, Abdulbaset Frefer, and G.R. Hyde, "Nanostructure Processing for Titanium-Based Materials," JOM, 44, 5 (1992) 26-29.

3. C. Suryanarayana, Guo-Hao Chen, and F.H. Froes, "Milling Maps for Phase Identification During Mechanical Alloying," Scripta Metall. Mater., 26 (1992) 1727-1732.

4. C. Suryanarayana, D. Mukhopadhyay, S.N. Patankar, and F.H. Froes, "Grain Size Effects in Nanocrystalline Materials," J. Mater. Res., 7 (1992) 2114-2118.

5. C. Suryanarayana, Guo-Hao Chen, and F.H. Froes, "Mechanical Alloying of Ti-Al-Nb Alloys," in Advancements in Synthesis and Processing, F.H. Froes, W. Wallace, R.A. Cull, and E. Struckholt (eds.), SAMPE, Covina, CA (1992) M671-M683.

6. C. Suryanarayana, Guo-Hao Chen, Abdulbaset Frefer, and F.H. Froes, "Structural Evolution of Mechanically Alloyed Ti-Al Alloys," Mater. Sci. \& Eng., A158 (1992) 93-101.

7. Guo-Hao Chen, C. Suryanarayana, and F.H. Froes, "Formation of the B2 Phase in Ti-Al-Nb Alloys by Mechanical Alloying," in Advances in Powder Metallurgy \& Particulate Materials 1992, Vol. 7 (Novel Powder Processing), compiled by J.M. Capus and R.M. German, MPIF, Princeton, NJ (1992) 183-194.

8. G.E. Korth, "Dynamic Consolidation of Mechanically Alloyed Nanocrystalline Al-Fe and TiAl-Nb Alloys, "in Advanced Synthesis of Engineered Structural Materials, J.J. Moore, E.J. Lavernia, and F.H. Froes (eds.), ASM International, Materials Park, OH (1993) 81-86.

9. D.K. Mukhopadhyay, C. Suryanarayana, and F.H. Froes, "Mechanical Alloying of AluminumIron Alloys, "in Advanced Synthesis of Engineered Structural Materials, J.J. Moore, E.J.

Lavernia, and F.H. Froes (eds.), ASM International, Materials Park, OH (1993) 189-195.

10. Guo-Hao Chen, C. Suryanarayana, and F.H. Froes, "Effect of Processing Parameters on Mechanical Alloying of $\mathrm{Ti}_{3} \mathrm{Al}$-Base Alloys," in Advanced Synthesis of Engineered Structural Materials, J.J. Moore, E.J. Lavernia, and F.H. Froes (eds.), ASM International, Materials Park, OH (1993) 205-212.

11. Abdulbaset Frefer, C. Suryanarayana, and F.H. Froes, "Effect of Mechanical Alloying on $\boldsymbol{\gamma}$ TiAl Alloys," in Advanced Synthesis of Engineered Structural Materials, J.J. Moore, E.J. Lavernia, and F.H. Froes (eds.), ASM International, Materials Park, OH (1993) 213-219.

12. K. Sato, K. Ishizaki, G.H. Chen, A. Frefer, C. Suryanarayana, and F.H. Froes, "Fine Structure Analysis of Mechanically Alloyed Titanium Aluminides," in Advanced Synthesis of Engineered Structural Materials, J.J. Moore, E.J. Lavernia, and F.H. Froes (eds.), ASM International, Materials Park, OH (1993) 221-225. 
13. C. Suryanarayana, G.E. Korth, Guo-Hao Chen, A. Frefer, and F.H. Froes, "Thermal Stability of Nanostructured Titanium Aluminides," Nanostructured Materials, 2 (1993) 527-535.

14. P.R. Taylor, S.A. Pirzada, D.L. Marshall, and S. Donahue, "Generation of Nanocrystalline Metals in a Transferred Arc Thermal Plasma Reactor," in Plasma Synthesis and Processing of Materials, K. Upadhya (ed.), TMS, Warrendale, PA (1993) 215-225.

15. C. Suryanarayana and F.H.Froes, "Nanocrystalline Structures from Amorphous Precursors," Nanostructured Materials, 3 (1993) 147-153.

16. Guo-Hao Chen, C. Suryanarayana, and F.H. Froes, "Nanostructure Formation in a Mechanically Alloyed Ti-24Al-11Nb Alloy," in Titanium '92 : Science and Technology, F.H. Froes and I.L. Caplan (eds.), TMS, Warrendale, PA (1993) 903-910.

17. Abdulbaset Frefer, C. Suryanarayana, and F.H. Froes, "Synthesis of $\gamma$-TiAl by Mechanical Alloying of Elemental Powders," in Titanium '92 : Science and Technology, F.H. Froes and I.L. Caplan (eds.), TMS, Warrendale, PA (1993) 933-940.

18. C. Suryanarayana and F.H. Froes, "Mechanical Alloying of Titanium-Base Alloys," Advanced Mater., 5 (1993) 96-106.

19. C. Suryanarayana and F.H. Froes, "Nanostructured Titanium Aluminides," Mater. Sci. \& Eng., A179/180 (1994) 108-111.

20. D.K. Mukhopadhyay, C. Suryanarayana, and F.H. Froes, "Synthesis of Nanocrystalline $\mathrm{Al}_{5} \mathrm{Fe}_{2}$ by Mechanical Alloying," Scripta Metall. Mater., 31 (1994) 333-338.

21. C.Suryanarayana, F.H. Froes, D.K. Mukhopadhyay, G. Cizmich, G.H. Chen, Z. Peng, and J. Mishurda, "Synthesis of Intermetallics by Mechanical Alloying," in Processing and Fabrication of Advanced Materials III, V.A. Ravi, T.S. Srivatsan, and J.J. Moore (eds.), TMS, Warrendale, PA (1994) 567-584.

22. Guo-Hao Chen, C. Suryanarayana, and F.H. Froes, "Structure of Mechanically Alloyed TiAl-Nb Powders," Metall. Mater. Trans. A (1995).

23. D.K. Mukhopadhyay, C. Suryanarayana, and F.H. Froes, "Structural Evolution in Mechanically Alloyed Al-Fe Powders," Metall. Mater. Trans. A, (1995). 